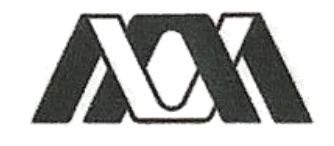

Casa abierta al tiempo

UNIVERSIDAD AUTÓNOMA METROPOLITANA

División de Ciencias Básicas e Ingeniería

Departamento de Química

Área de Biofisicoquímica

\title{
"Estudio fisicoquímico del ensamble molecular de la partícula del bacteriófago M13 y mutantes"
}

Tesis que presenta:

Q. Jessica Martínez Jiménez

Para obtener el grado de

Maestra en Ciencias (Química)

Dirigida por:

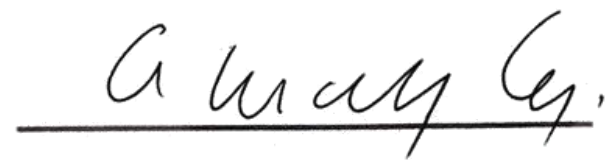

Dr. Andrés Hernández Arana

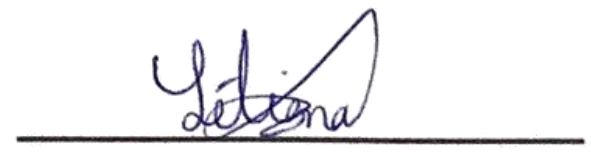

Dra. L. Irais Vera Robles

Sinodales:

Dr. Andrés Hernández Arana

Dr. Rafael Arturo Zubillaga Luna

Dra. Claudia Guadalupe Benítez Cardoza

Ciudad de México, 24 de marzo del 2020. 


\section{Agradecimientos}

A mis asesores Dr. Andrés Hernández y la Dra. L. Irais Vera por darme la oportunidad de estar en su grupo de investigación, gracias por su paciencia, apoyo y conocimiento para desarrollar esta tesis.

A mis sinodales por sus observaciones y a la dedicación de esta tesis.

Al Dr. Rafael Zubillaga le agradezco su paciencia, tiempo y enseñanzas en las clases que recibí durante la maestría.

A la técnica Patricia Castillo Ocampo del laboratorio de microscopía electrónica de la UAM-Iztapalapa por su valioso tiempo en atenderme y analizar mis muestras.

A Laboratorio de Biofísicoquímica de la UAM-Iztapalapa por permitirme trabajar a lo largo de la maestría.

Al Consejo Nacional de Ciencia y Tecnología (CONACyT) por la beca otorgada para la realización de la tesis de maestría, No. de becario/CVU: 743360. 


\section{Dedicatorias}

\section{A cada pieza del rompecabezas que forma parte de mi vida.}

Agradezco y dedico no solo este trabajo, sino toda mi vida a mis padres $y$ hermanos. Gracias por estar y confiar en mi en cada paso que doy.

A la Dra. L. Irais Vera desde que me integre a su grupo de investigación me ha brindado su paciencia, confianza y enseñanzas.

A Alejandra, Sonia, Elisa, Adriana, Ana, Cesar y Rafael por nuestra gran amistad. A mis compañeros y amigos del laboratorio Jaqueline, David, Arantxa y Roberto, por hacer a veces divertido y llevaderos mis días de trabajo.

A los miembros del laboratorio de Biofísicoquímica que hacen que mi estadía sea más agradable.

Gracias. 


\section{Resumen}

La síntesis de materiales inorgánicos se ha convertido en una gran área de investigación en química, biología y física. Durante los últimos años ha generado gran interés el uso de moléculas biológicas, ya que podrían potenciar el desarrollo de materiales con nuevas propiedades o con mejor desempeño, permitiendo generar nuevos productos y aplicaciones.

Como se sabe, la naturaleza es capaz de ensamblar estructuras con una complejidad notable que puede ser imitada en el laboratorio. Con esto en mente, se han utilizado organismos y moléculas biológicas que actúan como plantilla en la síntesis de materiales, ya que pueden controlar su composición, estructura espacial, ensamblado jerárquico y dimensiones.

En esta tesis se presenta el estudio y análisis del autoensamble de moléculas biológicas. Este trabajo se enfocó en la molécula del bacteriófago del M13, debido a la capacidad de autoorganizarse y la habilidad de unirse y nuclear diferentes materiales gracias a los grupos funcionales de las proteínas que forman la cápside del fago. Por lo tanto, empleamos este tipo de partículas virales en la síntesis y organización de nanopartículas (NP) de Au y Ag sobre su superficie. Para lograr esto primero se propuso realizar modificaciones genéticas sobre la superficie de la proteína p8, la cual cubre mayoritariamente el cuerpo del fago. En particular se realizaron mutantes que incorporan cisteínas ya que tiene afinidad a iones de metales nobles. El fago nativo y las mutantes obtenidas se caracterizaron mediante diferentes técnicas espectroscópicas, para obtener información del cambio estructural y empaquetamiento del fago.

Las mutantes obtenidas presentaron puentes disulfuro, los cuales se redujeron con DTT, para generar grupos SH. Estas mutantes se emplearon en la nucleación y síntesis de NP de Au y Ag. Estas NP crecieron en la superficie del fago M13 y adoptaron la forma de un rodillo ensamblado de NP. Estas estructuras se caracterizaron por técnicas espectroscópicas.

Mediante este estudio, se encontró que las mutaciones del fago M13 han sido determinantes para estudiar los cambios conformacionales de su estructura, debido a las interacciones que existe entre lo aminoácidos en la región hidrofóbica y por otro lado al haber insertado grupos afines a las NP han sido buenas plantillas para nuclear materiales inorgánicos. 


\section{Abreviaturas}

ADN Ácido desoxirribonucleico

ANS 1-anilino-8-naftalenosulfato

APTES 3-aminopropil trietoxisilano

ARN Ácido ribonucleico

ATR Reflectancia total atenuada

AuNR Nanovarillas de oro

Cf Concentración final

LC Cristales liquidos

DC Espectroscopía de dicroísmo circular

DLS Dispersión de luz dinámica

DSC Calorimetría diferencial de barrido

DTT Ditiotreitol

E. Coli Bacteria Escherichia coli

Fago-S Bacteriófago en forma de esferoide

IR Espectroscopía infrarroja

IPTG Isopropil- $\beta$-D-1-tiogalactopiranósido

LB Medio de cultivo Luria bertani

M Molaridad $\mathrm{mol} / \mathrm{L}$

NRMSD Desviación cuadrática media

NP Nanopartículas

PEG Polietilenglicol PB $\sim 8000 \mathrm{~g} / \mathrm{mol}$

PCR Reacción de cadena polimerasa 
$\mathrm{pl}$

ssADN

SATA

SATP

SAXS

SPR

TEOS

TEM

TMV

UV-Vis

X-Gal
Punto isoeléctrico

Cadena sencilla de acido desoxirribonucleico

$\mathrm{N}$-succinimidil S-acetiltioacetato

$\mathrm{N}$-succinimidil-S-acetiltiopropionato

Espectroscopía de rayos-X de bajo ángulo

Plasmón de resonancia superficial

Tetraetilortosilicato

Microscopía electrónica de transmisión

Virus del mosaico del tabaco

Espectroscopía ultravioleta-visible

5-bromo-4-cloro-3-indolil- $\beta$-D-galactopiranósido 


\section{$\underline{\underline{\text { Índice }}}$}

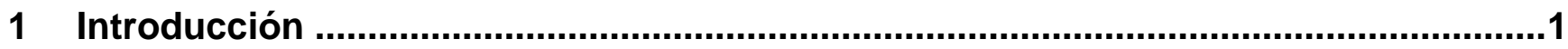

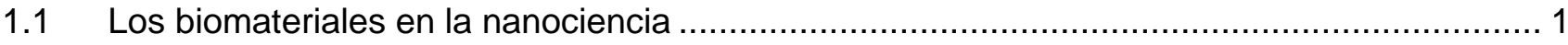

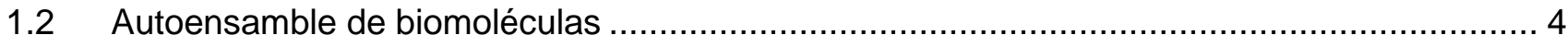

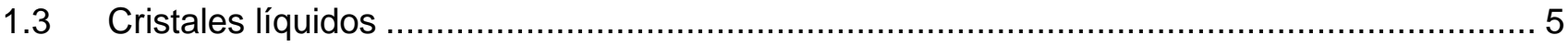

$1.4 \quad$ La estabilidad e interacciones en las proteínas ............................................................. 7

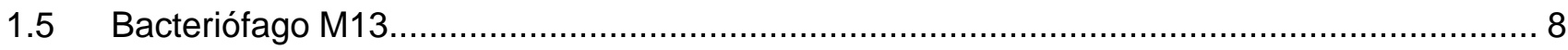

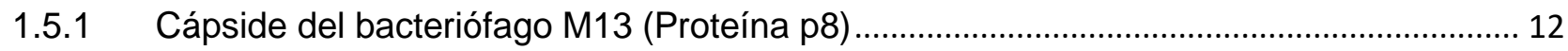

1.5.2 Estabilidad del bacteriófago M13 …............................................................................... 14

1.5.3 El bacteriófago M13 como cristal líquido .................................................................. 15

1.5.4 Bacteriófago M13 como plantilla .................................................................................... 20

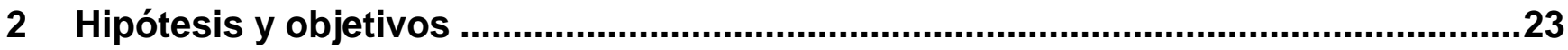

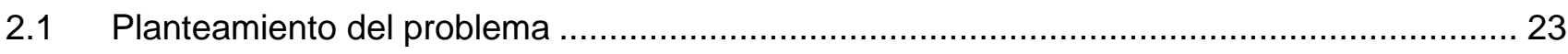

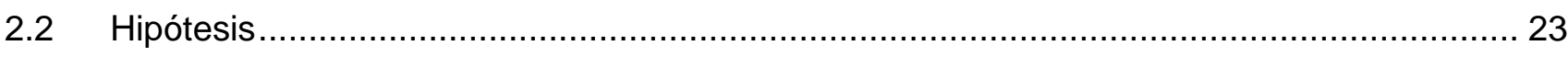

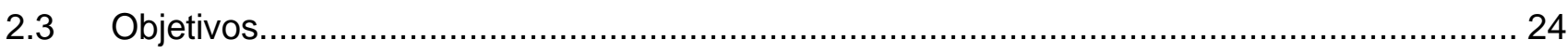

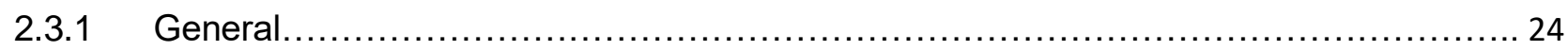

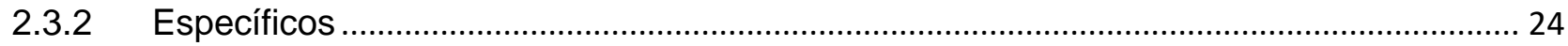

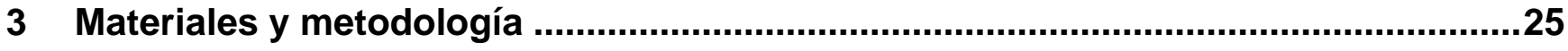

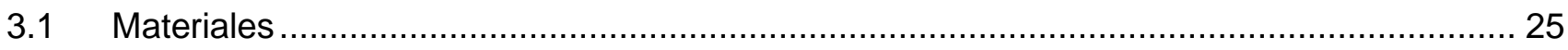

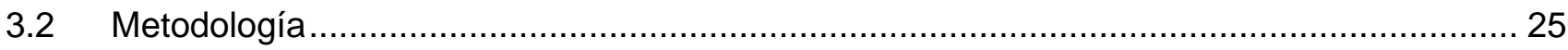

3.2.1 Amplificación y purificación del bacteriófago M13wt....................................................... 25

3.2.2 Modificación genética del bacteriófago M13 (M13mp18) ................................................ 26

3.2.3 Amplificación y purificación de las mutantes .................................................................... 27

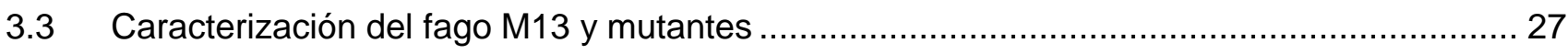

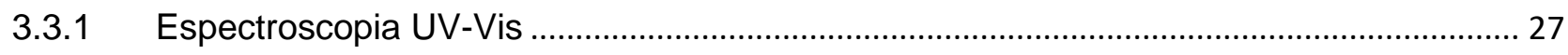

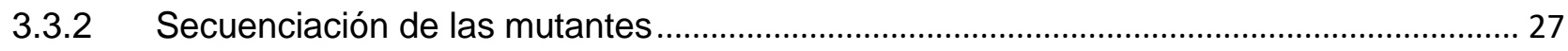

3.3.3 Reducción de Cistinas de las mutantes obtenidas ......................................................... 28

3.3.4 Espectroscopía de dicroísmo circular (DC) …............................................................... 28

3.3.5 Espectroscopia Infrarroja (FT-IR, Fourier) …................................................................. 29

3.3.6 Dispersión dinámica de luz (DLS) ................................................................................. 29

3.3.6.1 Determinación de la distribución de tamaño de partícula ............................................. 29

3.3.6.2 Determinación del punto isoeléctrico mediante el método de Potencial zeta (ZP) ...... 30

3.4 Bacteriófago M13 y mutantes como plantilla para síntesis de nanomateriales inorgánicos.. 31 
3.4.1 Nucleación y crecimiento de nanopartículas de oro y plata en la cápside del fago M13 y mutantes.

3.4.2 Caracterización de fago wt y mutantes con NPs de oro y plata por espectroscopia UV-Vis 31

3.4.3 Microscopía electrónica de transmisión (TEM) ………………………………............... 31

3.4.4 Síntesis y caracterización de películas delgadas de fago M13wt y mutantes ......................... 31

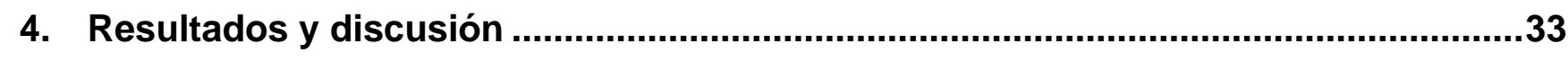

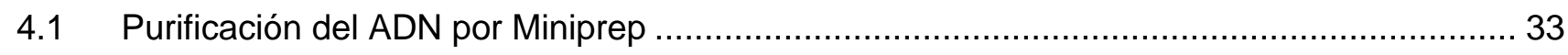

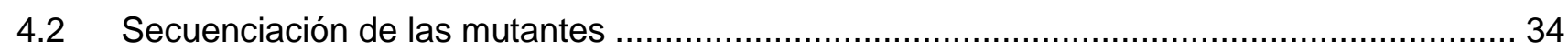

4.3 Amplificación, purificación y caracterización del bacteriófago M13wt y sus mutantes ........... 35

4.4 Efecto de las mutaciones sobre la estructura de la proteína p8 de la cápside del fago ......... 37

4.4.1 Estructura secundaria. Dicroísmo circular ………............................................................. 37

4.4.2 Estructura secundaria. Espectroscopía en el infrarrojo (FT-IR, Fourier) ……………….... 44

4.4.3 Microambiente de residuos de aminoácidos aromáticos. Dicroísmo circular ..................... 46

4.5 Dispersion dinámica de luz (DLS) del fago M13wt y mutantes .......................................... 48

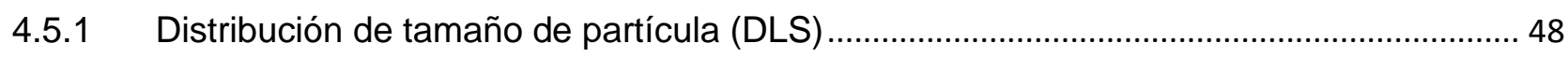

4.5.2 Determinación del punto isoeléctrico mediante el método de Potencial zeta (ZP) .......... 50

4.6 Bacteriófago M13 y mutantes como plantilla para síntesis de nanomateriales inorgánicos.. 52

4.6.1 Nucleación y crecimiento de nanopartículas de oro y plata en la cápside del fago M13 y mutantes. 52

4.6.2 Cristales líquidos en M13wt y mutantes (L14V/V31C y M28R/V31C) ............................... 57

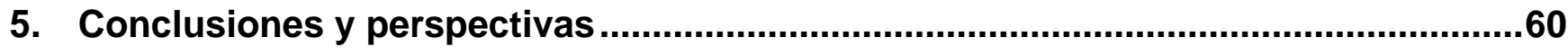

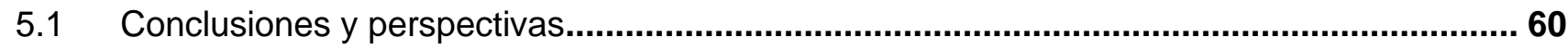

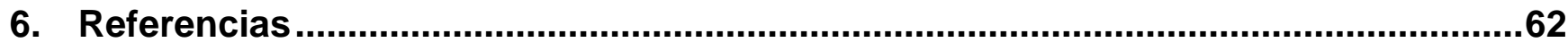




\section{Capítulo 1}

\section{Introducción}

\subsection{Los biomateriales en la nanociencia}

La nanociencia ha despertado un gran interés en generar nuevos y únicos materiales con estructuras complejas a nivel nanométrico, incrementando sus propiedades físicas, químicas y biológicas para aprovecharlas en diferentes aplicaciones o áreas, por ejemplo: en biomedicina e ingeniería biomédica, electrónica, producción y almacenamiento de energía, y óptica.[1,2] La nanobiotecnología está inspirada en estructuras biológicas utilizando técnicas biomiméticas para crear nuevos materiales con características estructurales definidas y organizadas jerárquicamente. De este modo, la biomimética es un campo interdisciplinario que aplica los principios de la química, física, biología e ingeniería, orientándose a la síntesis de nuevos materiales que imitan las funciones y diseños de la naturaleza o que siguen un diseño derivado de la naturaleza. [3] Ejemplos de biomateriales de este tipo, elaborados por la naturaleza se muestran en la Figura 1.

a

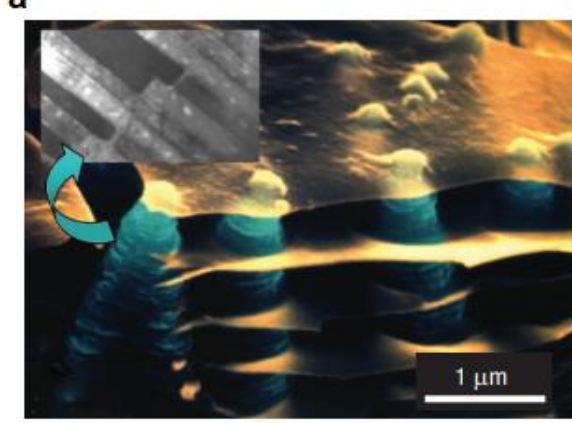

C

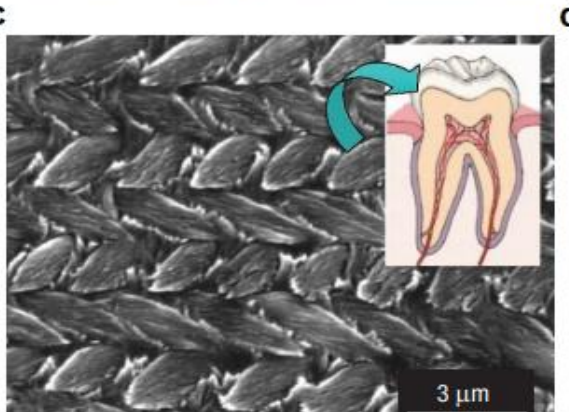

b

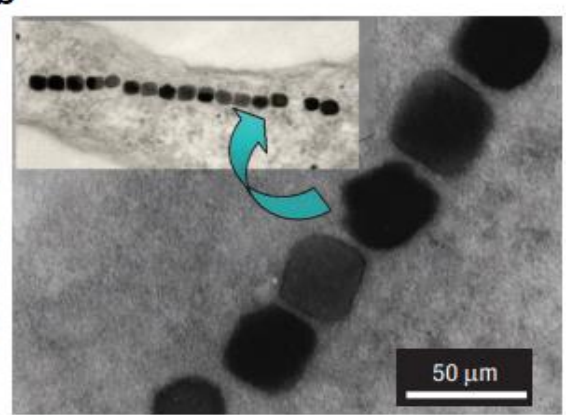

d

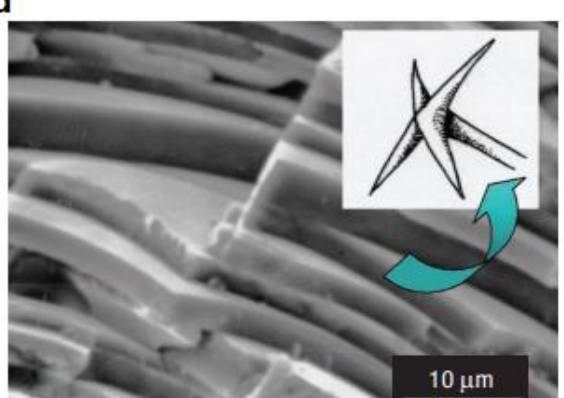

Figura1. Imágenes de microscopía electrónica de ejemplos de biomateriales a) Crecimiento de un borde de abulón formado por plaquetas de aragonita. b) Bacterias magnetotácticas que en su interior sintetizaron nanopartículas de magnetita. c) Ensamble en forma de varilla de cristales de hidroxiapatita con una arquitectura altamente ordenada d) Espícula de esponja Rosella en capas de sílice. 
En la síntesis de materiales nanoestructurados se han utilizado bioplantillas que proporcionan un soporte o plataforma que dicta la morfología, la topología y las propiedades resultantes que caracterizan al material.[3] Las técnicas biomiméticas buscan replicar las características morfológicas de una especie biológica o usando una estructura biológica con una organización definida para guiar el ensamblaje de materiales orgánicos o inorgánicos mediante interacciones covalentes, no covalentes y de reconocimiento molecular. Hay una gran variedad de especies biológicas utilizadas como bioplantillas que van desde moléculas sencillas como los oligonucleótidos, péptidos, proteínas hasta ensambles biomoleculares complejos como la seda o las alas de insectos o los virus. [2;4]

La creación de materiales nanoestructurados se ha basado en el autoensamble molecular, que es la formación espontánea de estructuras ordenadas, discretas y controladas a partir de unidades simples. Las técnicas de autoensamble molecular son muy versátiles, de bajo costo y susceptibles de llevarse a gran escala. [2,5]

La versatilidad de las partículas biológicas en los procesos de autoensamble, proporcionan un medio de replicación precisa con matrices orgánicas e inorgánicas para obtener estructuras jerárquicas sofisticadas y con propiedades asombrosas. Estos procesos de autoensamble ocurren cuando las partículas biológicas se organizan jerárquicamente a partir de un sustrato para obtener una plantilla y por consiguiente se ponen en contacto con un precursor o partículas pequeñas, las cuales pueden ser depositadas en el interior o exterior de la superficie de la plantilla.[6]

Recientemente ha llamado la atención el uso de biomoléculas como plantillas para la síntesis de materiales biomiméticos funcionales como, por ejemplo, en la reparación y reconstrucción del esmalte dental por procesos de mineralización biomimética. Este esmalte tiene una estructura compleja en forma de agujas formadas por cristales de apatita. Para reconstruir este esmalte, se ha usado el esmalte existente como plantilla; y sobre esta se organizan y se ensamblan estructuras jerárquicas de cristales de mezclas de ácido glutámico-nanopartículas de apatita, resultando una fuerte adsorción en el tejido natural que ayuda en la regeneración de este esmalte. [6]. Ver figura 2 a). 
Otro ejemplo es el presentado por Xiang et al. [8] Ellos usaron la biomolécula del ADN, que, por su peculiar estructura de doble hélice, se ha utilizado como plantilla para el ensamble de partículas metálicas. Sintetizaron superestructuras quirales helicoidales anisotrópicas con forma de "nanovarillas" de oro (AuNR), usando plantillas con estructura de origami ADN bidimensional. Estas forman patrones asimétricos en forma de " $X$ " centrosimétrica por la interacción entre cada dos nanovarillas con la plantilla de ADN. De esta manera cada hebra de ADN se apila a lo largo de una dirección normal y por lo tanto esta gira alrededor del director normal de la superestructura. Estos materiales por sus propiedades quirales se han utilizado en la actividad óptica plasmónica y fotónica. Figura 2 b).

Otras partículas que se han utilizado como plantillas son los virus, debido a la versatilidad en su manipulación morfológica para la síntesis de materiales inorgánicos. La estructura de los virus se considera como un ensamble supramolecular constituido por un ácido nucleico (ADN o ARN) protegido por una cápside de proteínas. Por ejemplo, H. B. Yoav, et al. [7] han usado el virus filamentoso de la planta del tabaco (Tobacco Mosaic Virus, TMV), para la construcción de películas delgadas como biosensores electroquímicos decorados con oro ( $\mathrm{Au}$ ) y níquel (Ni), teniendo como principal aplicación el análisis de esquizofrenia. Este virus por su morfología filamentosa es capaz de organizarse en nanoestructuras tridimensionales, y a altas concentraciones tiene la capacidad de organizarse como cristal líquido. Figura $3 \mathrm{c}$ ).
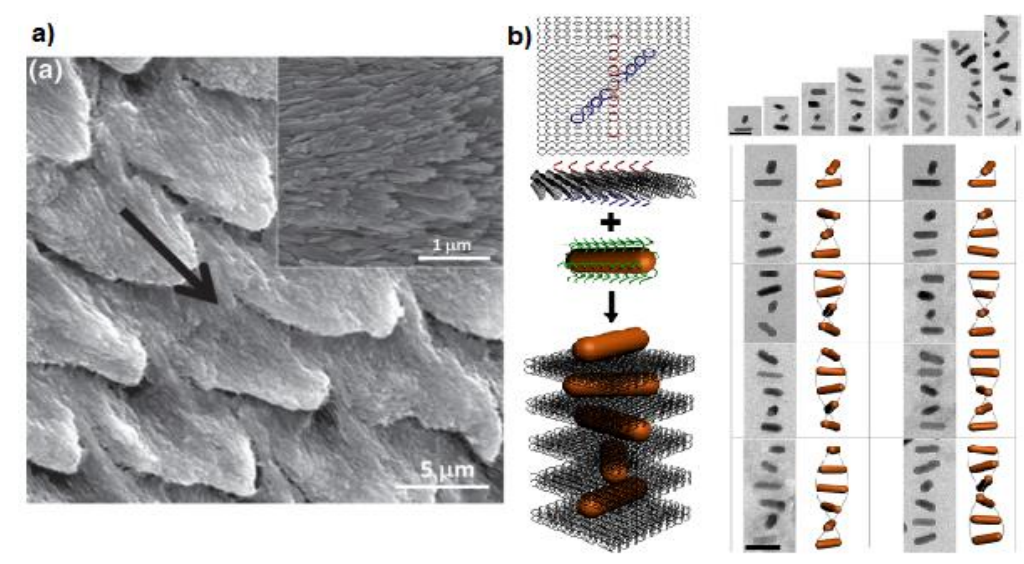

c)

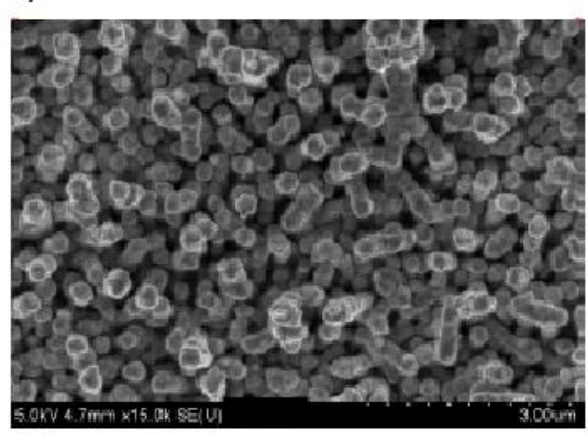

Figura 2. a) Imagen de microscopía electrónica que muestra la estructura formada el ácido glutámico-nanoparticulas de apatita para la reconstrucción del esmalte dental. Tomado de la referencia [6] b) Representación del autoensamble de nanovarillas de oro en forma de "X" centroisometrica usando como plantillas de origami de ADN. Tomado de la referencia [8] c) Imagen de TEM de los electrodos usando como bioplantilla el virus de planta mosaico del tabaco (TMV). Tomado de la referencia [7]. 


\subsection{Autoensamble de biomoléculas}

El autoensamble es la organización espontánea de moléculas en condiciones de equilibrio termodinámico en arreglos estructurales bien definidos y estables. Está autoorganización o autoensamble de diferentes moléculas se da debido a las interacciones no covalentes como son los enlaces puentes de hidrógeno, interacciones electrostáticas, interacciones hidrofóbicas e interacciones de Van Der Waals. [2;10;11]

En el diseño de estructuras auto-ensambladas se emplean principalmente las técnicas de síntesis química, crecimiento de cristales y en la autoorganización de nanoestructuras de cero (0D) una (1D) y dos dimensiones (2D). [14]

Existen dos tipos de autoensamble: estático y dinámico. El autoensamblaje estático denota un proceso en la formación de estructuras ordenadas que son formadas cuando el sistema alcanza un mínimo de energía. Algunos ejemplos son las nanopartículas, los cristales líquidos y los sistemas supramoleculares jerárquicos.[13] El autoensamble dinámico involucra aquellas interacciones responsables de la formación de estructuras entre componentes que producen que el sistema disipe energía. Este tipo de estructuras complejas las podemos encontrar en los sistemas de reparación y organización de tejidos. [12;13]

Los procesos de autoensamble principalmente se encuentra en la naturaleza en los procesos biológicos, como tal en el plegamiento de proteínas en la estructura nativa, en complejos proteína-proteína, la asociación antígeno-anticuerpo, la traducción y transcripción del código genético, la formación de las unidades mayor y menor de los ribosomas y su ensamble con RNA mensajero durante la traducción.

Muchos sistemas biológicos debido a su arquitectura son excelentes plataformas para el adecuado control del proceso de autoensamble, ya que su forma y composición permiten el reconocimiento molecular y organización de otras moléculas en torno a su estructura. De la misma manera, la interacción de las moléculas con su entorno influye en la dinámica del proceso de organización. Por lo tanto, la estructura autoensamblada es el resultado de las interacciones: repulsivas y atractivas de corto y largo alcance en diferentes sistemas químicos y condiciones físicas. Algunos ejemplos de autoensamble molecular son: la formación de cristales líquidos, polímeros, coloides, por mencionar algunos. 


\subsection{Cristales líquidos}

Durante los últimos años ha habido gran interés en el estudio del autoensamble de moléculas para la formación de cristales líquidos (LC); estos se han considerado como el cuarto estado de la materia, debido a que muestran propiedades tanto del estado sólido como del líquido. Las moléculas (mesógenos) en los LC tienen propiedades únicas, ya que poseen un orden de largo alcance, presentan fluidez como un líquido, pero al mismo tiempo restringen parcialmente el movimiento de las moléculas, tal como sucede en los cristales. [15]

En la síntesis de materiales, los cristales líquidos han tomado gran importancia debido a que los mesógenos presentan movilidad y un orden intrínseco de acuerdo con algunos parámetros externos, como la temperatura o la aplicación de campos eléctricos. El ordenamiento de los mesógenos está controlado por condiciones termodinámicas, mediante las interacciones intermoleculares, como son los enlaces de hidrógeno o las interacciones iónicas, hidrofóbicas, por mencionar algunas. [15,16]

Los LC pueden clasificarse en dos tipos, en función de la concentración: termotrópicos y liotrópicos. Los LC termotrópicos los mesógenos están estructurados en función de la temperatura y presentan transiciones de fase (se re-organizan) a medida que la temperatura cambia. En este tipo de cristal líquido termotrópico los mesógenos presentan una estructura molecular anisotrópica debido a que estas moléculas exhiben una parte central que es un cuerpo rígido que le da la característica anisotrópica y una parte lateral que exhibe una región flexible que le da movilidad. Los LC liotrópicos están formados por mesógenos anfipáticos en un solvente polar o apolar, que a una determinada concentración, temperatura y presión se organizan, sin poseer necesariamente anisotropía en la forma. [15,17]

Así los LC pueden autoorganizarse en diferentes fases nanoestructuradas, por ejemplo: en capas, estructuras columnares, micelares, etc. Para identificar las fases de los cristales líquidos se utiliza la técnica de microscopia de luz polarizada, entre otras. En esta técnica sobre el LC se hace incidir luz polarizada, la cual es desviada al atravesar la muestra, cambiando la polarización de la luz. Otras técnicas utilizadas es la difracción de rayos $X$ a bajo ángulo, difracción de neutrones, resonancia magnética nuclear y microscopia electrónica de criofractura. [16] 
Los cristales líquidos pueden clasificarse en función de la simetría de las fases debida a la orientación y grados de libertad traslacional de los mesógenos como esméctica, nemática y colestérica.

La fase nemática es aquella donde el eje principal de las moléculas está alineado en la misma dirección y a largo alcance. Mientras que las posiciones de sus centros de masa no poseen orden de largo alcance. En este tipo de fase las moléculas tienen anisotropía definida a través de los ejes más largos, por lo tanto, poseen momentos dipolares fuertes y grupos polarizables. Esta fase aparece a altas temperaturas. La orientación molecular a una dirección bien definida que se conoce como el vector director $n$ y se muestra en la Figura 3a. $[15,18]$

En la fase tipo esméctico, las moléculas presentan estructuras estratificadas con un espaciado entre capas definidas, entre cada capa perpendicular al vector $n$, las moléculas pueden deslizarse libremente una sobre otra y entre cada estratificación puede existir una diversidad de arreglos moleculares, en estos arreglos, sus ejes principales son paralelos y su centro de masa se encuentra entre cada plano. Esta fase aparece a bajas temperaturas y presenta menor fluidez que la fase nemática como se observa en la Figura 3b. [15,18]

En la fase colestérica las moléculas poseen un orden de orientación de largo alcance, apilándose entre capas muy delgadas que forman un pequeño ángulo entre sí. Entre cada capa tiene una rotación con respecto a un eje de torsión alineándose en el vector director $n$ que gira uniformemente a través de un círculo completo que avanza a través de la fase y la distancia necesaria para que se complete el circulo se le llama pitch $(P) \circ$ inclinación. Y la longitud de la periodicidad es la mitad de la distancia P/2, ver Figura 3c. [15,18] 


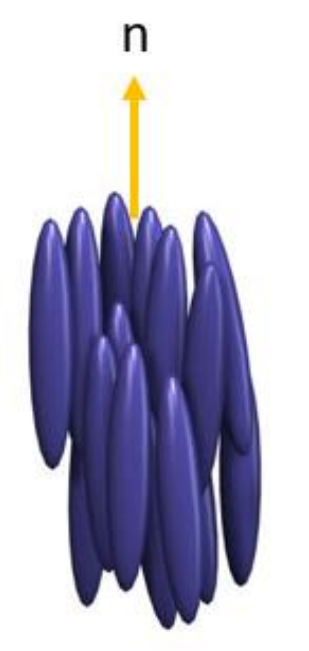

a) Nemática

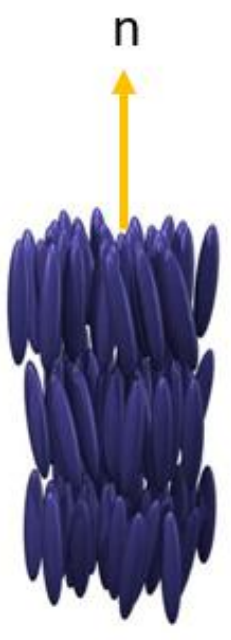

b) Esméctico

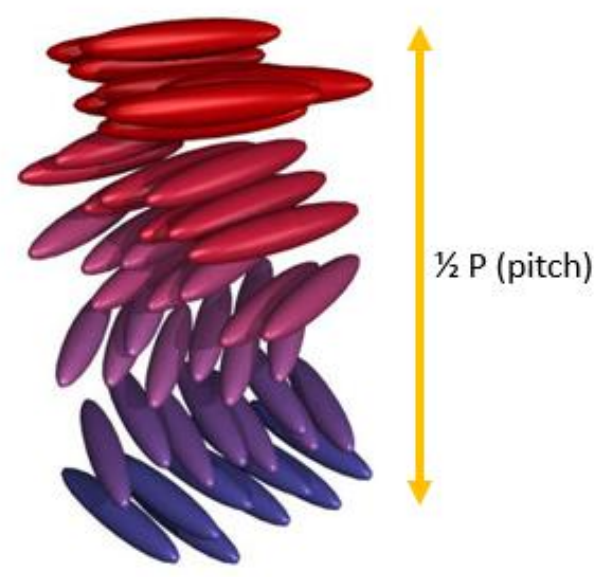

c) Colestérica

Figura 3. Imagen de las diferentes fases de cristal líquido. Tomado de la referencia [21]

\subsection{La estabilidad e interacciones en las proteínas}

Las proteínas están involucradas en todos los procesos biológicos con una diversidad de propiedades físicas y químicas. Algunas funciones que pueden realizar las proteínas son catalizar reacciones, identificar moléculas (reconocimiento molecular) y permitir su interacción (unión a ligandos) que a su vez puede activar otras funciones en las células como transportar moléculas, etc. También pueden ensamblarse y formar "máquinas celulares" (formadas por decenas de proteínas que trabajan simultáneamente) que permiten realizar funciones más complejas como la replicación (replisoma), transcripción (transcriptoma) y la traducción (ribosoma). Incluso puede organizarse en estructuras más complejas que delimiten las células de su entorno (membrana celular), que protejan material genético (cápsides virales), etc. [19,20]

En los estudios funcionales que involucran proteínas nativas y recombinantes es importante estudiar la conformación de la proteína, que está condicionada en adaptarse a partir de las interacciones químicas como son los enlaces disulfuro, enlaces de hidrogeno, interacciones hidrofóbicas, iónicas y de Van Der Waals. De la misma manera se sabe que la secuencia de aminoácidos es muy importante en el plegamiento de la proteína. 
Conjuntamente, las propiedades estructurales y funcionales de las proteínas se ven afectadas por cambios repentinos en su ambiente. Algunos factores involucrados en estos cambios son variaciones en el $\mathrm{pH}$, la fuerza iónica, fluctuaciones en la temperatura o en agentes desnaturalizantes.[19]

Para el análisis de estabilidad estructural en proteínas se han empleado diferentes técnicas calorimétricas y espectroscópicas, por ejemplo: dicroísmo circular (DC), absorbancia UV-Vis, ensayos de actividad en fluorescencia y calorimetría diferencial de barrido (DSC). [16]

\subsection{Bacteriófago M13}

Los virus son ensambles biomoleculares que están compuestos por proteínas y ácidos nucleicos (ADN o RNA). Las proteínas forman una "coraza" que puede adoptar diferente forma (esférica, helicoidal, icosaédrica, compleja) y tamaño, su principal función es "proteger" el material genético (ADN o RNA) e identificar a las células blanco. Los virus son agentes infecciosos que sólo pueden replicarse dentro de las células.[22]

Durante los últimos años ha habido un gran interés en utilizar los virus, como bioplantilla en la síntesis de materiales debido a que el tamaño (nanométrico) y la superficie proteínica (grupos funcionales) están controlados genéticamente, pero pueden ser manipulados mediante ingeniería genética. Además, los grupos químicos de las proteínas también pueden ser modificados por técnicas de bioconjugación. Estas modificaciones cambian las propiedades de los virus y nos permite utilizarlos como bloques de construcción "hechos a la medida" para el diseño y síntesis de materiales.

Los virus poseen una estructura externa llamada cápside que está constituida por uno o más tipos de proteínas, que tienen la función de proteger y empaquetar el genoma viral. Esta cápside es una estructura bien definida armónica y funcional. Las proteínas están arregladas de manera espontánea por $n$ copias de una o muy pocas proteínas en la cápside viral. Además, la estructura de las proteínas confiere a la partícula viral la estabilidad suficiente para soportar condiciones ambientales relativamente extremas, como son los cambios de temperatura, de $\mathrm{pH}$ y la presencia de solventes orgánicos.[22] 
Existen diferentes formas de cápsides virales que han causado impacto en diferentes áreas de investigación y han encontrado potenciales aplicaciones en la medicina, óptica, generación y almacenamiento de energía, por mencionar algunas. Las cápsides que más se han estudiado son las de virus esféricos, icosaédricos y helicoidales, ver Figura 4. Pero en los últimos años se ha tenido gran interés en estudiar a los virus filamentosos, por la versatilidad que tiene en la organización jerárquica para la construcción de novedosos materiales de escala nano a micrométrica.[23]

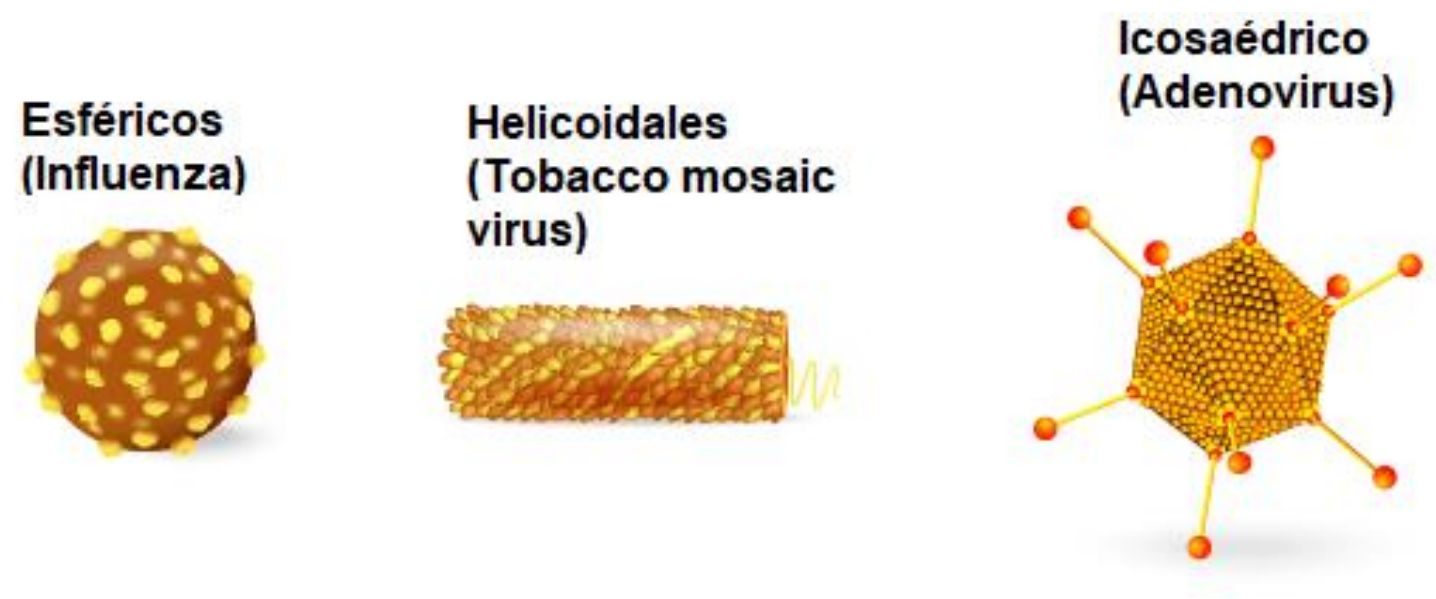

Figura 4. Ejemplos de diferentes estructuras de cápside de virus.

Los bacteriófagos (fagos) son virus filamentosos que infectan a específicamente a bacterias, de ahí su nombre de bacteriófagos. La replicación de estos depende de la maquinaria enzimática de la célula hospedera. Se consideran los entes biológicos más numerosos y diversos de la biosfera. Específicamente existen bacteriófagos filamentosos que infectan a células de Escherichia Coli (E. coli), las cuales poseen el plásmido conjugativo Ff, responsable de la formación del $F$ pilus que reconoce las proteínas de la cápside. Estos fagos forman una familia denominada inoviridae de la cual algunas especies representativas son fagos $\mathrm{f} 1, \mathrm{fd} \mathrm{y}$ M13.[24,26]

El fago M13 tiene estructura de rodillo con un diámetro de $6.5 \mathrm{~nm}$ y una longitud aproximadamente de $800 \mathrm{~nm}$. En su interior posee una cadena circular sencilla de acido desoxirribonucleico (SSADN) que está formada por 6407 nucleótidos que contiene los 11 genes implicados en el proceso de infección, replicación, ensamble y formación de la cápside viral. La cápside ésta constituida por 5 diferentes proteínas ( 5 genes del genoma); en un extremo 
se encuentra las proteínas $p 7$ y p9, y en el otro extremo se encuentra las proteínas p6 y p3. La proteína p3 es la encargada del reconocimiento del F pilus y de la inyección del ssADN dentro de la célula bacteriana. La proteína p8, de la cual hay alrededor de 2700 unidades, es la proteína mayoritaria y cubre la parte alargada o cuerpo de la cápside. [25,26] La estructura del fago M13 se muestra en la Figura 5.

\begin{tabular}{|llll|}
\hline Proteína & $\begin{array}{l}\text { No. de } \\
\text { aminoácidos }\end{array}$ & $\begin{array}{l}\text { Peso Molecular } \\
\text { (Da) }\end{array}$ & $\begin{array}{l}\text { Copias por } \\
\text { fago }\end{array}$ \\
\hline p3 & 406 & 42,500 & $\sim 5$ \\
\hline p6 & 112 & 12,300 & $\sim 5$ \\
\hline p7 & 33 & 3,600 & $\sim 5$ \\
\hline p8 & 50 & 5,200 & $\sim 2700$ \\
\hline p9 & 32 & 3,600 & $\sim 5$ \\
\hline
\end{tabular}

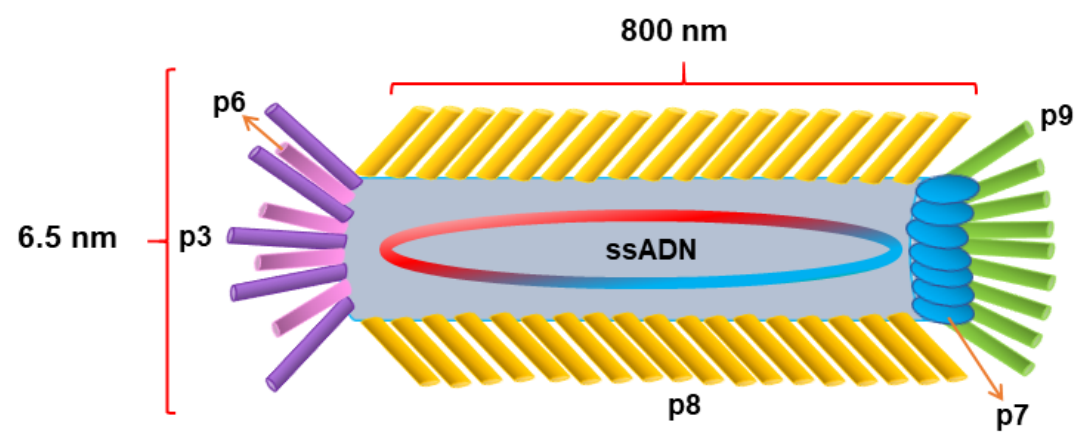

Figura 5. a) Tabla de las proteínas que conforman al bacteriófago M13. tomado de la referencia [72]. b) Estructura del bacteriófago M13, se muestra la ssADN cubierta por la cápside, constituida por la proteína p8, mientras que en los extremos se ubican las proteínas p7, p9, p3 y p6. Tomado de la referencia [24]

Como se ha mencionado, el fago M13 infecta solamente a cepas de E.coli que sean portadoras del plásmido conjungativo $\mathrm{F}$, que es responsable de la formación del F-pilus. El extremo amino terminal de la proteína p3 interacciona con el F pilus de la bacteria depositando el ssADN. Una vez adentro, la molécula de ssADN es empleada como molde por las polimerasas para sintetizar la hebra complementaria, formando una doble cadena de ADN, llamada forma 
replicativa (dsRF). La replicación de las dsRF es iniciada por la proteína p2 del fago y con la ayuda de la polimerasa de la bacteria, de esta manera se empieza a producir las copias necesarias de moldes para iniciar la transcripción de los 11 genes que solo 5 de ellos están implicados en el ensamble de la cápside del fago y los demás implican en el proceso la replicación y ensamble. Figura 6 . Las proteínas p1 y p4 son necesarias para el ensamblaje del fago y se encuentran en la membrana interna y externa de la célula hospedera para generar un poro que es necesario para la extrusión del fago. [24,26] Figura 7.

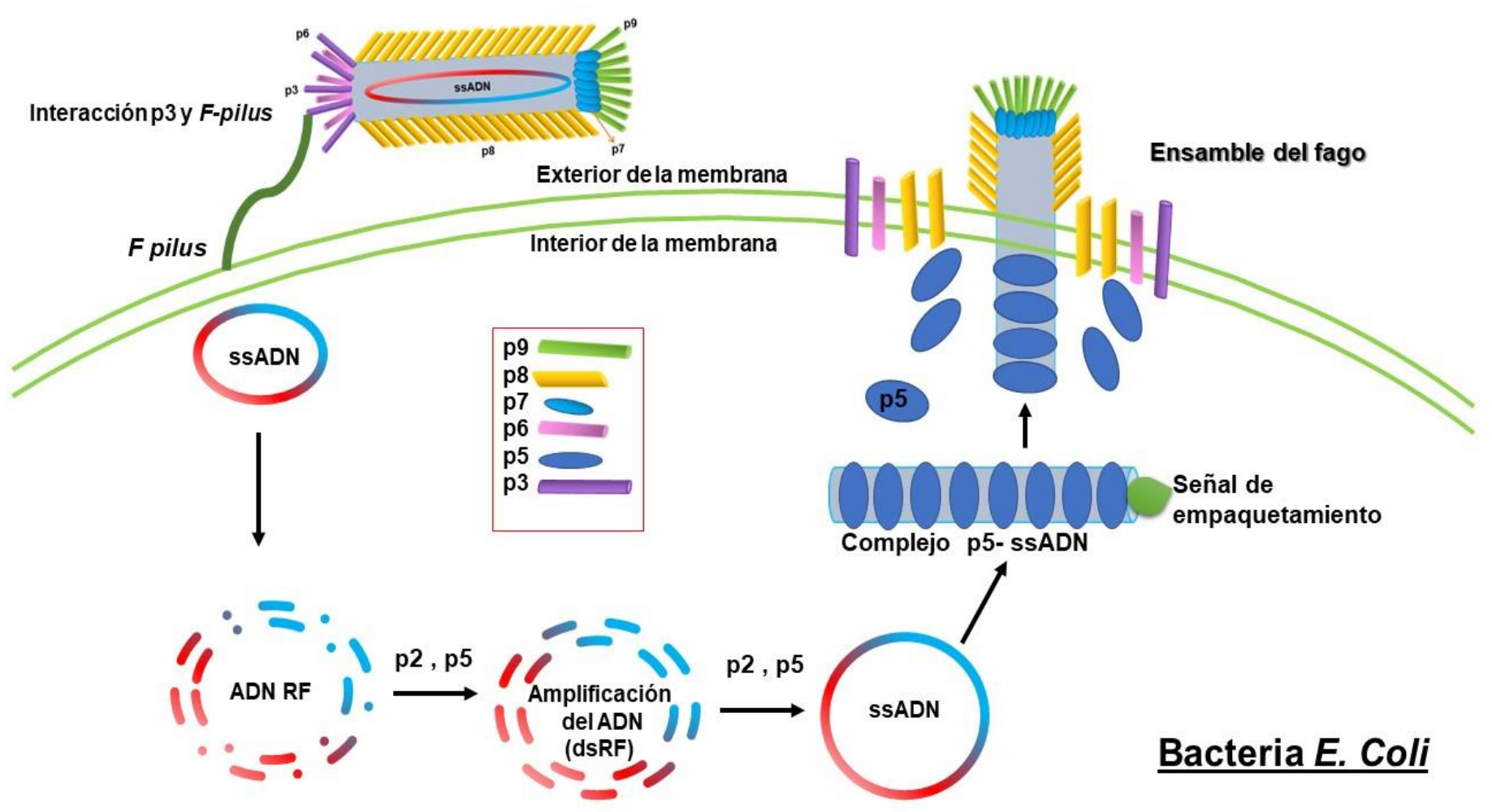

Figura 6. Ciclo de infección del bacteriófago M13 en su célula hospedera Escherichia Coli.

Después de este proceso, la proteína p5 del fago se encargará de separar la hebra replicativa y formará un complejo con ella (p5-ssADN), formando una precápside. La ssADN en el complejo posee una señal de empaquetamiento que interactúa en la membrana celular para ser extruida, el ensamblaje empieza con las proteínas p7 y p9, después en el complejo p5ssADN, la p5 es reemplazada por dos proteínas p8, obteniendo así un complejo p8-ssADN. En el proceso de extrusión se genera el ensamble de la cápside del fago, en este paso las proteínas p8 tendrán cambios en sus propiedades estructurales (pierden el péptido señal). 
Posteriormente, las proteínas p3 y p6 se posicionan en el extremo finalizando el ensamble del fago. Este proceso se observa en la Figura 7. [24,25]

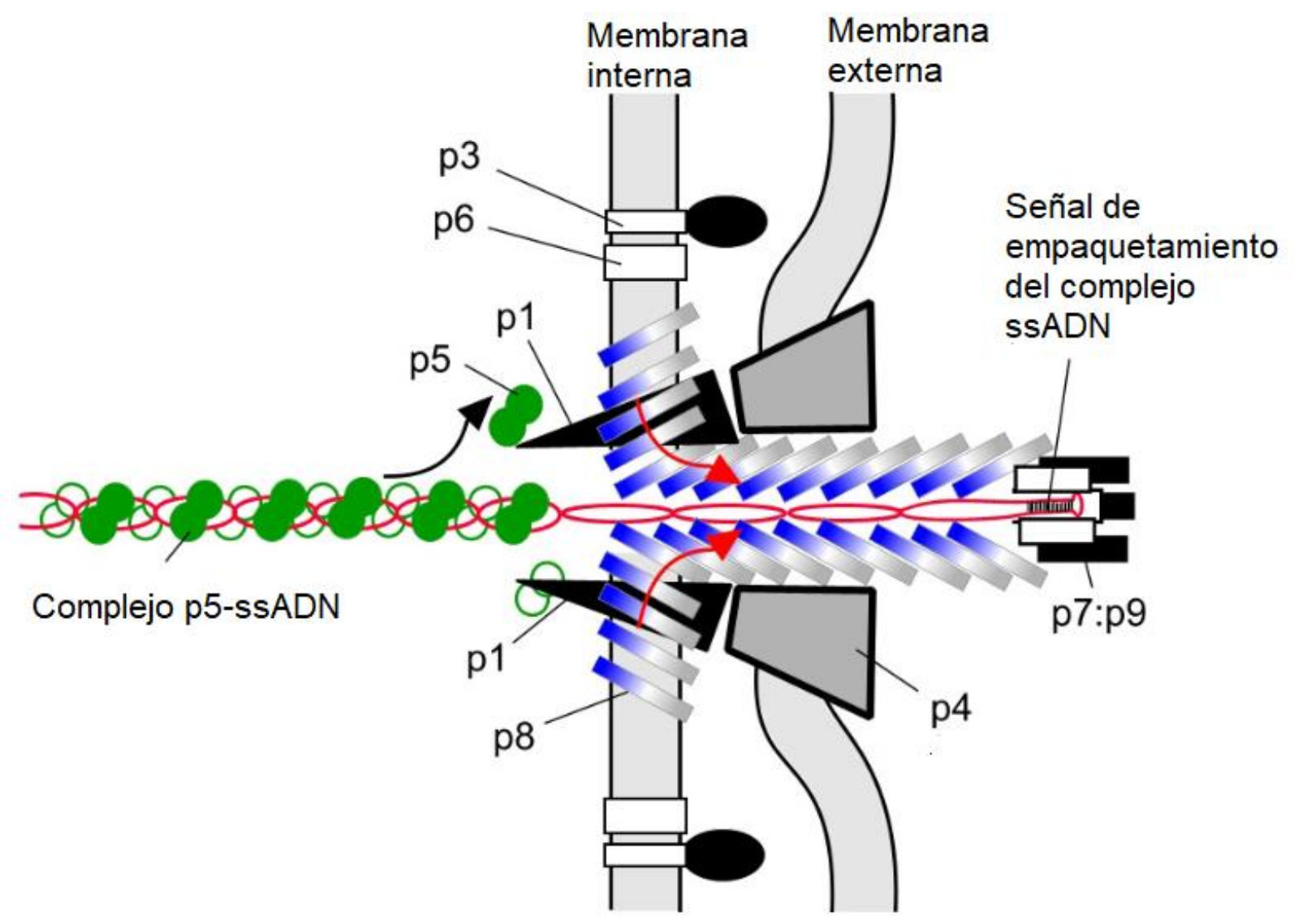

Figura 7. Ensamble de la cápside del fago M13 en la membrana celular.

\subsubsection{Cápside del bacteriófago M13 (Proteína p8)}

La proteína p8 es la más abundante de la cápside del fago (hay aproximadamente 2700 unidades de esta proteína), se encuentran alrededor del eje del filamento en capas con una simetría C5 y un eje de doble tornillo con un pitch de 33 angstroms (Á). [28] Está formada por 50 aminoácidos, con un peso molecular de 5200 daltones (Da). Cada proteína p8 tiene una estructura secundaria tipo a-hélice que mide alrededor de $1 \mathrm{~nm}$ de ancho y de $7 \mathrm{~nm}$ de largo. La $\alpha$-hélice se encuentra inclinada respecto al eje del virus en un ángulo aproximado de $20^{\circ} \mathrm{y}$ 
entre cada subunidad adyacente en los extremos N-terminal hay una distancia de $2.7 \mathrm{~nm}$ de separación (ver Figura 8a). [29]

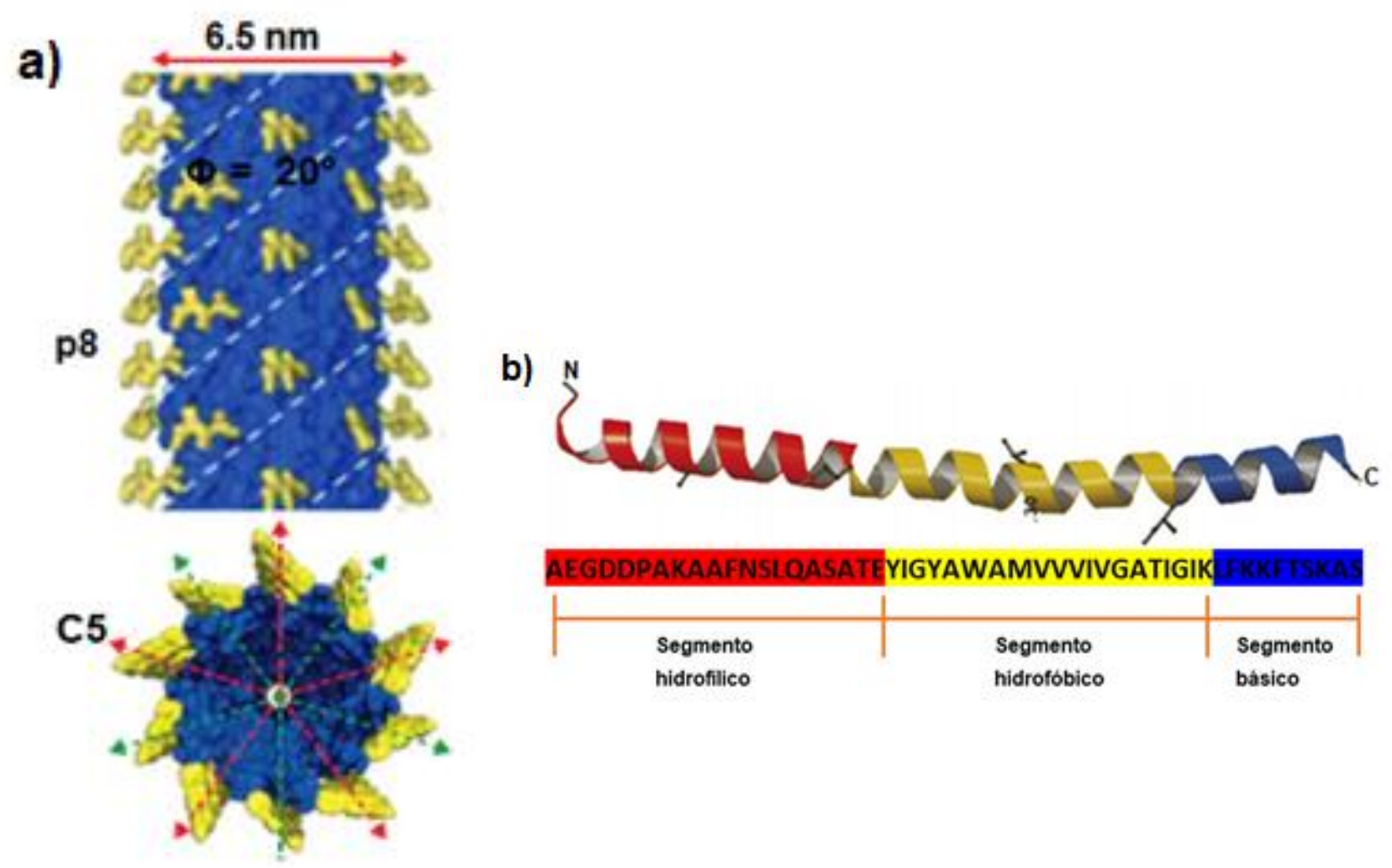

Figura 8. a) Estructura de la cápside del bacteriófago M13. Tomado de la referencia [39] b) Estructura y secuencia de la proteína p8. Modificado de la referencia. Tomado de la referencia [72]

La p8 consiste en tres dominios: el extremo C-terminal está constituido por 10 aminoácidos que apuntan hacia el interior del fago y que interaccionan con el ADN viral. La región intermedia de la proteína es hidrofóbica y está compuesta por 20 aminoácidos. El extremo N-terminal está orientada hacia el exterior del fago, se integra por 20 aminoácidos que se ubican en la superficie del fago. En esta región (Figura 8b) hay una gran cantidad de aminoácidos ácidos que son los responsables de la solubilidad del fago.[30]

En la actualidad, el bacteriófago M13 ha suscitado gran interés en investigaciones orientadas en el desarrollo de materiales, debido a sus características estructurales y propiedades biofísicoquímicas. Una peculiaridad importante del fago es que el control sobre su estructura y ensamble no se limita a una sola partícula; en su lugar es bien conocido que a ciertas concentraciones presentan un comportamiento de cristal líquido debido a las interacciones que se presentan entre las proteínas p8-p8 de fagos adyacentes (uniones intermoleculares), las 
cuales contribuyen a mantener la estabilidad estructural de los LC. El genoma del M13 es pequeño y manipulable, lo que permite realizar modificar los genes y que se expresen en la superficie del fago, para incrementar la capacidad como plantilla de reconocimiento y síntesis.

\subsubsection{Estabilidad del bacteriófago M13}

Debido a que el bacteriófago M13 ha sido empleado como plantilla en la síntesis de materiales, es importante estudiar su estabilidad estructural, para encontrar las mejores condiciones de síntesis en función del material final y de las propiedades que nos interese explotar. Ya que no necesariamente todas las reacciones pueden ocurrir en solución acuosa, varios grupos de investigación han estudiado la estabilidad del M13 en solventes orgánicos, [35] en mezclas de disolventes,[36] en presencia de detergentes iónicos [32], a diferentes valores de pH (desde 2 hasta 12). [33] Incluso se ha estudiado la estabilidad térmica de la cápside en solución acuosa y en mezclas de solventes [12], lo que ha permitido vislumbrar un mecanismo de desensamble. [31]

Por supuesto, el ensamble del fago es entre otros factores consecuencia de las interacciones (covalentes y no covalentes) que se establecen entre las diferentes moléculas que forman la cápside, siendo las principales las interacciones entre el ssADN-p8 y p8-p8. Estas interacciones están dictadas por la secuencia de la proteína p8, mientras que el sSADN interacciona con los aminoácidos básicos del extremo C-terminal de la p8 (la carga negativa de SSADN es estabilizada con las cargas positivas de los grupos amino), la región hidrofóbica permite el empaquetamiento (interacción) entre proteínas p8 adyacentes. La importancia de la secuencia de los aminoácidos en la estabilidad estructural del fago M13 ha quedado demostrada en varios estudios. La proteína p8 es principalmente responsable de las propiedades del fago M13, como su estabilidad en un intervalo de $\mathrm{pH}$ de 2 a 12 a una temperatura de $37 \mathrm{C}^{\circ} \cdot[37]$

Es notable la capacidad del fago M13 para tolerar mutaciones sin perder su infectividad ni su capacidad de formar partículas viables como ha revisado Makoswki.[37] El extremo N-terminal de la proteína p8 es capaz de tolerar la inserción de péptidos ajenos a la secuencia de la proteína, modificando las propiedades de la superficie de la cápside, pero sin afectar el 
empaquetamiento y ensamble del fago M13. Lo que indicaría que la región hidrofóbica es la principal responsable de la estabilidad estructural del fago.

Por otro lado, Khan et al. [38], investigaron la estabilidad conformacional de la p8 introduciendo mutaciones aleatorias en la región hidrofóbica. Sustituyeron simultáneamente la tirosina en la posición 24 por cisteína y la valina en la posición 31 por alanina (Y24C-V31A). Posteriormente, analizaron la disponibilidad de los grupos cisteína en el fago nativo (forma filamentosa) y en forma de esferoide (S); para lo cual agregaron cloroformo a la solución. Ellos encontraron que en el fago nativo los grupos S-H sufrían reacciones lo que indicaba que a pesar de encontrarse en la región hidrofóbica están altamente disponibles, mientras que los mismos grupos en el fago $S$ difícilmente sufren reacciones debido a que están impedidos estéricamente, incluso los tioles de diferentes p8 están suficientemente cerca para formar dímeros mediante puentes disulfuro.

En resumen, el estudio sistemático de la secuencia de aminoácidos permite entender qué interacciones son responsables de la estabilidad del fago y de su ensamble (empaquetamiento), debido a que la naturaleza química de los aminoácidos, principalmente los de la región hidrofóbica de la proteína p8, influyen en el empaquetamiento del fago.

Para el análisis conformacional y ambiental de la estructura del fago se han empleado varios métodos analíticos, como son; espectroscopía de dicroísmo circular (DC), fluorescencia, espectroscopía infrarroja (IR), dispersión de luz (DLS), por mencionar algunas.

\subsubsection{El bacteriófago M13 como cristal líquido}

Las biomoléculas han mostrado ser excelentes bloques de construcción en la síntesis de cristales líquidos (LC) debido a sus muy particulares características: polimorfismo, monodispersidad, anisotropía, propiedades ópticas únicas como la birrefringencia. En particular, el fago M13 ha generado gran interés por su capacidad de auto-organizarse en estructuras más complejas para formar LC, teniendo como resultado ensambles supramoleculares a través de interacciones intermoleculares débiles. Por lo tanto, lo importante de estos LC es que pueden funcionar como plataformas para sintetizar y diseñar 
nuevos materiales con propiedades novedosas a la medida, ya que la superficie de la cápside puede ser modificada químicamente o genéticamente. [15;40]

El bacteriófago M13 bajo las condiciones adecuadas se organiza espontáneamente en LC. Estos pueden adoptar las diferentes fases: nemática, colestérica y esméctica, las cuales se generan en función de la concentración o de la temperatura. Las fases nemáticas se obtienen a concentraciones relativamente bajas (0.1-0.2 $\left.\mathrm{mgml}^{-1}\right)$, a medida que aumenta la concentración la fase cambia a colestérica $\left(0.2-0.5 \mathrm{mgml}^{-1}\right)$ y si la concentración continúa incrementando se obtiene una fase esméctica (4-6 $\left.\mathrm{mgml}^{-1}\right)$. Ver figura 9 a). Sin embargo, se ha observado que el método de preparación también influye en la formación de distintas fases así Chung et al., trabajaron con el fago M13 sintetizando películas delgadas por el método de dip-coating obteniendo diferentes fases de LC. Ellos argumentan que las fuerzas interfaciales se modifican debido a la fuerza de "pulling" debida a la velocidad de extracción del sustrato, la concentración iónica, la química de la superficie del fago y las propiedades de la superficie del sustrato, ver figura 9 b).[39]

\section{Concentración}

Nemática

$0.1-0.2 \frac{m g}{m l}$

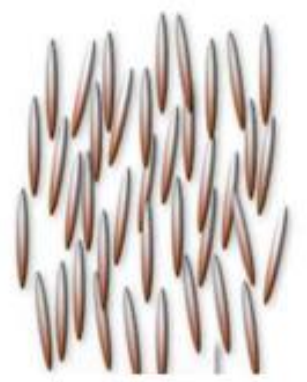

Colestérica

$0.2-0.5 \frac{m g}{m l}$

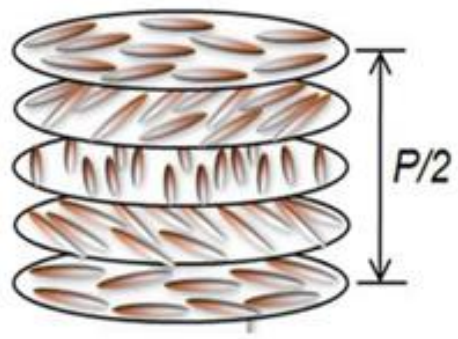

Esméctica

4-6 $\frac{m g}{m l}$

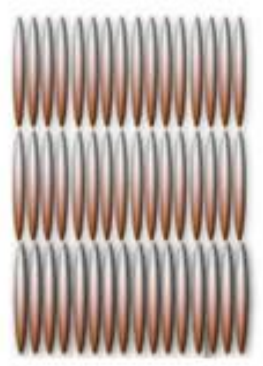

Figura 9. a) Fases de cristal líquido del bacteriófago M13 obtenidas a diferentes concentraciones. Tomado de la referencia [39] 


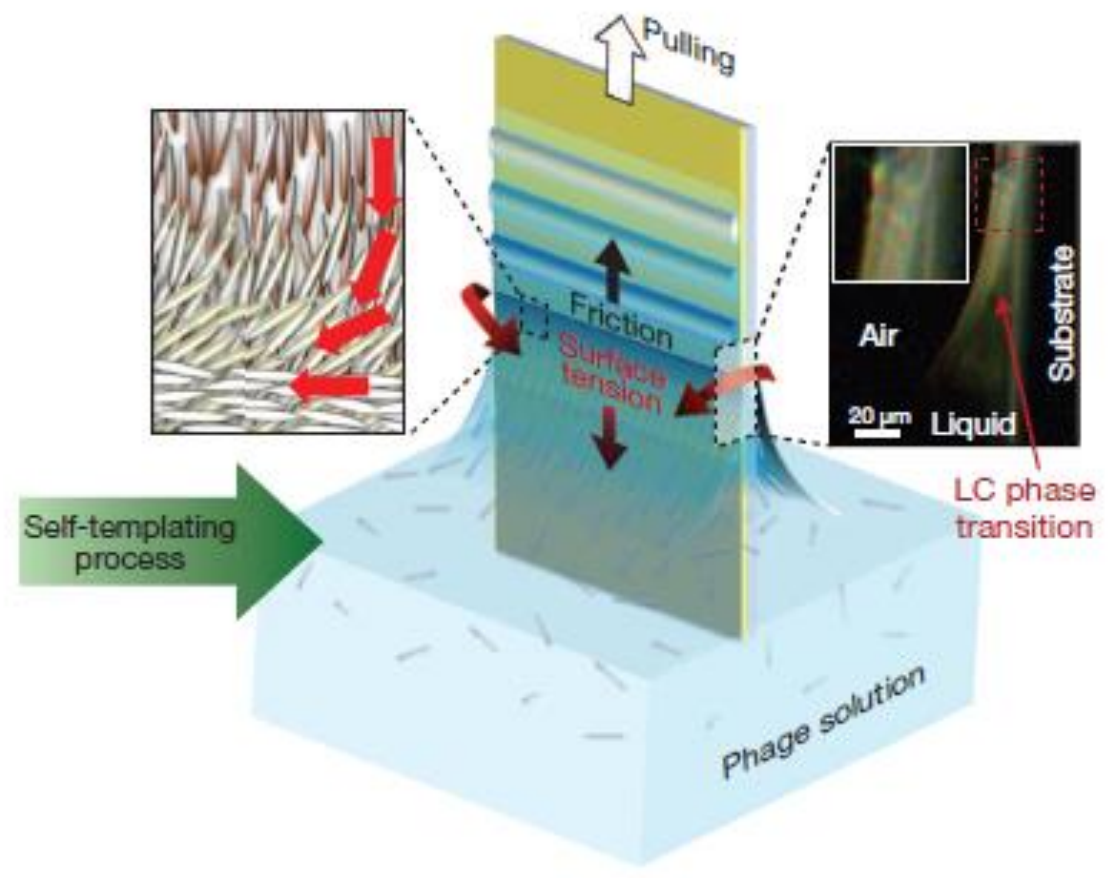

Figura 9. b) Esquema del autoensamble de las partículas de M13 en un substrato generando cristales líquidos en diferentes fases. Tomado de la referencia [39]

Con este método y usando el fago M13 a diferentes concentraciones obtuvieron 3 variantes de las fases de cristal líquido: nemática ortogonal, helicoidal colestérica y helicoidal esméctico. La obtención de estas fases se verificó por diferentes técnicas de análisis (difracción de rayos $\mathrm{X}$ a bajo ángulo, microscopia de luz polarizada, microscopia de fuerza atómica). En la Figura 10a se muestran las estructuras obtenidas empleando una solución de fago a la misma concentración, pero con una velocidad de extracción que disminuye a medida que se va extrayendo el sustrato. Estas franjas están formadas por estructuras que forman surcos y crestas y en ellas se ve claramente la orientación del fago, como puede apreciarse por microscopía de fuerza atómica en la Figura 10 b). 


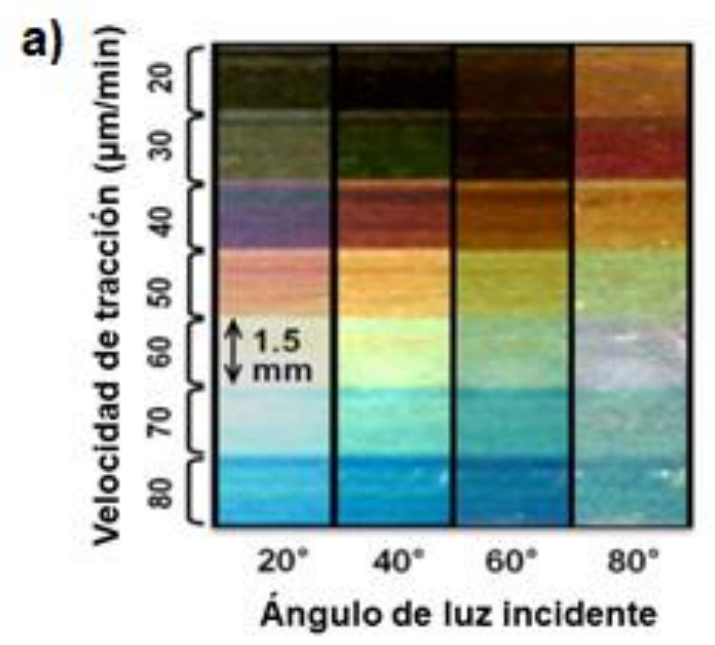

b)
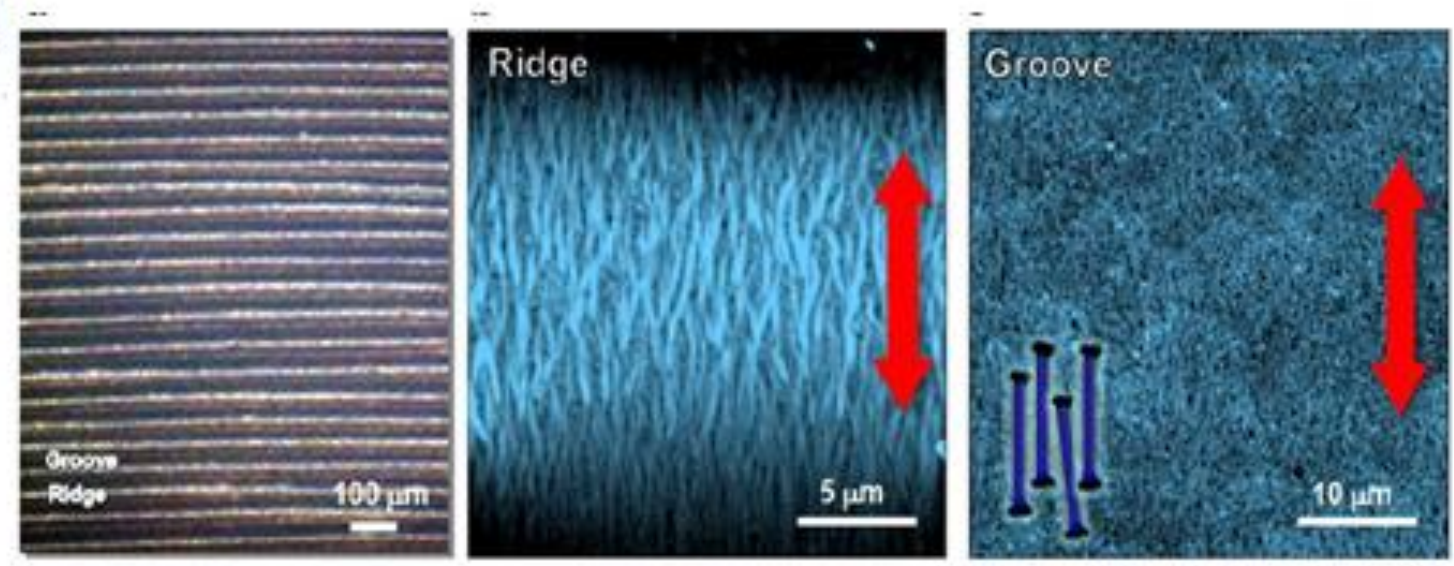

Figura10. a) Imágenes obtenidas por microscopia de luz polarizada del fago M13wt. b) Imágenes obtenidas por AFM, se muestran las estructuras que opto el bacteriófago M13. Tomado de la referencia [39].

Por otro lado, L. Shuaiyu. et al. empleando el fago M13 produjeron LC con arreglo colestérico. Ellos estudiaron el efecto de la temperatura en las transiciones de fase. De este modo observaron transición de fase de colestérica a nemática al aumentar la temperatura en el intervalo de $60^{\circ} \mathrm{C}$ a $40^{\circ} \mathrm{C}$. Observaron que la transición de fase era reversible, concluyendo de manera directa que la concentración del fago y la fuerza iónica de la suspensión no son los únicos factores que promueven la transición de fases.[40] Figura 11. 


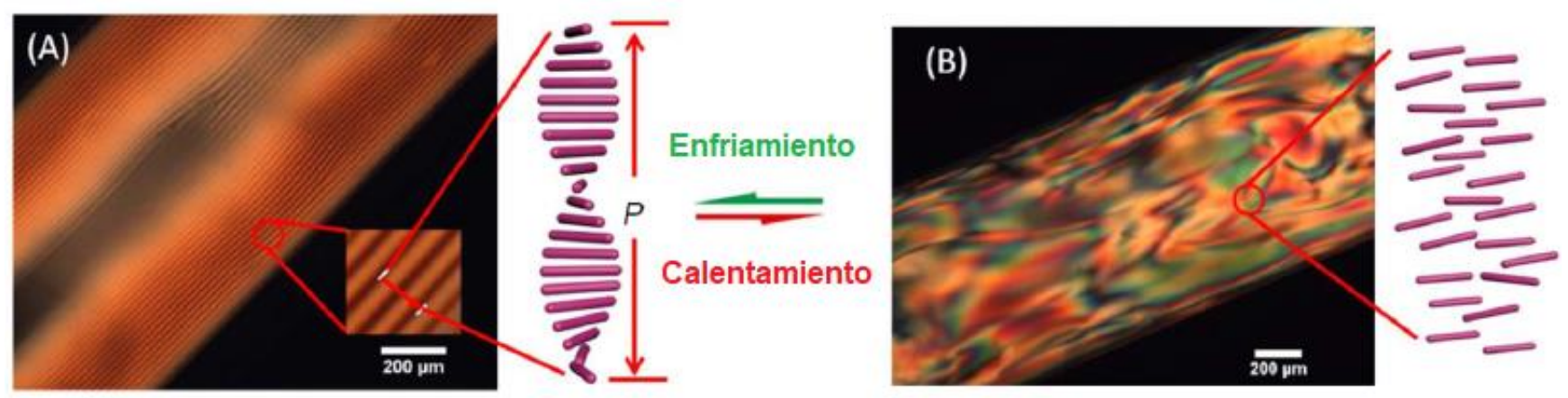

Figura 11. Imágenes obtenidas por microscopía de luz polarizada de LCs del fago M13, en la imagen A) se muestra una imagen típica de una fase colestérica, en el esquema se muestra la posición de cada fago (barras rosas), en la imagen B) se observa una imagen característica de una fase nemática, y el esquema la orientación de los fagos. Como se observa esta transición sucede al cambiar la temperatura del LC. Tomada de la referencia [40].

Estudios espectroscópicos como dicroísmo circular (DC) y fluorescencia intrínseca, mostraron que la transición de fase está asociada al cambio conformacional de la proteína p8 que forma la cápside del fago. En general la región hidrofóbica es responsable de las interacciones entre las proteínas p8 y en particular el aminoácido triptófano (W26) juega un rol importante en el empaquetamiento de la proteína, debido a que hay contactos directos entre p8-p8 por enlaces hidrogeno o por apilamientos de enlaces pi ( $\pi-\pi)$. En principio cualquier modificación de este aminoácido o de su ambiente debería afectar el ensamble de la cápside del fago. Por lo tanto, ellos analizaron el ambiente alrededor de éste el triptófano agregando a la solución del fago M13 moléculas de 1-anilino-8-naftalenosulfonato (ANS). El efecto de agregar esta molécula fue evaluado por fluorescencia a diferentes temperaturas y observaron un desplazamiento del máximo en función de la temperatura, el cual fue reversible y coincidente con la temperatura de transición. Del mismo modo realizaron el análisis estructural del fago mediante DC observando ligeras variaciones en el espectro en función de la temperatura. Si bien estas variaciones, aparentemente no afectan la estructura $\alpha$-hélice de la proteína p8 coinciden con la transición de fase, como puede analizar en la Figura 12.[40] 

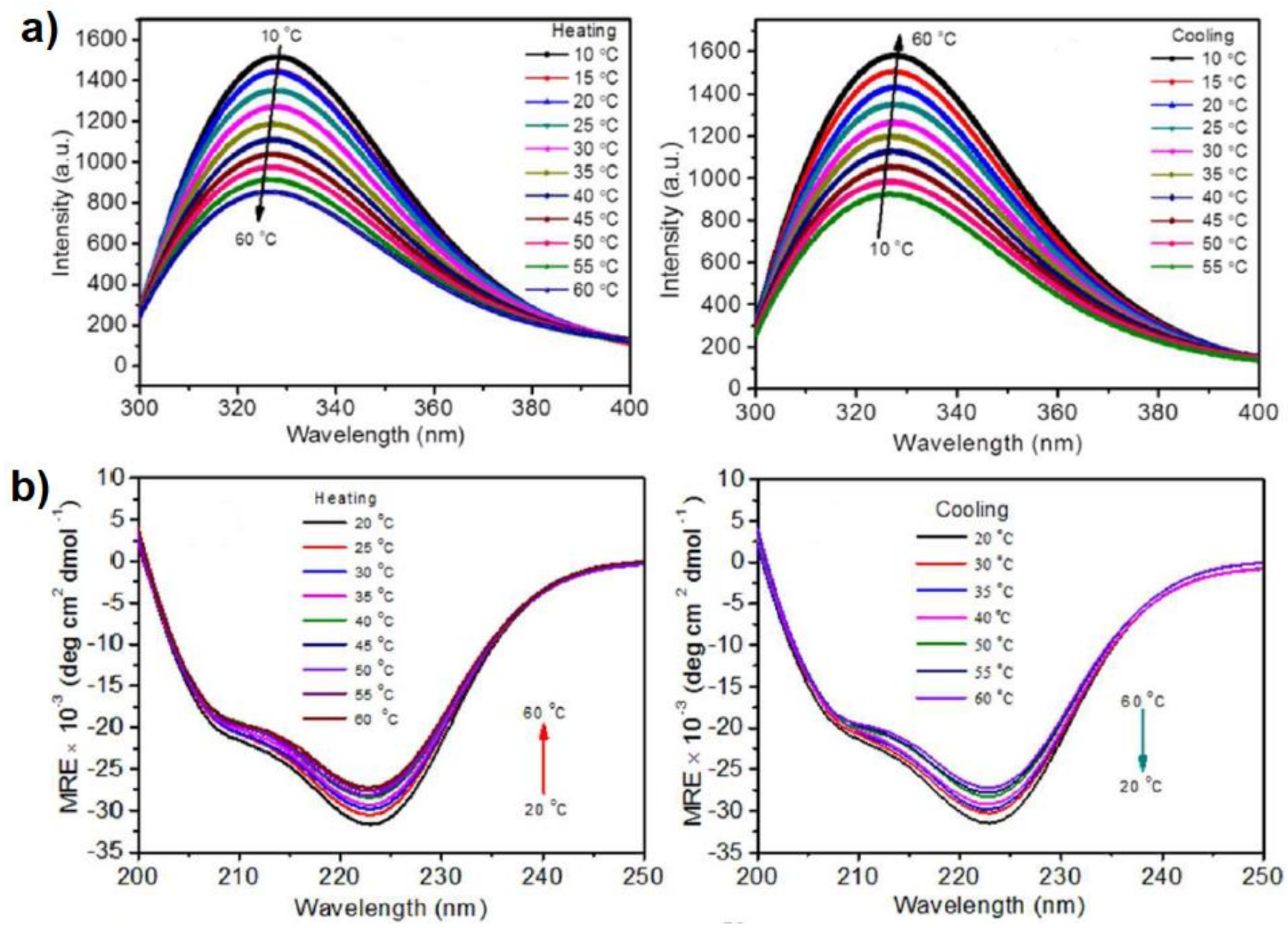

Figura 12. Imágenes a) Se muestran los espectros de fluorescencia intrínseca a diferentes temperaturas de calentamiento y enfriamiento. b) Espectros de dicroísmo circular (DC) a diferentes temperaturas de calentamiento y enfriamiento tomadas de la referencia [40].

\subsubsection{Bacteriófago M13 como plantilla}

Gracias a las características únicas del fago M13 tales como monodispersidad, estabilidad química y térmica, modificación de la superficie (química y genética), autoorganización en LC es una excelente partícula para emplearse como plantilla para la nucleación, biomineralización de materiales inorgánicos ordenados y auto-ensamblados. La síntesis de materiales específicos puede alcanzarse modificando la cápside del fago al insertar grupos funcionales afines a estos materiales.[11] Y luego aprovechando la capacidad del fago de autoorganizarse se puede emplear como plataforma para arreglar materiales en 3D. 
Un ejemplo de este tipo de aplicación se realizó en nuestro laboratorio [41] al usar como plantilla al bacteriófago M13 para la síntesis de estructuras mesoporosas de $\mathrm{SiO}_{2}$ decoradas con nanopartículas de oro y platino.

Por la técnica de bioconjugación se modificaron a los grupos amino de la proteína p8 de la cápside del fago insertando grupos tioacetato, que posteriormente se desacetilaron para producir SH. Se escogió este grupo debido a su afinidad con iones de metales como $\mathrm{Au}, \mathrm{Ag}$, $\mathrm{Pd}$, etc. De tal forma que sirvieran como puntos de nucleación para sintetizar NPs. Se usaron dos moléculas de diferente longitud $\mathrm{N}$-succinimidil S-acetiltioacetato (SATA) o N-succinimidil S-acetiltiopropionato (SATP) para realizar esta reacción y al fago obtenido se le llamo M13$\mathrm{SH}$. Para la síntesis de los mesoporos se empleó una mezcla de tetraetilortosilicato/3aminopropil trietoxisilano (TEOS/APTES) que en presencia de M13-SH (a concentraciones de $4 \mathrm{mg} / \mathrm{mL}$ ) se autoensambló en fases hexagonales y sobre la superficie se polimerizó $\mathrm{SiO}_{2}$. En las etapas iniciales de polimerización se agregó una solución que contenía iones de $\mathrm{Au}^{3+}$, los cuales nuclearon en la superficie del fago en los grupos $\mathrm{SH}$.

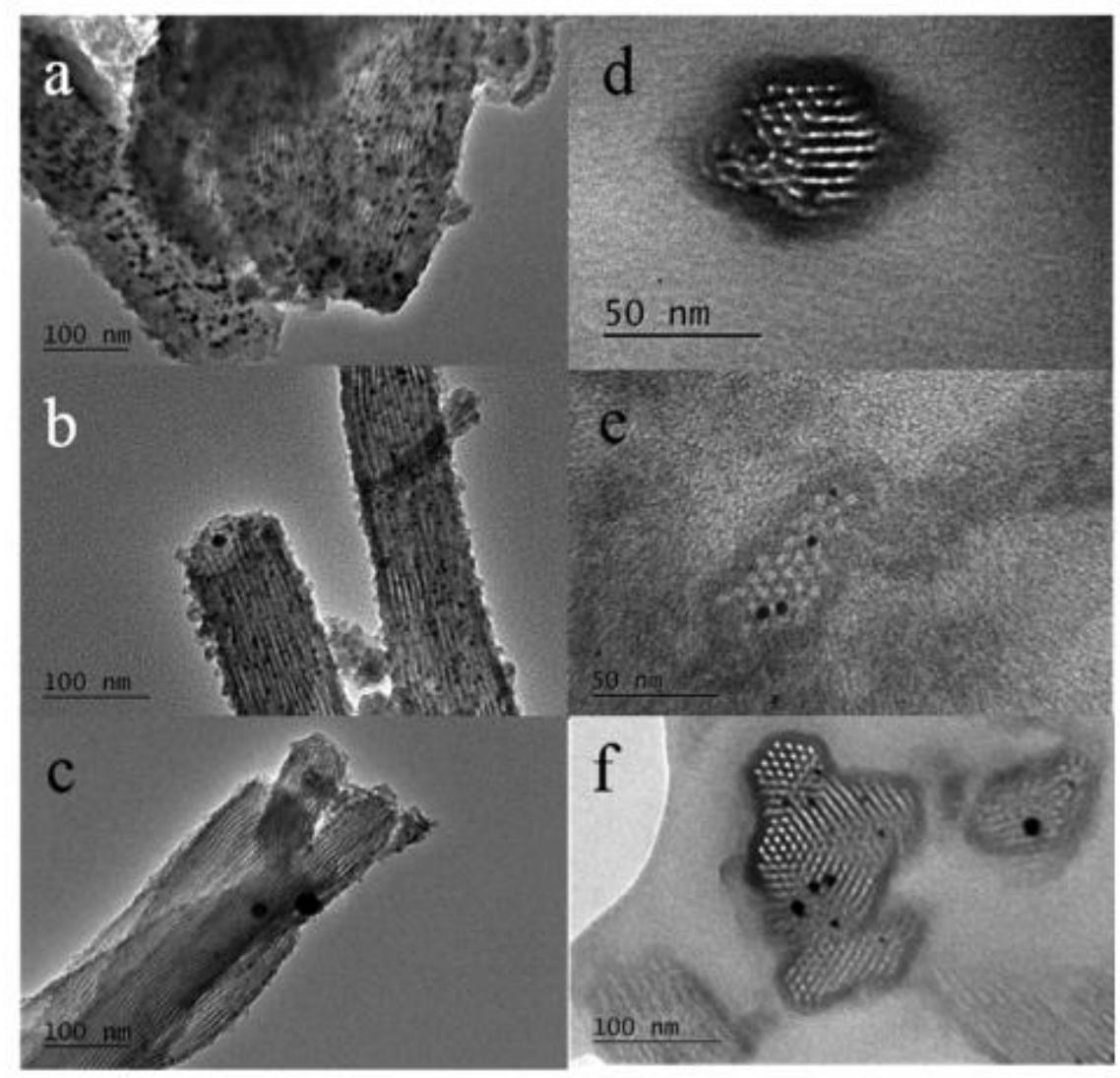

Figura 13. Imágenes TEM tomada de la referencia [35]. Se muestra los mesoporos formados por el bacteriófago M13, a) y d) son mesoporos funcionalizados con SATA, b) y e) funcionalizados con SATP, c) y f) son imágenes del M13 sin ninguna modificación química. Tomada de la referencia [41] 
De acuerdo con los resultados de la caracterización de los mesoporos (espectroscopía de rayos-X a bajo ángulo (SAXS), espectroscopía infrarroja (IR), espectroscopía UV-Vis y microscopía electrónica de transmisión (TEM)), se propuso que el fago se organizó en estructuras de LC hexagonales y en la superficie polimerizó el $\mathrm{SiO}_{2}$. Los mesoporos de fago sin funcionalizar, tienen un tamaño de poro $\sim 4.5 \mathrm{~nm}$ y un espesor de pared de $\sim 1.8 \mathrm{~nm}$ y las nanopartículas se encuentran en la superficie e incluso pueden estar obstruyendo la entrada del poro. En contraste, los mesoporos obtenidos con M13-SH contenían nanopartículas incrustadas en las paredes del material y se liberaba el canal del poro (ver figura 13). Esta característica de poro libre es muy ventajosa ya que varios materiales pueden viajar en los poros teniendo una gran variedad de aplicaciones en catálisis. Por lo tanto, los autores observaron la virtud de usar el bacteriófago como plantilla en la nucleación de materiales y síntesis de materiales mesoporosos, sin afectar la estructura del bacteriófago M13. [41] 


\section{Capítulo 2}

\section{Hipótesis y objetivos}

\subsection{Planteamiento del problema}

Recientemente se ha tenido interés en generar materiales innovadores a escala nanométrica proporcionando un mayor beneficio en costo y en sustentabilidad. Lo cual nos obliga a buscar nuevas herramientas, como es el uso de moléculas biológicas como bioplantillas para la síntesis de materiales (inorgánicos, híbridos, etc.). En particular, el bacteriófago M13, por su fácil manipulación y capacidad de autoorganización en cristales líquidos, puede emplearse como plataforma para sintetizar y ordenar materiales. En este trabajo se ha propuesto estudiar la influencia de los aminoácidos (aa) de la proteína p8, en las propiedades estructurales de la cápside. Así mismo, se propone introducir cisteínas (C) que contengan grupos afines para la síntesis de nanopartículas (NP) de metales nobles. Con este estudio nos proponemos contestar las siguientes preguntas. ¿El bacteriófago M13 es capaz de tolerar mutaciones en la región hidrofóbica de la proteína $\mathrm{p} 8, \sin$ afectar la estructura hélice $\alpha$ y el autoensamble en la cápside? ¿Es posible que estas mutaciones sirvan como puntos de nucleación para la síntesis de NP de Au y Ag?

\subsection{Hipótesis}

Ya que se ha reportado que el fago es una partícula cuya proteína p8 tolera casi cualquier mutación sin afectar la ensamble y la estructura de la proteína p8, nuestra hipótesis de trabajo es que podemos mutar los aminoácidos (aa) valina en la posición 31 por cisteínas sin afectar la estructura y que simultáneamente sirvan como puntos de nucleación para la obtención de NP. 


\subsection{Objetivos}

\subsubsection{General}

Estudiar la estructura del bacteriófago M13wt (fago nativo) y de las mutantes L14V/V31C y M28R/V31C, mediante técnicas espectroscópicas para entender la influencia que la identidad del aminoácido juega en la p8 y en el ensamble del fago.

\subsubsection{Específicos}

Realizar mutaciones funcionales en la parte hidrofóbica de la proteína p8. De manera específica estas mutaciones deberán incluir la inserción de cisteínas.

- Caracterizar estructuralmente por técnicas espectroscópicas (espectroscopía UVVisible, dispersión dinámica de luz (DLS), dicroísmo circular (DC) e infrarrojo (IR)) al bacteriófago M13wt y mutantes obtenidas.

* Estudiar el uso de las mutantes de M13 como plantillas el M13 para la síntesis y ordenamiento de NP metálicas de Au y Ag. 


\section{Capítulo 3}

\section{Materiales y metodología}

\subsection{Materiales}

Vector M13mp18 y Q5 Hig-Fidelity DNA Polymerase de New England Biolabs, bacteria E. coli cepa XL1-Blue de Stratagene, medios de cultivo Luria-Bertani Broth Base (LB), Luria-Bertani Agar de Invitrogen, Polietilenglicol MM 8,000 (PEG), marcadores (1 Kb ladder) y reveladores de DNA (EZ-Vision-Two), IPTG $(40 \mu \mathrm{g} / \mathrm{mL})$ y X-Gal $(32 \mu \mathrm{g} / \mathrm{mL})$ de Amresco, cloruro de sodio $(\mathrm{NaCl})$, tetraciclina , tetracloruro de oro trihidratado $\left(\mathrm{HAuCl}_{4} .3 \mathrm{H}_{2} \mathrm{O}\right)$, borohidruro de sodio $\left(\mathrm{NaBH}_{4}\right)$ y nitrato de plata $\left(\mathrm{AgNO}_{3}\right)$ de Sigma-Aldrich, dithiothreitol (DTT) de Bio-rad, ácido bórico $\left(\mathrm{H}_{3} \mathrm{BO}_{3}\right.$,Tecnica Química), hidróxido de sodio $(\mathrm{NaOH})$ de Merck y agua desionizada MilliQ.

\subsection{Metodología}

\subsubsection{Amplificación y purificación del bacteriófago M13wt}

Para la amplificación del fago, se inoculó $250 \mathrm{~mL}$ de LB con $2.5 \mathrm{~mL}$ de E. coli (XL1-Blue), crecida durante la noche y suplementado con tetraciclina $\left(\mathrm{Cf}=10 \mu \mathrm{g} \mathrm{mL}^{-1}\right)$, el medio inoculado se creció un lapso de $16 \mathrm{hr}$, a $32 \stackrel{\circ}{\circ}$ con agitación a $240 \mathrm{rpm}$. Para la purificación del fago, el cultivo se centrifugó por 15 minutos a $9820 \times \mathrm{g}$ a una temperatura de $4{ }^{\circ} \mathrm{C}$. Se recolectó el sobrenadante, donde se encuentra el fago amplificado, se adicionó 1/5 del volumen recolectado de una mezcla de PEG $(20 \%)$ y $\mathrm{NaCl}(2.5 \mathrm{M})$, y se incubó por $2 \mathrm{hr}$ en hielo. Después se centrifugó nuevamente por 10 minutos a 15,344 x g a $4{ }^{\circ} \mathrm{C}$. Se recolectó el sedimento y se resuspendió en agua estéril. El fago se precipito nuevamente ( $P E G$ y $\mathrm{NaCl})$. Finalmente, el sedimento se resuspendió en el volumen adecuado de agua estéril o buffer. 


\subsubsection{Modificación genética del bacteriófago M13 (M13mp18)}

En este trabajo se diseñaron dos mutantes, dichos cambios son en la región hidrofóbica de la proteína p8 de la cápside del fago M13. Como se ha mencionado, esta región contribuye a la estabilidad estructural.

La secuencia de aa de la proteína p8 del fago M13 silvestre (wt), se muestra a continuación:

1

10

20

30

gct gag ggt gac gat ccc gca aaa gcg gcc ttt aac tcc ctg caa gcc tca gcg acc gaa tat atc ggt tat gcg tgg gcg atg gtt gtt

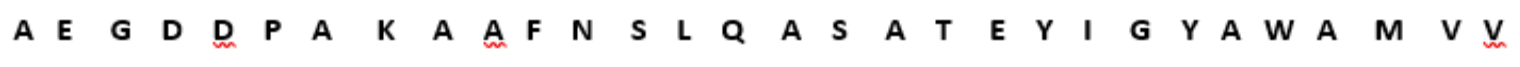

40

50

gtc att gtc ggc gca act atc ggt atc aag ctg ttt aag aaa ttc acc tcg aaa gca agc

$\begin{array}{llllllllllllllllllll}\text { V } & \text { I } & \text { V } & G & \text { A } & \text { T } & \text { I } & G & \text { I } & K & \text { L } & F & K & K & F & \text { T } & \text { S } & K & A & S\end{array}$

Entonces se diseñaron primers, de tal suerte que en el gen p8 el codón que codifica para la valina (V) 31 se sustituyera por un codón que codifica para cisteína (C), sin embargo, ocurrió otra mutación en la posición de leucina ( $(L) 14$ por valina $(V)$ espontáneamente; a esta mutante se le nombró L14V/V31C. De igual manera se diseñó otra mutante, que en la misma posición de valina (V) 31 se sustituyera por el codón que codifica para cisteína (C) y el codón de metionina $(M) 28$ por arginina $(R)$, denominada M28R/V31C.

Mediante el método de mutagénesis dirigida por reacción en cadena de la polimerasa (PCR, en inglés), se realizaron los cambios a la secuencia de la proteína p8. Cada mutante se preparó de acuerdo con el protocolo de la Q5 Hig-Fidelity DNA Polymerase. El producto de PCR se transformó en células competentes de E.coli (XL1-Blue) y se plantó en cajas de LB suplementados con tetraciclina, IPTG $\left(C f=40 \mu \mathrm{gL}^{-1}\right)$ y $X-G a l\left(C f=32 \mu \mathrm{gL}^{-1}\right)$

Las placas obtenidas se amplificaron en $5 \mathrm{~mL}$ de medio LB suplementado con tetraciclina por un lapso de $5 \mathrm{hr}$ a una temperatura de $37^{\circ} \mathrm{C}$ a $240 \mathrm{rpm}$. El cultivo se centrifugó a 9820 x g por 15 minutos, se recolectó el sobrenadante de cada mutante y se almacenó a $4{ }^{\circ} \mathrm{C}$. Estas muestras se emplearon como stocks de M13 mutante para la amplificación a gran escala. El sedimento obtenido se empleó para la extracción y purificación del ADN, de acuerdo con el protocolo de GenElute Plasmid Miniprep Kit. 


\subsubsection{Amplificación y purificación de las mutantes}

Para la amplificación de las mutantes se inoculó $250 \mathrm{~mL}$ de LB con $2.5 \mathrm{~mL}$ de E. coli (XL1Blue), crecida durante la noche y suplementado con tetraciclina $\left(C f=10 \mu \mathrm{g} \mathrm{m}^{-1}\right)$, El medio inoculado se creció un lapso de $4 \mathrm{hr}$, a $32{ }^{\circ} \mathrm{C}$ con agitación a $240 \mathrm{rpm}$. Para la purificación del fago, el cultivo se centrifugo por 15 minutos a $9,820 \times \mathrm{g}$ a una temperatura de $4 \stackrel{\circ}{\circ} \mathrm{C}$. Se recolectó el sobrenadante, donde se encuentra el fago amplificado, se adicionó 1/5 del volumen recolectado de una mezcla de PEG $(20 \%)$ y $\mathrm{NaCl}(2.5 \mathrm{M})$, se incubó por $2 \mathrm{hr}$ en hielo. Después se centrifugó nuevamente por 10 minutos a 15,344 x g a $4 \stackrel{\circ}{\circ}$. Se recolectó el sedimento y se resuspendió en agua estéril. El fago se precipito nuevamente (PEG y NaCl). Finalmente, el sedimento se resuspendió en el volumen adecuado de agua estéril o buffer.

\subsection{Caracterización del fago M13 y mutantes}

\subsubsection{Espectroscopia UV-Vis}

La concentración de la solución del fago M13 se calcula de acuerdo con la ecuación 1:

$$
A_{269}-A_{320}=C \cdot l \cdot \varepsilon .
$$

Donde $C$ es la concentración en $\mathrm{mgmL}^{-1}, l$ es la longitud del paso óptico $(1 \mathrm{~cm})$ y $\varepsilon$ es el coeficiente de extinción que es igual a $3.84 \mathrm{~cm}^{2} \mathrm{mg}^{-1}$. Se considera la absorción característica a $269 \mathrm{~nm}$, ya que a esta longitud de onda se obtiene la contribución de la proteína p8 y el ADN viral presente en el fago. La absorción se midió en un espectrofotómetro Nanodrop 2000 (Thermo Scientific). Las mutantes se cuantificaron por el mismo método. Sin embargo, el máximo de absorción se desplazó, probablemente debido a la introducción de cistinas interpartícula entre proteínas p8.

\subsubsection{Secuenciación de las mutantes}

El ADN obtenido de las miniprep se secuenció por tecnología capilar en los Laboratorios de Servicios Genómicos LANGEBIO. 


\subsubsection{Reducción de Cistinas de las mutantes obtenidas}

Debido a que se introducen grupos tioles en la proteína p8 y a la reactividad de estos grupos con otros adyacentes existe la posibilidad de que durante el ensamble de la cápside se oxiden $y$ formen cistinas. Para regenerar los grupos tiol, estos se reducen con DTT como se describe a continuación. A una suspensión diluida de fago M13 en buffer de boratos (1M) se agregó la cantidad adecuada de DTT para obtenerlo una concentración final de $0.01 \mathrm{M}$. La reacción se incubó a $37^{\circ} \mathrm{C}$ durante $20 \mathrm{hr}$ con agitación constante (200 rpm). Después se dializó en agua estéril y con agitación moderada durante $48 \mathrm{hr}$. El fago se concentró nuevamente mediante precipitación con PEG y NaCl. Inmediatamente se caracterizó por espectroscopía UV-Vis para confirmar el corrimiento del máximo de absorción a 269 nm, característico del fago.

\subsubsection{Espectroscopía de dicroísmo circular (DC)}

El análisis de estructura secundaria se realizó por dicroísmo circular (DC) en el intervalo de 190-250 nm (UV-lejano). Para este estudio se preparó una solución de fagos M13 a una concentración de $0.1 \mathrm{mg} \mathrm{mL}^{-1}$ en agua milli-Q previamente desgasificada y estéril, se empleó una celda de cuarzo de $0.1 \mathrm{~cm}$ de paso óptico. Cada espectro se realizó con un tiempo de respuesta de 4 segundos, a una velocidad de barrido de $5 \mathrm{~nm} \mathrm{~min}{ }^{-1}$ con un ancho de banda de $2 \mathrm{~nm}$ y los datos obtenidos se registraron cada $0.2 \mathrm{~nm}$. Cada espectro es reportado en elipticidad del residuo medio (MRE) en grados $\mathrm{cm}^{2} \mathrm{dmol}^{-1}$

$$
M R E=\frac{(\theta o b s)(M R W)}{(10)(C)(l)}
$$

La $\theta o b s$ es la señal observada en el espectro en miligrados, MRW es la masa molar del residuo medio, para el caso de las muestras del fago M13 se uso el valor en $104 \mathrm{~g} \mathrm{~mol}^{-1}, l$ es la longitud del paso óptico en cm y $C$ es la concentración del fago $\mathrm{M} 13$ en $\mathrm{mg} \mathrm{mL}^{-1}$. Para este análisis se usó un espectropolarímetro Jasco modelo $\mathrm{J}-715$, el cual tiene integrado un controlador de temperatura Peltier PTC-348WI. 


\subsubsection{Espectroscopia Infrarroja (FT-IR, Fourier)}

El análisis de las vibraciones del fago se estudió por espectroscopia infrarroja (FT-IR) acoplado a un Attenuated Total Reflection (ATR). Las muestras se obtuvieron en forma de película a partir de una solución de fago $\left(0.1 \mathrm{mg} \mathrm{mL}^{-1}\right)$. Se empleó un equipo Perkin Elmer modelo Spectrum GX. El intervalo de medición fue de $320-4000 \mathrm{~cm}^{-1}$, con una resolución de $4 \mathrm{~cm}^{-1} \mathrm{y}$ los datos se guardaron cada $\mathrm{cm}^{-1}$.

\subsubsection{Dispersión dinámica de luz (DLS)}

\subsubsection{Determinación de la distribución de tamaño de partícula}

El tamaño de partícula del M13wt y de las mutantes se determinó mediante la técnica de dispersión dinámica de luz (DLS). En un experimento típico se tomó $1 \mathrm{~mL}$ de cada muestra a una concentración de $0.1 \mathrm{mg} \mathrm{mL}^{-1}$, usando una celda de $1 \mathrm{~cm}$ de paso óptico (modelo DTS0012). Los parámetros para el análisis del tamaño de partícula se ajustaron en el equipo Malvern Zetasizer Nano modelo ZSP, con un láser de $10 \mathrm{mV}$ de He-Ne a una longitud de onda de $632.8 \mathrm{~nm}$. A continuación, se dan los parámetros usados en cada experimento:

- Tipo de método: Size

- Material: Proteína, índice de refracción $=1.450$, absorción $=0.001$.

- Dispersante: agua, temperatura $=25^{\circ} \mathrm{C}$, viscosidad $=0.8872 \mathrm{cP}$, índice de refracción $=$ 1.330 .

- Temperatura: $25^{\circ} \mathrm{C}$, tiempo de equilibrio $=120 \mathrm{~s}$.

- Medición: ángulo de medida = 173 backscatter (NIBS default), duración de la medición $=$ manual, número de corridas $=10$, duración de corridas $=10 \mathrm{~s}$, número de medidas $=$ 10 , retraso entre mediciones $=0 \mathrm{~s}$. 


\subsubsection{Determinación del punto isoeléctrico mediante el método de Potencial zeta (ZP)}

El análisis de punto isoeléctrico del M13wt y de las mutantes se determinó por la técnica de titulación (Multipurpose titrator MPT-2), este experimento requirió $10.0 \mathrm{~mL}$ de cada muestra a una concentración de $1 \times 10^{10}$ fagos $\mathrm{mL}^{-1}$. Para obtener estas concentraciones se usó la ecuación 3, donde PFU es la unidad formadora de placas (fagos $\mathrm{mL}^{-1}$ ).

$$
\text { PFU }=\frac{\left(A_{269}-A_{320}\right)\left(\frac{6 \times 10^{16} \text { fagos }}{m L}\right)}{\# \text { de bases }}
$$

Se consideraron las absorbancias a una longitud de onda de 269 y $320 \mathrm{~nm}$. El número de bases del vector M13mp18 es $7249 \mathrm{pb}$.

A continuación, se dan los parámetros usados en cada experimento:

- Tipo de método: pH titulación

- Material: Proteína, índice de refracción $=1.450$, absorción $=0.001$.

- Dispersante: agua, temperatura $=25^{\circ} \mathrm{C}$, viscosidad $=0.8872 \mathrm{cP}$, índice de refracción $=$ 78.5 .

- Selección $\mathrm{F}(\kappa a)$ : Modelo = Smoluchowski, valor $\mathrm{F}(\kappa a)=1.50$.

- Temperatura: $25^{\circ} \mathrm{C}$, tiempo de equilibrio $=120 \mathrm{~s}$.

- Medición: ángulo de medida $=173^{\circ}$ backscatter (NIBS default), duración de la medición $=$ automático, número de medidas $=3$, retraso entre mediciones $=0 \mathrm{~s}$.

- Medición de potencial zeta: Automático, número de mediciones $=3$, retraso entre mediciones $=0 \mathrm{~s}$.

- Titulación: ácido $=\mathrm{HCl}$, concentración $=0.1 \mathrm{M}$, base $=\mathrm{NaOH}$, concentración $=0.12 \mathrm{M}$.

- Secuencia de $\mathrm{pH}$ : $\mathrm{pH}$ de inicio $3.0, \mathrm{pH}$ final $=12.0$, incrementos $=0.02$, puntos $=45, \mathrm{pH}$ de tolerancia $=0.5$. 


\subsection{Bacteriófago M13 y mutantes como plantilla para síntesis de nanomateriales inorgánicos}

\subsubsection{Nucleación y crecimiento de nanopartículas de oro y plata en la cápside del fago M13 y mutantes}

Como se mencionó, los grupos tioles $(\mathrm{SH})$ poseen una afinidad a iones de metales nobles como el $\mathrm{Au}, \mathrm{Ag}, \mathrm{Cu}$, etc. y son altamente empleados en moléculas estabilizantes de NP de estos materiales. En este trabajo se nuclearon NP de Au y Ag en la proteína p8 de la cápside del fago M13 y mutantes. A una alícuota de $20 \mu \mathrm{L}$ de fago ( $\left.2 \mathrm{mg} \mathrm{mL}^{-1}\right)$, se agregó $100 \mu \mathrm{L}$ de $\mathrm{HAuCl}_{4} 3 \mathrm{H}_{2} \mathrm{O}(5 \mathrm{mM})$ y se incubó por 16 horas a temperatura ambiente.

Finalmente, se realizó la reducción adicionando $100 \mu \mathrm{L} \mathrm{NaBH} 4(5 \mathrm{mM})$. Para la síntesis de NP de plata se usó la misma metodología empleando una solución de $\mathrm{AgNO}_{3}$ (5 mM). Esta reacción se hizo simultáneamente con M13 wt y cada una de las mutantes.

\subsubsection{Caracterización de fago wt y mutantes con NPs de oro y plata por espectroscopia UV-Vis}

La solución de M13-NP se caracterizó por espectroscopía UV-Vis, usando un espectrofotómetro Hewlett Packard en el intervalo de 200-800 nm. Los espectros se hicieron empleando una celda de cuarzo (QS de un volumen de $300 \mu \mathrm{L}$ ) de $1 \mathrm{~cm}$ de paso óptico.

\subsubsection{Microscopía electrónica de transmisión (TEM)}

La caracterización del fago nativo y las mutantes decoradas con nanopartículas de oro y plata, se hizo mediante microscopía electrónica de transmisión (TEM). Las imágenes se sacaron en un equipo JEOL 2010 (Field emission) operado a 200 kV en modo campo claro. Se tomaron 3 $\mu \mathrm{L}$ de cada muestra y se depositaron en una rejilla rejillas de cobre (200 mesh), a la cual se le retiró el exceso de líquido y se dejó secar a temperatura ambiente.

\subsubsection{Síntesis y caracterización de películas delgadas de fago M13wt y mutantes}

La síntesis de películas delgadas se llevó a cabo con soluciones de M13 (wt y mutantes), la concentración de las muestras del M13wt es de $7 \mathrm{mg} \mathrm{mL}^{-1}$ y para las mutantes reducidas y sin 
reducir se utilizó a una concentración de $0.1 \mathrm{mg} \mathrm{mL}^{-1}$. La solución se depositó en forma de gota, (alícuotas de $10 \mu \mathrm{L}$ de cada fago) a un ángulo de $45^{\circ}$ sobre un portaobjetos previamente limpiado (Figura 14). Inmediatamente se tapó con un cubreobjetos y se dejó reposar por 1 mes. Después de ese tiempo, se observó cada película usando un microscopio MEIJI (con un lente objetivo de 100X) y equipado con polarizadores Thorlabs LMR1.

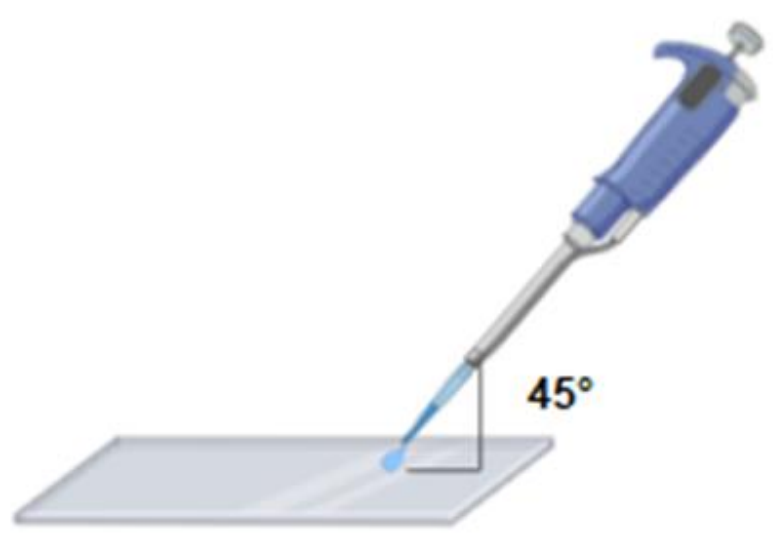

Figura 14. Deposición de la muestra en el cubreobjetos en un ángulo de $45^{\circ}$. 


\section{Capítullo 4}

\section{Resultados y discusión}

\subsection{Purificación del ADN por Miniprep}

Posterior a la purificación del ADN se realizó un gel de agarosa para verificar el tamaño y la pureza del ADN del M13wt y de las mutantes L14V/V31C y M28R/V31C, observándose (Figura 15) que las mutantes poseen el mismo peso del fago M13wt (alrededor de 7249 pares de bases, bp).

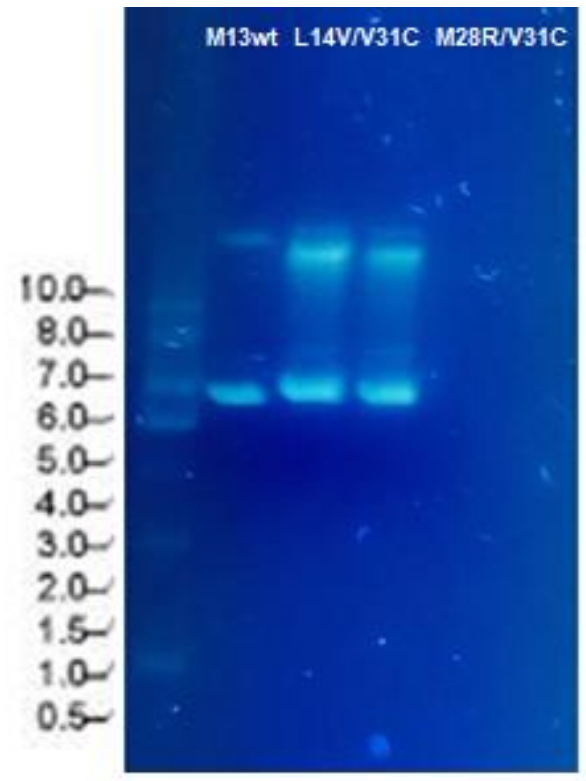

Figura 15. Gel de agarosa (1\%, p/v). El primer carril PM contiene el marcador de peso molecular (Quick Load DNA Marker, Broad Range, New England, BioLabs), los carriles M13wt, L14V/V31C y M28R/V31C, corresponde al fago nativo y a las mutantes. En todos se observan dos bandas, una para el plásmido relajado y otra del plásmido superenrrollado ( $~ 7 \mathrm{Kbp}$ ) 


\subsection{Secuenciación de las mutantes}

Los electroferogramas obtenidos de la secuenciación se muestran en la figura 16. Estos muestran que se obtuvieron las mutaciones deseadas en la secuencia de la proteína p8 del bacteriófago M13.
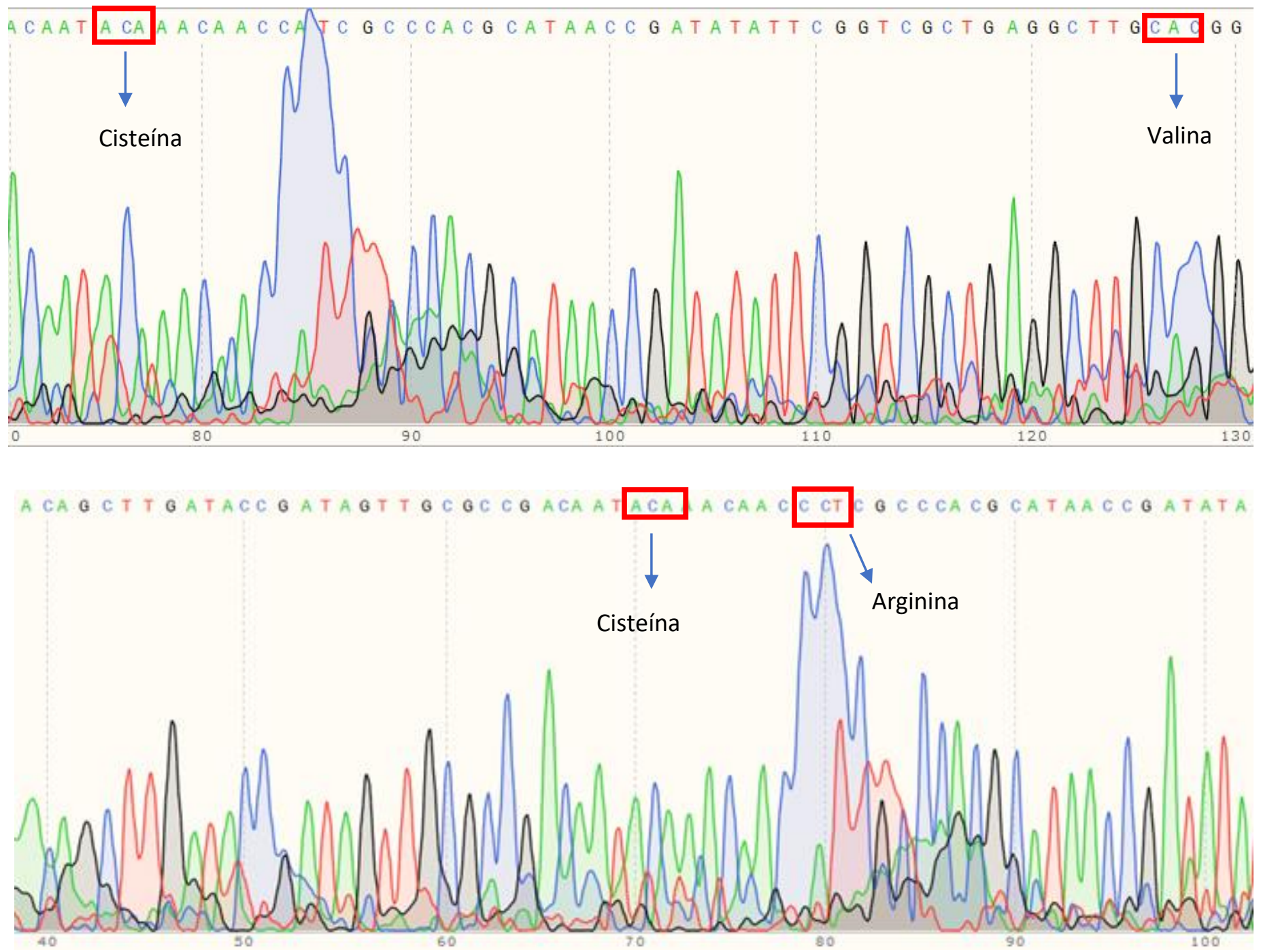

Figura 16. Se muestran los electroferogramas de la secuenciación de las mutantes, en la parte superior se muestra la mutante L14/V31C e inferior a la mutante M28R/V31C. 


\subsection{Amplificación, purificación y caracterización del bacteriófago M13wt y sus mutantes}

Como se ha mencionado en el capítulo 3 se determinó la concentración del fago por la técnica de espectroscopia UV-Vis de acuerdo con la ecuación 1. El espectro de absorción UV característico del fago M13wt, cepa silvestre (gráfico en color negro en la figura 17) exhibe un máximo a una longitud de onda a $269 \mathrm{~nm}$. En esta región se observa la contribución de las proteínas y sSADN, mientras en $320 \mathrm{~nm}$ se detecta la dispersión de la luz debida a agregados de partículas de fagos no ensamblados. Para determinar el correcto ensamble del fago se usó la relación de la absorción a las longitudes de onda 260 y $280 \mathrm{~nm}$, dicha relación debe estar alrededor de: $\frac{A_{260}}{A_{280}} \approx 1.3$.

En la figura 17 se muestran los espectros que se obtuvieron de las mutantes L14V/V31C y M28R/V31C. En el caso de estas dos mutantes, se observa un corrimiento al azul del máximo, el cual ocurre cerca de $262 \mathrm{~nm}$ (figura 17a) probablemente debido a la formación de cistinas, que contribuyen a la absorción en esta región. Por lo anterior, hipotetizamos que subunidades de proteína p8 localizadas en partículas virales vecinas pueden formar puentes disulfuro interpartícula. Entonces, al realizarse la reducción de dichos puentes disulfuro en las mutantes, habría una corrección en el máximo de absorción que regresaría a aproximadamente 269 nm. Esta observación se muestra en la figura 17 b). 


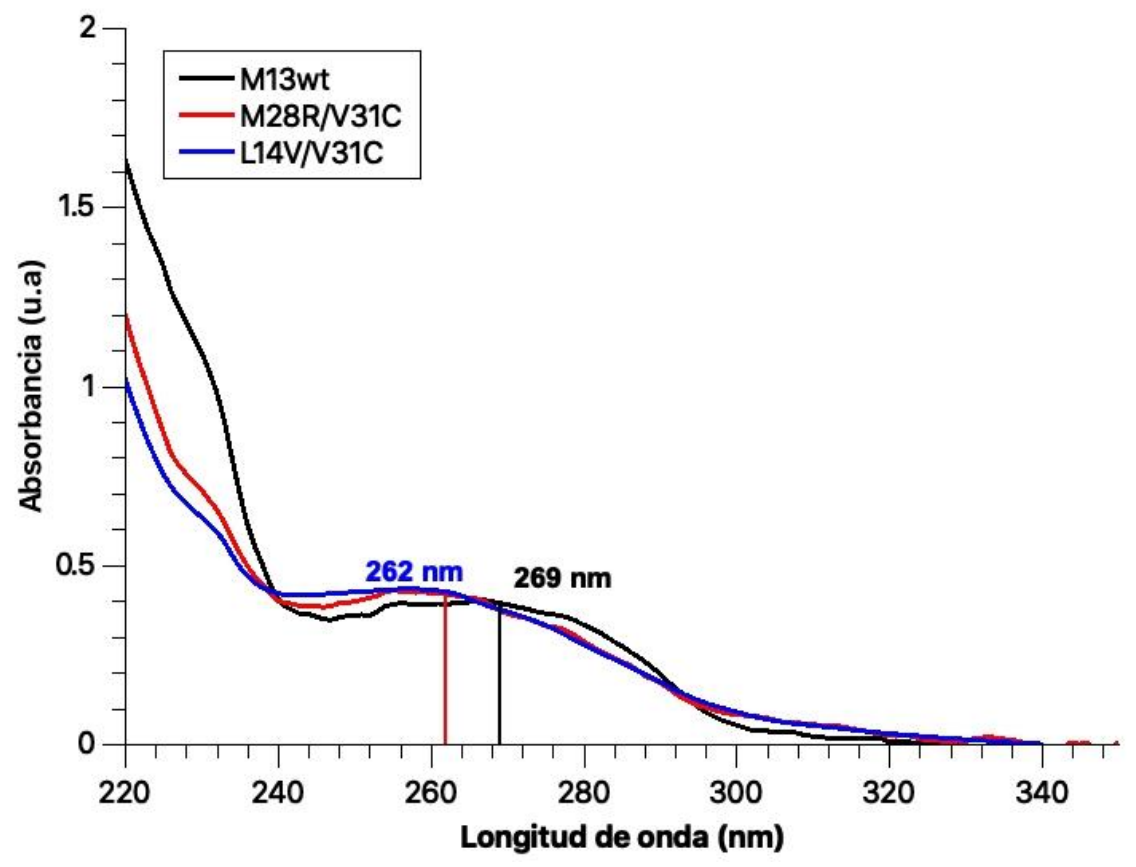

Figura 17a. Espectros de UV-Vis del fago M13wt, L14V/V31C y M28R/V31C. Se muestra la diferencia en los máximos de absorción, las mutantes L14V/V31C y M28R/V31C previo a la reducción del enlace cistina.

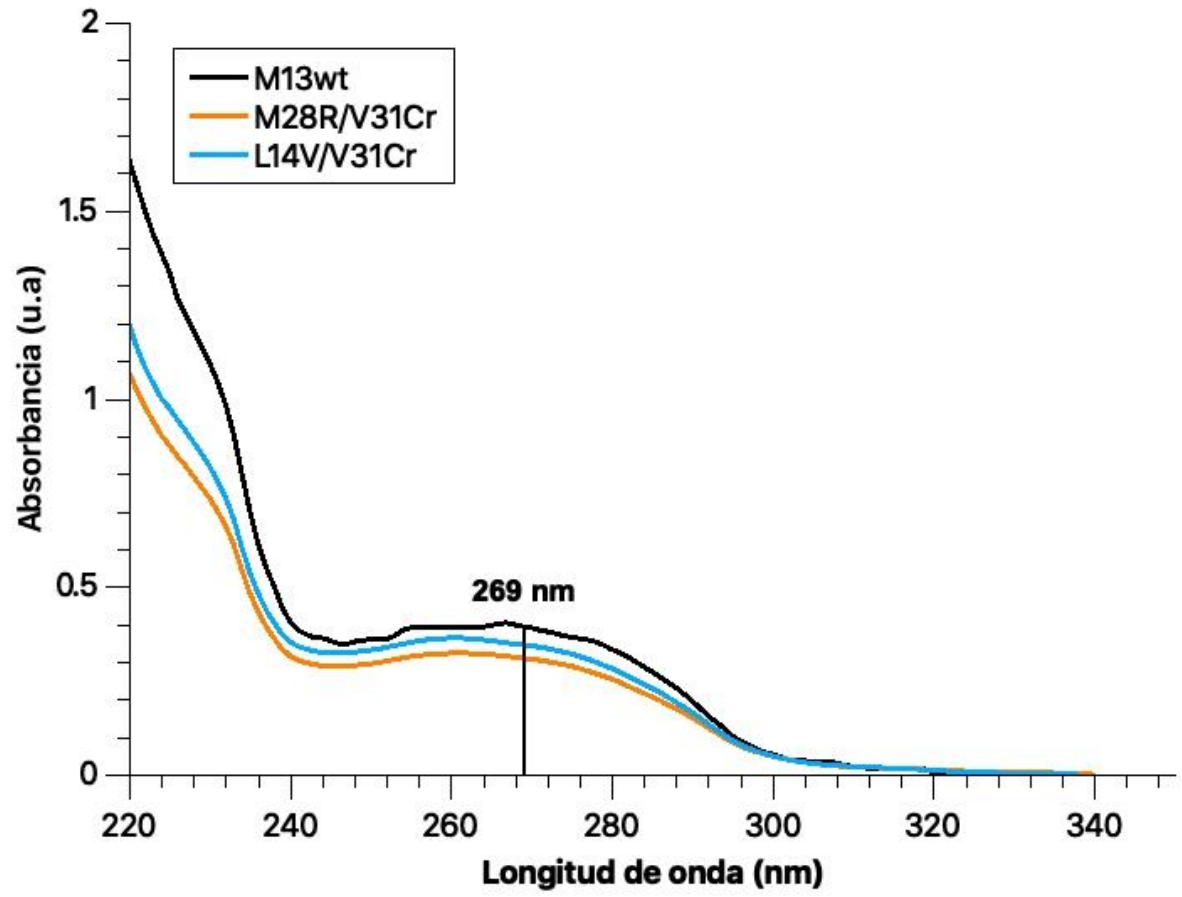

Figura 17 b. Espectros de UV-Vis del fago M13wt, L14V/V31C y M28R/V31C.) Se muestran los espectros de las mutantes después de la reducción de los puentes disulfuro, mostrando el desplazamiento a $269 \mathrm{~nm}$ para las tres muestras. 


\subsection{Efecto de las mutaciones sobre la estructura de la proteína p8 de la cápside del fago}

\subsubsection{Estructura secundaria. Dicroísmo circular}

Para obtener información acerca de la estructura secundaria de la proteína p8 se obtuvieron espectros de dicroísmo circular (DC) en la región comprendida entre 250 y 190 nm (UV-lejano). En esta zona espectral, la señal de DC (elipticidad) es un reflejo, principalmente, de la interacción entre los cromóforos de amida [53] y depende, por lo tanto, del arreglo espacial que éstos tengan en un polipéptido o proteína.[53] El espectro de DC se puede considerar, entonces, como una suma de contribuciones de los diferentes tipos de estructura secundaria presentes en una proteína. Por otro lado, si consideramos que en la partícula del virus M13 el $98 \%$ en masa de la proteína total corresponde a la p8, es evidente que la señal de DC de la parte proteínica del virus será fundamentalmente debida a la conformación de esta proteína dentro del ensamblado del virus. Sin embargo, el virus está constituido también por un 13\% de ADN, y esta biomolécula presenta señal de elipticidad en el UV-lejano, aunque ésta es, en general, bastante menor que la de las proteínas.[30] En principio, entonces, el espectro DC del virus en el UV-lejano contiene también contribuciones provenientes tanto del ADN como de interacciones ADN-p8.

La Figura 18 se muestran los espectros DC del virus M13wt (fago nativo) y las mutantes L14V/V31C y M28R/V31C reducidas (señalado como subíndice "r") y sin reducir, en la zona de 250 a $190 \mathrm{~nm}$. Para el virus silvestre, el espectro es muy similar al reportado anteriormente [10;24]; las bandas intensas cerca de 222, 208 y $192 \mathrm{~nm}$, son típicas de proteínas con un alto contenido de hélice $\alpha$ [43], si bien la magnitud de la elipticidad es bastante mayor a 222 que a $208 \mathrm{~nm}$. Esta característica del fago M13 ha sido atribuida a una señal particularmente intensa del único residuo de triptófano de la p8, o bien a una interacción particular entre la p8 y el ADN $[30 ; 43,44]$. 

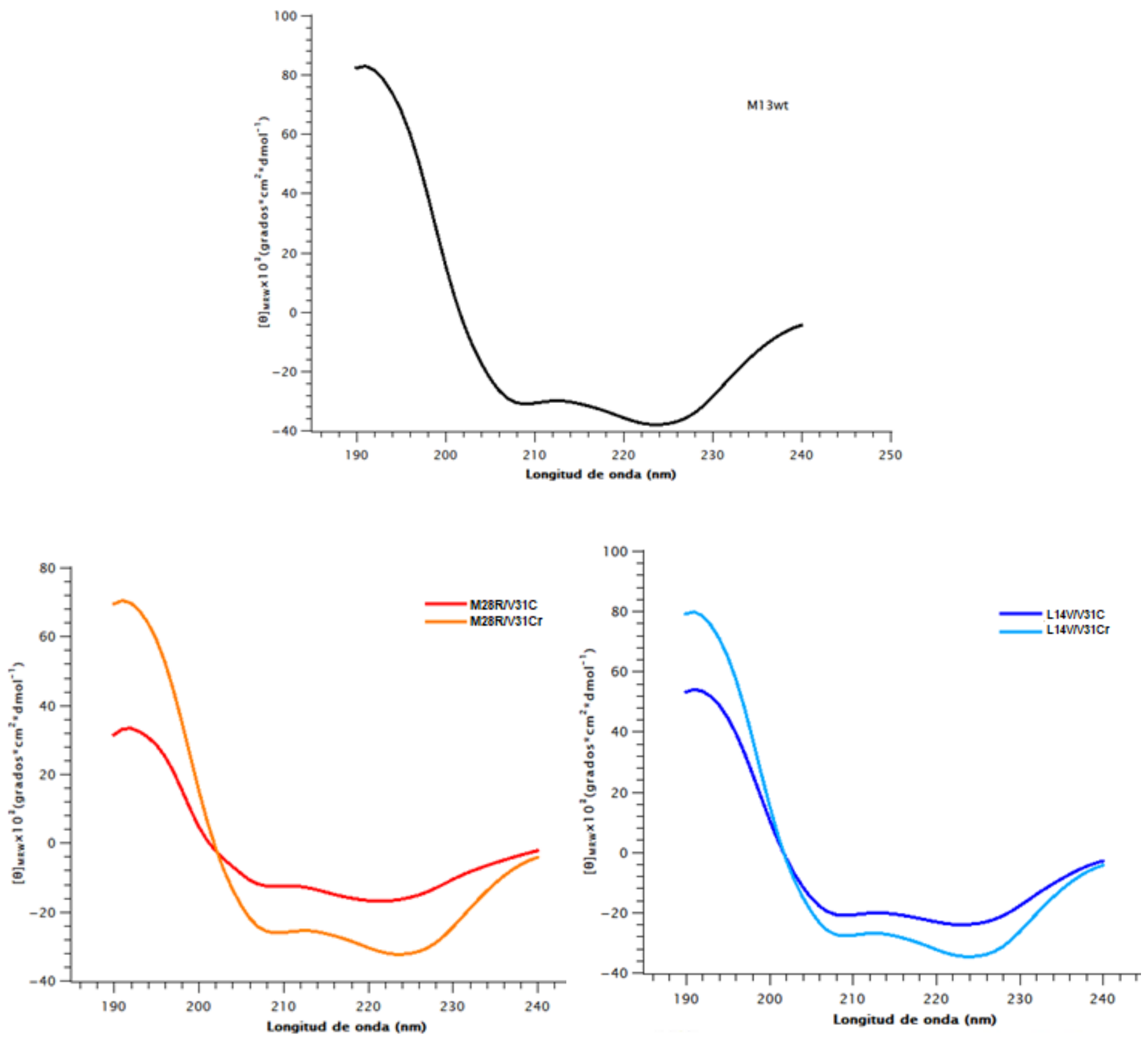

Figura 18. Espectros de DC, se muestra en la región UV-lejana, del fago M13wt y mutantes.

Como puede apreciarse en la Figura 18, los espectros de todas las mutantes estudiadas muestran la misma forma que el espectro de M13 silvestre, pero se notan disminuciones en la

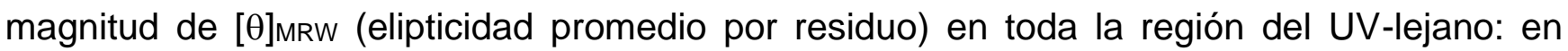

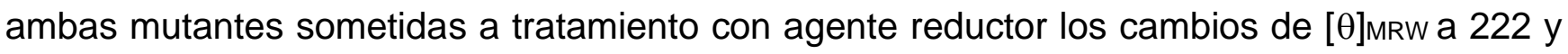
$208 \mathrm{~nm}$, con respecto a M13wt, son relativamente menores (entre 7 y $13 \%$, aproximadamente), mientras que en las mutantes sin reducir los cambios son bastantes mayores (de 34 a 54\%). 
En todos los espectros, sin embargo, se observa que la relación ([$[\theta]_{\mathrm{MRW}}, 222$ / $[\theta]_{\mathrm{MRW}}$, 208) tiene valores entre 1.42 y 1.5, que es el valor característico del virus M13wt.[30] Con el objetivo de determinar en forma cuantitativa los cambios observados en los espectros de DC, éstos fueron analizados para estimar el contenido de estructuras secundarias en cada una de las muestras. Usamos los algoritmos CONTIN-LL [46] y SELCON3 [47], que se encuentran implementados en el servidor web DichroWeb [48]. Dichos algoritmos permiten determinar cuatro tipos de estructura secundaria: hélice $\alpha$, segmentos $\beta$, giros (turns), y segmentos no estructurados regularmente (unordered); a su vez, las hélices $\alpha$ y los segmentos $\beta$ son divididos en dos clases, regulares e irregulares. Para calcular los contenidos (porcentajes) de estructura secundaria los algoritmos usan bases de datos compuestas por espectros de DC de varias proteínas con diferentes tipos de plegamiento, y cuyas estructuras tridimensionales se han determinado por difracción de rayos-X; en este trabajo se empleó el dataset 4, que incluye 42 espectros de proteínas globulares en estado nativo. Además, DichroWeb proporciona el espectro de la proteína analizada reconstruido a partir de los resultados, así como el valor de NRMSD (normalized root mean square deviation), que es un indicador de la diferencia entre el espectro experimental y el reconstruido; es decir, cuanto más parecidos son los espectros experimental y reconstruido menor es el valor de NRMSD, por lo que este parámetro puede considerarse como indicador de la bondad del ajuste (goodness of fit). Se ha mencionado que un valor pequeño de NRMSD (menor de 0.22 ) indica, en varios casos, una estimación confiable del contenido estructuras secundarias, que será bastante parecida a la determinada por difracción de rayos- $\mathrm{X}[49]$. 


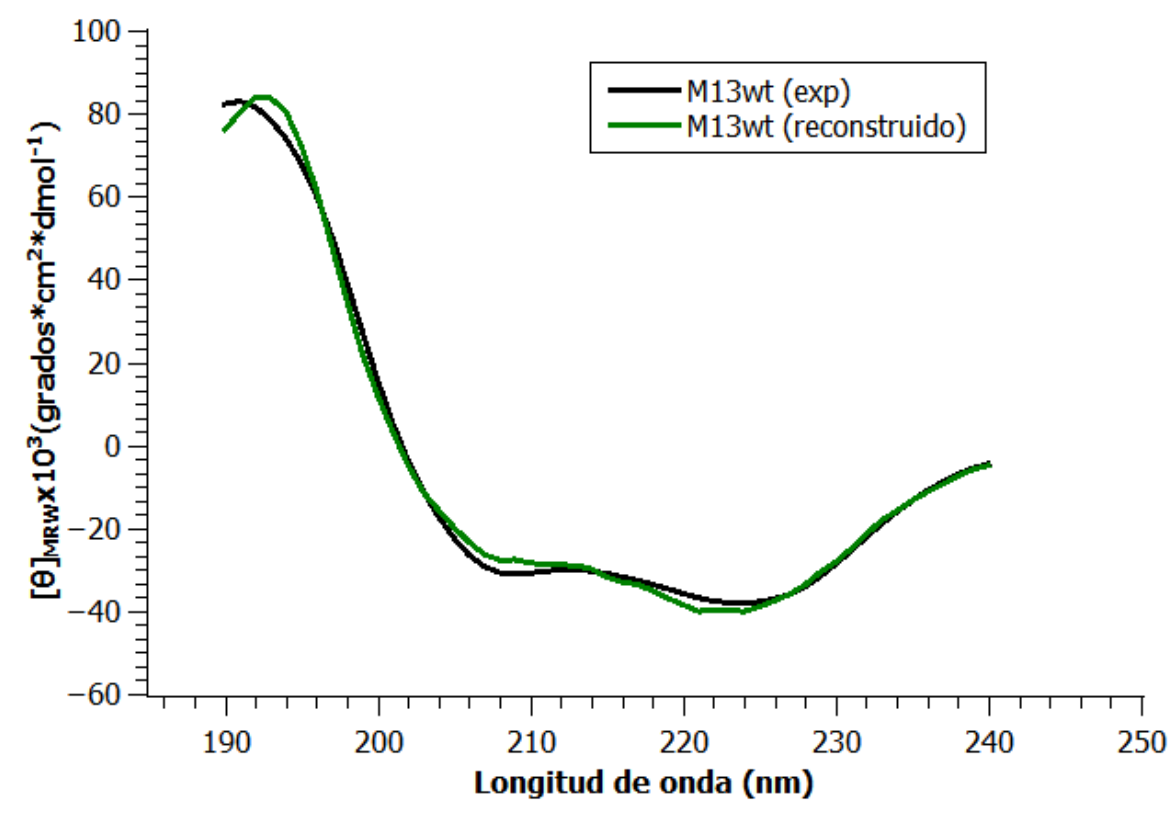

Figura 19. Resultados de análisis del fago M13wt experimental y reconstruido por el método CONTIN-LL. Datos obtenidos de la refrencia [46]

Los resultados del análisis estructural para el espectro del M13wt se presentan en las Tablas 2 y 3, que corresponden a los métodos CONTIN-LL y SELCON3, respectivamente. Como puede verse, ambos métodos arrojan valores muy parecidos entre sí. Sin embargo, CONTINLL dio valores de NRMSD menores (ver Tablas 2 y 3), lo que indica un mejor ajuste con éste método, como puede apreciarse en las gráficas de los espectros experimental y reconstruido (Figura 19). Tomando en cuenta lo anterior, los análisis de los espectros restantes se hicieron usando CONTIN-LL.

Tabla 2. Valores de método CONTIN-LL [46].

\begin{tabular}{|l|r|r|r|r|r|r|r|r|}
\hline Muestra & Helix 1 & \multicolumn{1}{c}{ Helix 2 } & Strand 2 & Turns & Unordered & Total & \multicolumn{2}{c|}{ NMRSD } \\
\hline M13wt & 0.593 & 0.338 & 0.031 & 0.038 & & 1 & 0.065 \\
\hline M28R/V31C & 0.284 & 0.204 & 0.058 & 0.185 & 0.269 & 1 & 0.05 \\
\hline M28R/V31Cr & 0.537 & 0.283 & 0.024 & 0.066 & 0.089 & 0.999 & 0.062 \\
\hline L14V/V31C & 0.42 & 0.241 & 0.038 & 0.12 & 0.18 & 0.999 & 0.073 \\
\hline L14V/V31Cr & 0.571 & 0.341 & 0.046 & 0.043 & & 1.001 & 0.066 \\
\hline
\end{tabular}


Tabla 3. Valores de método SELCON3[47].

\begin{tabular}{|l|r|r|r|r|r|r|r|r|}
\hline Muestra & Hellix 1 & Hellix 2 & \multicolumn{1}{|c}{ Strand 2 } & Strand 22 & Turns & \multicolumn{1}{c|}{ Unordered } & Total & \multicolumn{1}{c|}{ NMRSD } \\
\hline M13wt & 0.615 & 0.281 & 0.02 & 0.017 & 0.063 & 0.005 & 1.001 & 0.065 \\
\hline M28R/V31C & 0.272 & 0.19 & 0.033 & 0.057 & 0.199 & 0.249 & 1 & 0.05 \\
\hline M28R/V31Cr & 0.59 & 0.245 & 0.03 & 0.003 & 0.132 & & 1 & 0.062 \\
\hline L14V/V31C & 0.437 & 0.204 & 0.046 & 0.031 & 0.129 & 0.153 & 1 & 0.073 \\
\hline L14V/V31Cr & 0.607 & 0.295 & 0.02 & 0.024 & 0.039 & 0.015 & 1 & 0.066 \\
\hline
\end{tabular}

En la Figura 20 se presentan los espectros experimentales y reconstruidos de las variantes estudiadas; como puede verse, en todos los casos el espectro reconstruido es muy similar al experimental, lo cual da como resultado valores de NRMSD menores 0.07 o menores.

a)

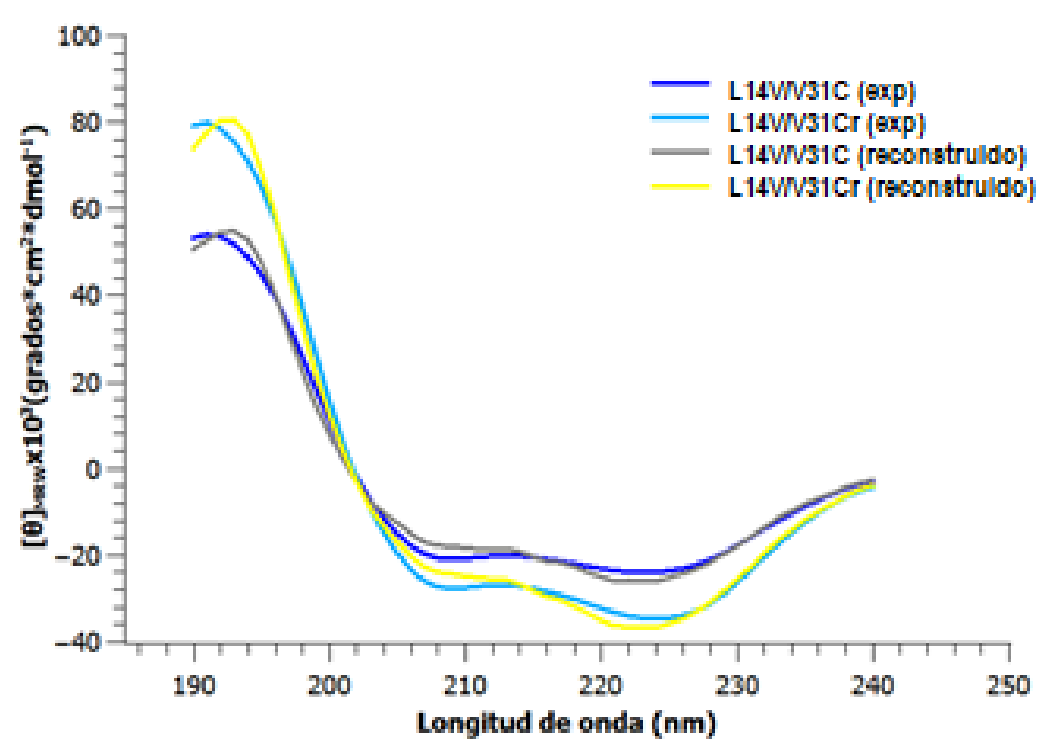

b)

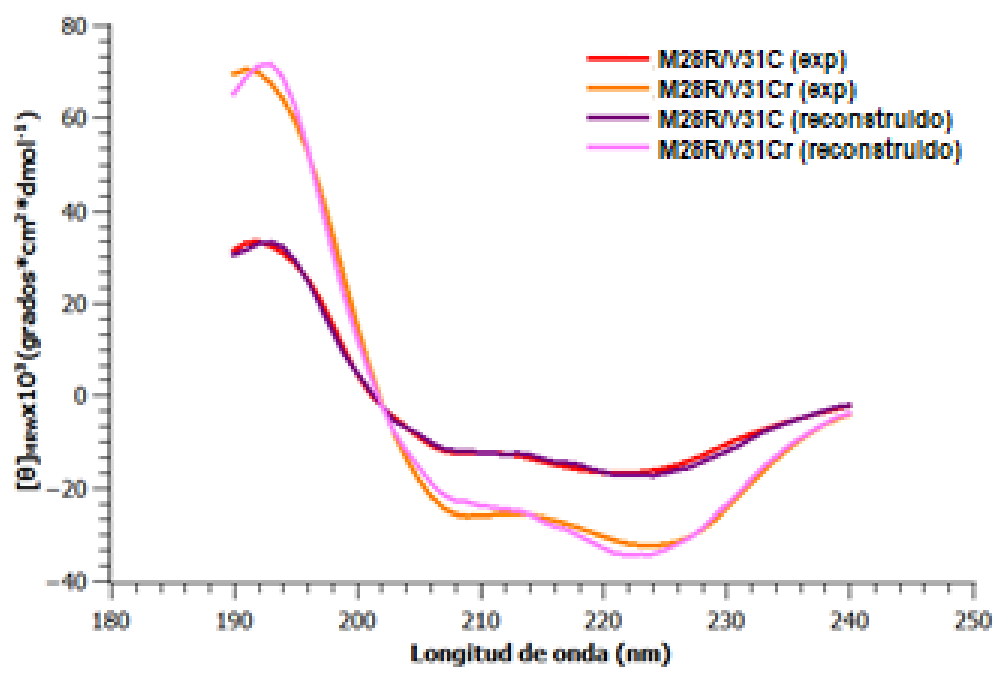

Figura 20. Resultados de análisis de las variantes del fago M13 (a)L14V/V31C y b) M28R/V31C experimental y reconstruido por el método CONTIN-LL. Datos obtenidos de la referencia [46] 
El gráfico de barras de la Figura 21 permite hacer una comparación general de los porcentajes de los diferentes tipos de estructuras secundarias presentes en el M13wt y en sus variantes mutadas que se obtuvieron del análisis; para simplificar la comparación, se consideran en esta figura los contenidos totales de hélice $\alpha$ y segmentos $\beta$. El fago M13wt presenta el mayor porcentaje de hélice total (93\%), mientras que las mutantes reducidas L14V/V31Cr y M28/V31Cr tienen porcentajes ligeramente menores (91 y 82\%); desde luego, en estas tres partículas virales el contenido de otras estructuras en la proteína p8 es poco relevante $(7 \%$ como máximo) y, tal vez, no significativo ya que este valor está dentro del error calculado para los métodos de análisis [50]. Los resultados anteriores señalan, entonces, que en las mutantes L14V/V31Cr y M28/V31Cr la proteína p8 tiene una estructura secundaria básicamente helicoidal, muy parecida a la del virus M13wt.

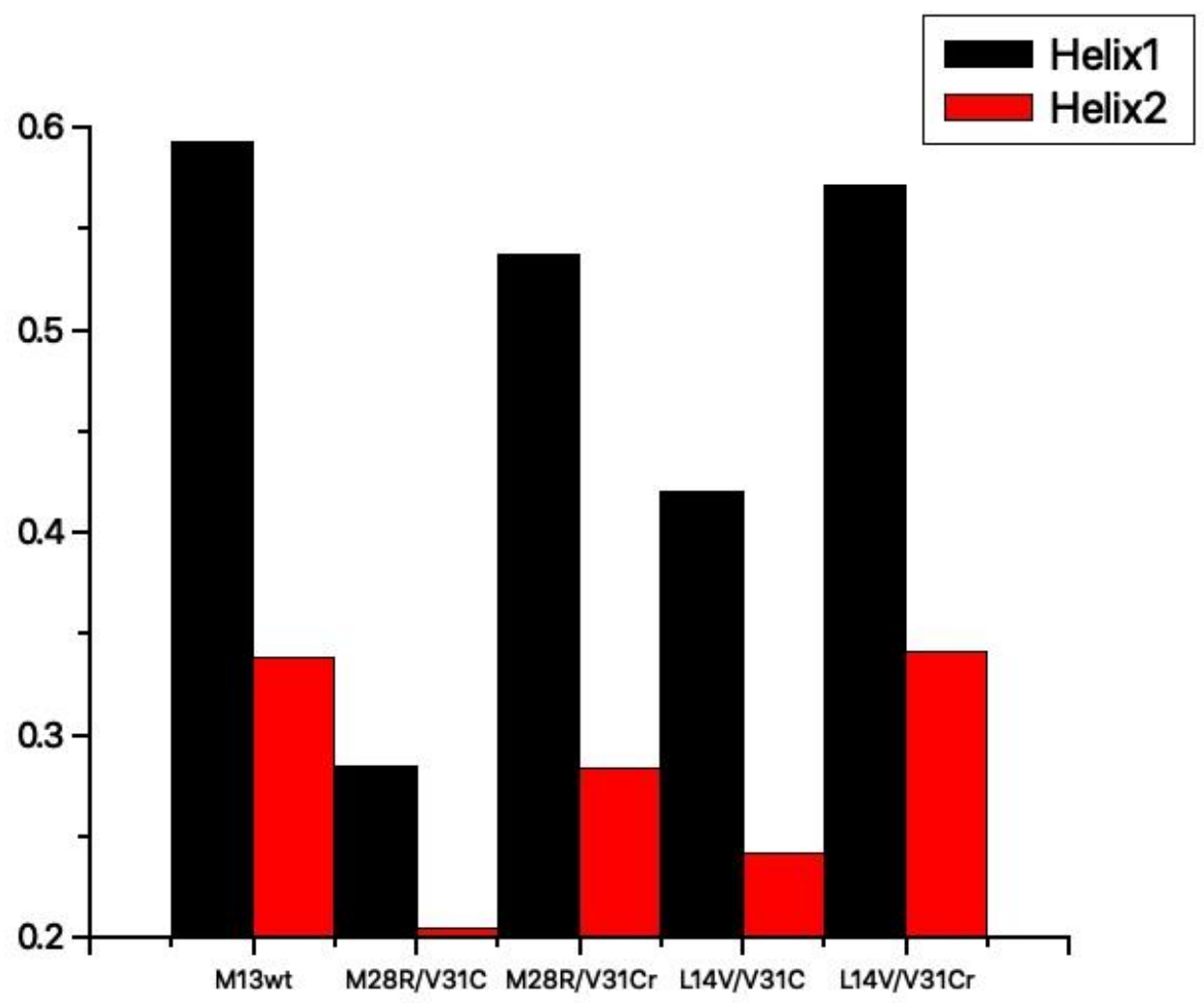

Figura 21. Resultados de análisis del fago M13wt y mutantes. Datos obtenidos de la referencia [46] 
En contraste con los resultados obtenidos para las formas reducidas de L14V/V31Cr y M28R/V31Cr, las formas no reducidas de éstas dieron porcentajes de hélice total significativamente menores, y en consecuencia porcentajes mayores de otros tipos estructurales, que los del fago silvestre (Figura 21). Destacan los contenidos relativamente altos de giros (12 a 19\%) y segmentos no estructurados ( 18 a $27 \%$ ) en las variantes L14V/V31C y M28R/V31C no reducidas. Estos resultados sugieren que en estos dos casos la conformación secundaria de p8, ensamblada en forma de partícula viral, se ve notablemente afectada.

Por otra parte, en la Figura 22 se puede notar que la presencia de un residuo de arginina en la mutante M28R/V31C reducida y sin reducir, condujo a una disminución del contenido de hélices en p8, con respecto a las formas respectivas de la mutante L14V/V31C, la cual conserva un residuo de metionina en la posición 28 (región hidrofóbica).

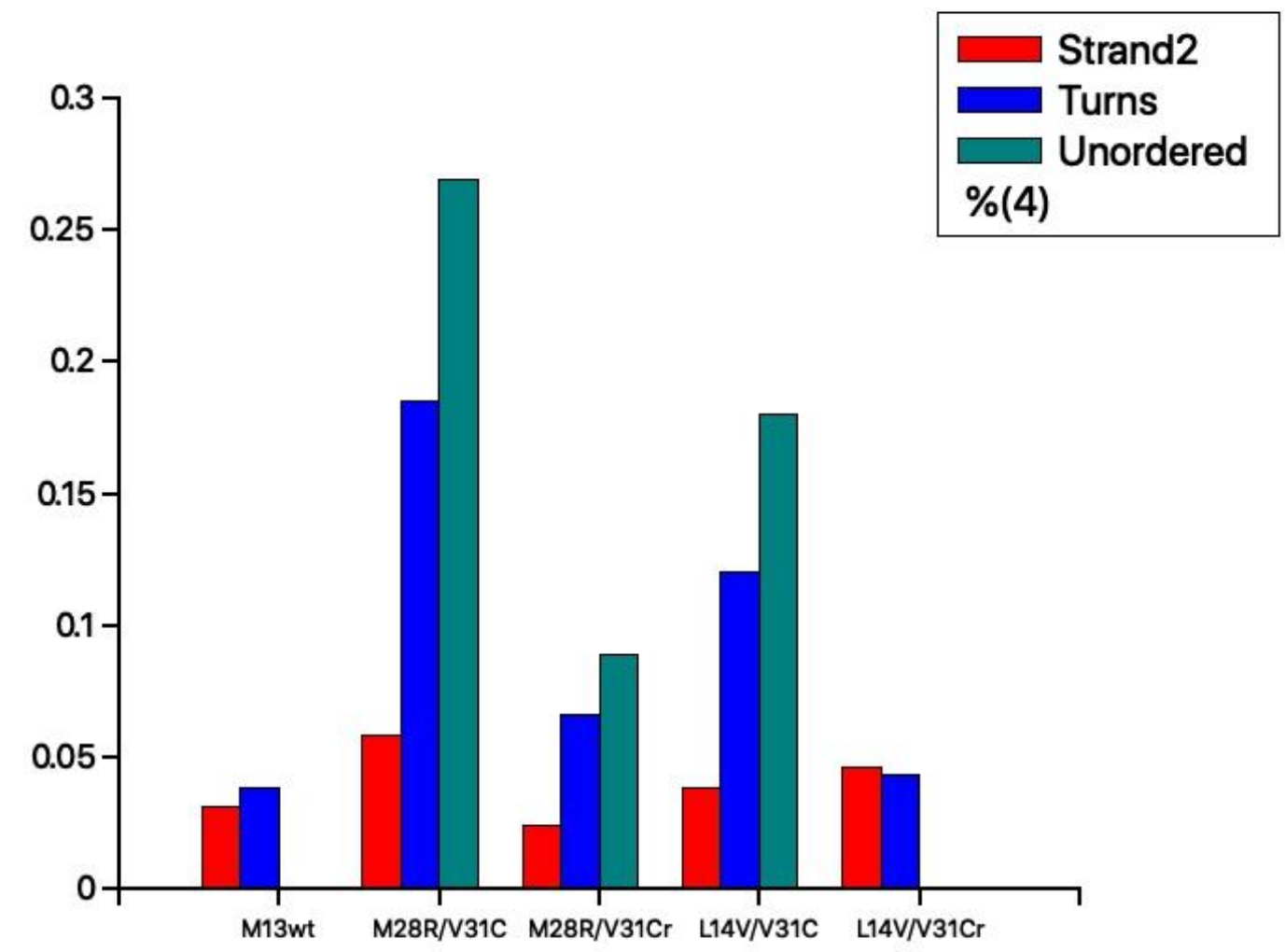

Figura 22. Resultados de análisis del fago M13wt y mutantes. Datos obtenidos de la referencia [46] 


\subsubsection{Estructura secundaria. Espectroscopía en el infrarrojo (FT-IR, Fourier)}

Si bien es fundamental conocer la estructura de la proteína p8, ya que determina la forma del fago ensamblado, los espectros de DC nos dan un panorama general, pero no son capaces de identificar plenamente la formación de puentes disulfuro $u$ otras interacciones que podrían ser importantes en la estructura del fago. Para obtener información acerca de los enlaces y grupos funcionales de la proteína p8 se obtuvieron espectros de infrarrojo en la región comprendida entre 4000 y $320 \mathrm{~cm}^{-1}$. Figura 23 (a y b).

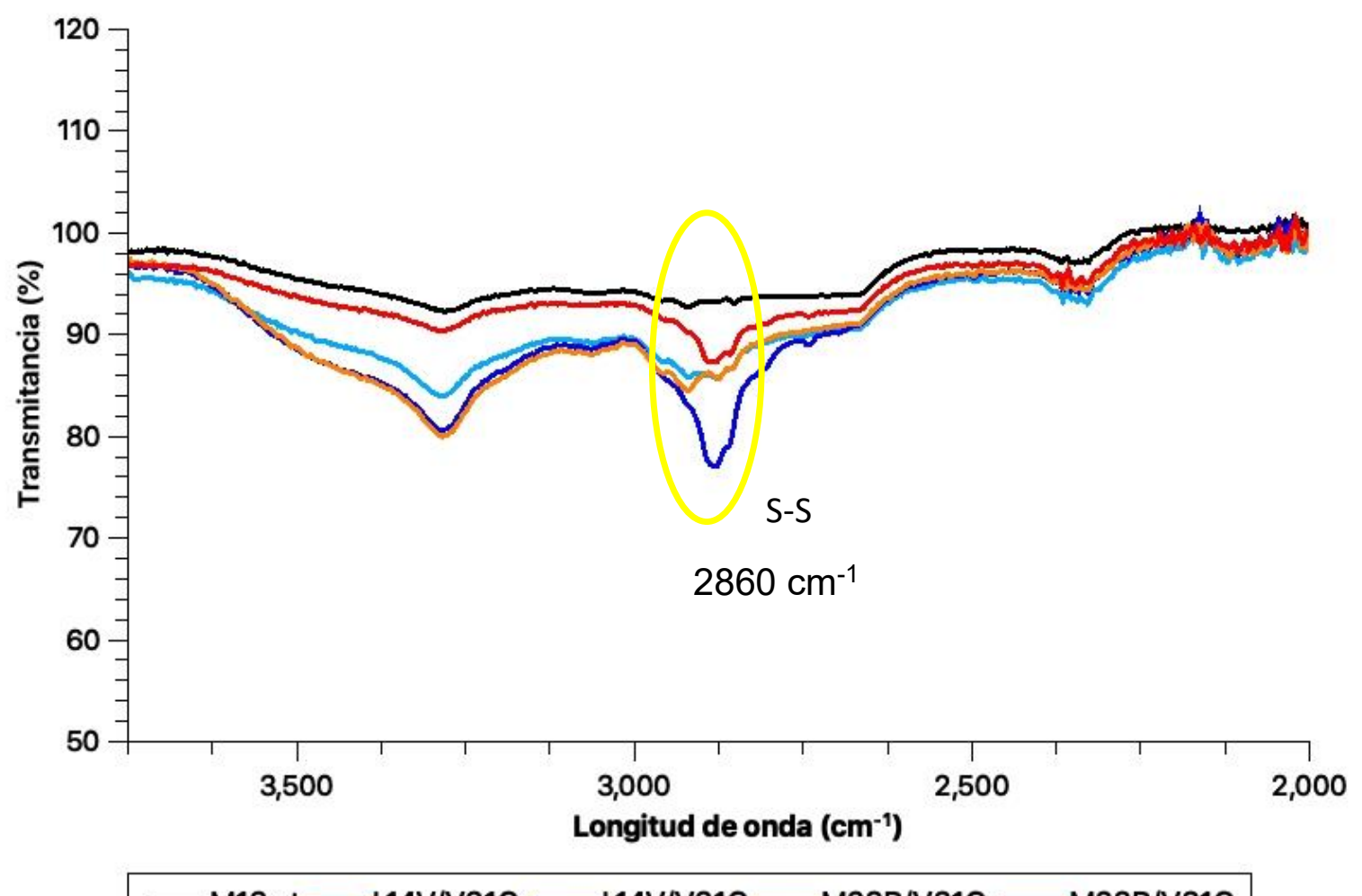

Figura 23. a) Espectros de infrarrojo, se muestran las vibraciones de M13wt y las mutantes L14V/V31C y M28R/V31C (antes y después del tratamiento con DTT). Se observan las bandas características de los enlaces disulfuros. 


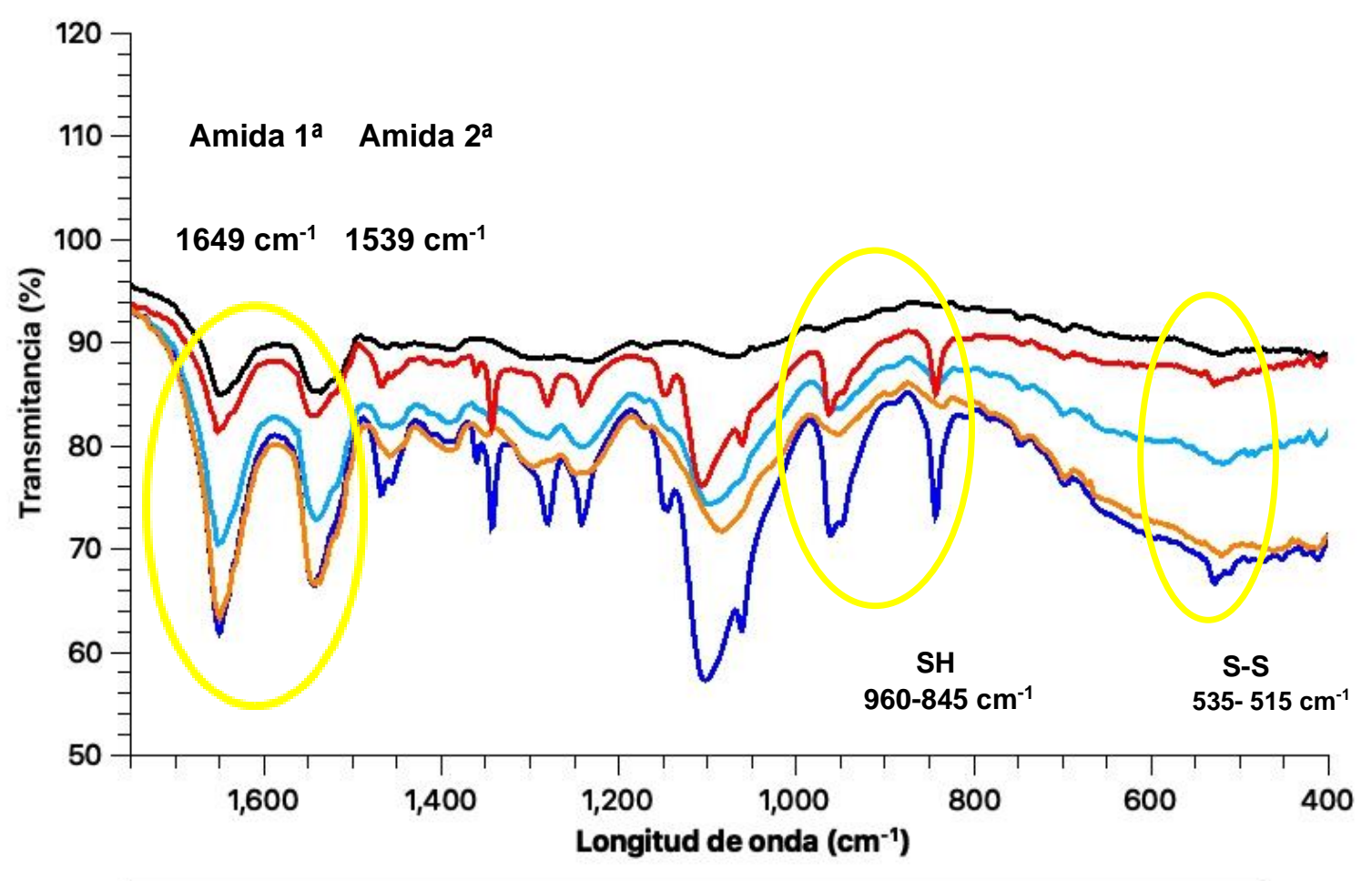

$-\mathrm{M} 13 \mathrm{wt}-\mathrm{L} 14 \mathrm{~V} / \mathrm{V} 31 \mathrm{Cr}-\mathrm{L} 14 \mathrm{~V} / \mathrm{V} 31 \mathrm{C}-\mathrm{M} 28 \mathrm{R} / \mathrm{V} 31 \mathrm{Cr}-\mathrm{M} 28 \mathrm{R} / \mathrm{V} 31 \mathrm{C}$

Figura 23. b) Espectros de infrarrojo, se muestran las vibraciones de M13wt y las mutantes L14V/V31C y M28R/V31C (antes y después del tratamiento reductor). Se observan las bandas características de la estructura secundaria de los enlaces amida primaria y secundaria. Al haber introducido grupos tioles se observan en las mutantes las vibraciones $\mathrm{SH}$ y de los enlaces disulfuros.

En la Figura 23 b) se muestra el espectro del fago silvestre, en el cual se aprecian las bandas de las vibraciones (simétricas) de amida I y amida II a 1649 y $1539 \mathrm{~cm}^{-1}$, típicas de estructura secundaria hélice $\alpha$ [51], además de las bandas asignadas a vibraciones de otros grupos (metilo (29), metileno, etc.) que corresponden a lo reportado en la literatura. El espectro de las mutantes L14R/V31C y M28R/V31C muestra algunas diferencias importantes; algunas bandas se definen más claramente y otras aparecen. A 535 y $515 \mathrm{~cm}^{-1}$ se observan bandas débiles asociadas a vibraciones $S-S$, las cuales desaparecen los mínimos intensidad después de reducir las muestras con DTT, lo que apoya su asignación. Las bandas a 845 y $960 \mathrm{~cm}^{-1}$ no están presente en M13wt y corresponden a vibraciones de estiramiento y doblamiento de C-S, probablemente acopladas a C-C en el caso de las mutantes. La intensidad de las bandas disminuye considerablemente después de la reducción y sufren corrimientos de algunos $\mathrm{cm}^{-}$ ${ }^{1}$.75;76] Por otro lado, las bandas a 1040, 1100, 1345 y $1429 \mathrm{~cm}^{-1}$ no aparecen en la M13wt y sufren ligeros corrimientos después la reducción. Estas bandas podrían estar asociadas a 
cambios conformacionales de la p8, que si bien no alteran la estructura de hélice $\alpha$ probablemente afecten las interacciones de las cadenas de los aminoácidos de las proteínas en el fago ensamblado. Un comportamiento similar se observa en las bandas entre 2800-2900 $\mathrm{cm}^{-1}$ asociadas a vibraciones de estiramiento de $\mathrm{CH}_{3}$ y $\mathrm{CH}_{2}$, las cuales sufren desplazamientos respecto de la wt y después de la reducción. Las bandas a $2860 \mathrm{~cm}^{-1}$, también podría estar relacionada a vibraciones S-S. Se observa que las bandas no necesariamente aparecen donde indica la literatura, esto se deba probablemente al cambio en el microambiente de los aminoácidos antes y después de la mutación. Sin embargo, la hipótesis de la formación de disulfuros se fundamenta en que esta reacción ocurre en el periplasma de E. coli y la proteína p8 lo "atraviesa" durante el ensamble del fago. De acuerdo con los resultados se observa de manera importante que la formación de S-S no afecta el máximo ni la intensidad de las bandas amida, por lo que concluimos que la estructura hélice alfa de la p8 se conserva, aunque con algunos cambios como se describió.

\subsubsection{Microambiente de residuos de aminoácidos aromáticos. Dicroísmo circular}

En el virus M13wt, las bandas de absorción de luz y de DC en la llamada región aromática o UV-cercano (310-250 nm) son debidas tanto al ADN como a las proteínas de la cápside. En la Figura 24 se muestran los espectros de DC del M13wt y de las mutantes estudiadas en dicha región espectral. Las bandas observadas entre 270 y 300 nm, que presentan resolución apreciable en picos individuales (estructura fina), son seguramente debidas a residuos aromáticos de la p8 (W26, Y21 y Y24), ya que el ADN muestra señales intensas pero carentes de estructura fina [10;43]. Esto es, las bandas individuales de triptófano $(W)$ y tirosina $(Y)$ estarían empalmadas con bandas muy anchas de ADN. De hecho, los espectros de la Figura 22 muestran un aumento considerable de ruido electrónico por debajo de los $285 \mathrm{~nm}$, debido probablemente a la gran absorción de luz por parte del ADN. Además, las tres cadenas laterales de fenilalanina encontradas en p8 podrían contribuir a la señal de DC entre 260 y 270 nm, que es la región donde la fenilalanina da señales de absorción y DC, aunque éstas son de baja intensidad [52,53].

La forma general del espectro del M13 silvestre en el UV-cercano es muy parecida a la reportada previamente [20], aunque con diferencia relativamente importante en la magnitud. Dicha diferencia se debe a la diferente concentración reportada por González, et al. [30] de 
$1 \mathrm{mgmL}^{-1} \mathrm{y}$ en este trabajo que fue de $0.5 \mathrm{mgmL}^{-1}$, lo cual puede conducir a diferente interacción de las partículas virales entre sí. Sin embargo, en el estudio presente todas las muestras usadas tuvieron una concentración similar, por lo que son directamente comparables. En general, las mismas bandas de DC están presentes en todos los espectros de la Figura 24; tomando como referencia el M13wt, en los espectros de L14V/V31C y M28R/V31C solamente se aprecian pequeños corrimientos en los extremos de dichas bandas; esto indica que la polaridad del entorno de los residuos $\mathrm{Y}$ y W se conserva prácticamente inalterado [53]. En lo que toca a las formas reducidas de las mutantes, sus espectros se asemejan bastante en magnitud global a la del M13 silvestre, sugiriendo que las diferentes interacciones (p8-p8, p8ADN, e interpartícula) que pueden afectar la rigidez de las cadenas laterales aromáticas están bastante conservadas.[53] En contraste, los espectros de las formas no reducidas de ambas mutantes difieren en mayor grado del espectro del virus silvestre. La mutante L14V/V31C no reducida muestra el espectro de menor magnitud de los cinco espectros en la Figura 24, mientras que $\mathrm{M} 28 \mathrm{R} / \mathrm{V} 31 \mathrm{C}$ no reducida tiene el espectro con la mayor magnitud de todos. Estas observaciones sugieren que las interacciones entre las partículas virales, posiblemente debidas a la formación de enlaces S-S, estarían afectando de manera diferente la rigidez del entorno del triptófano y las tirosinas de p8.

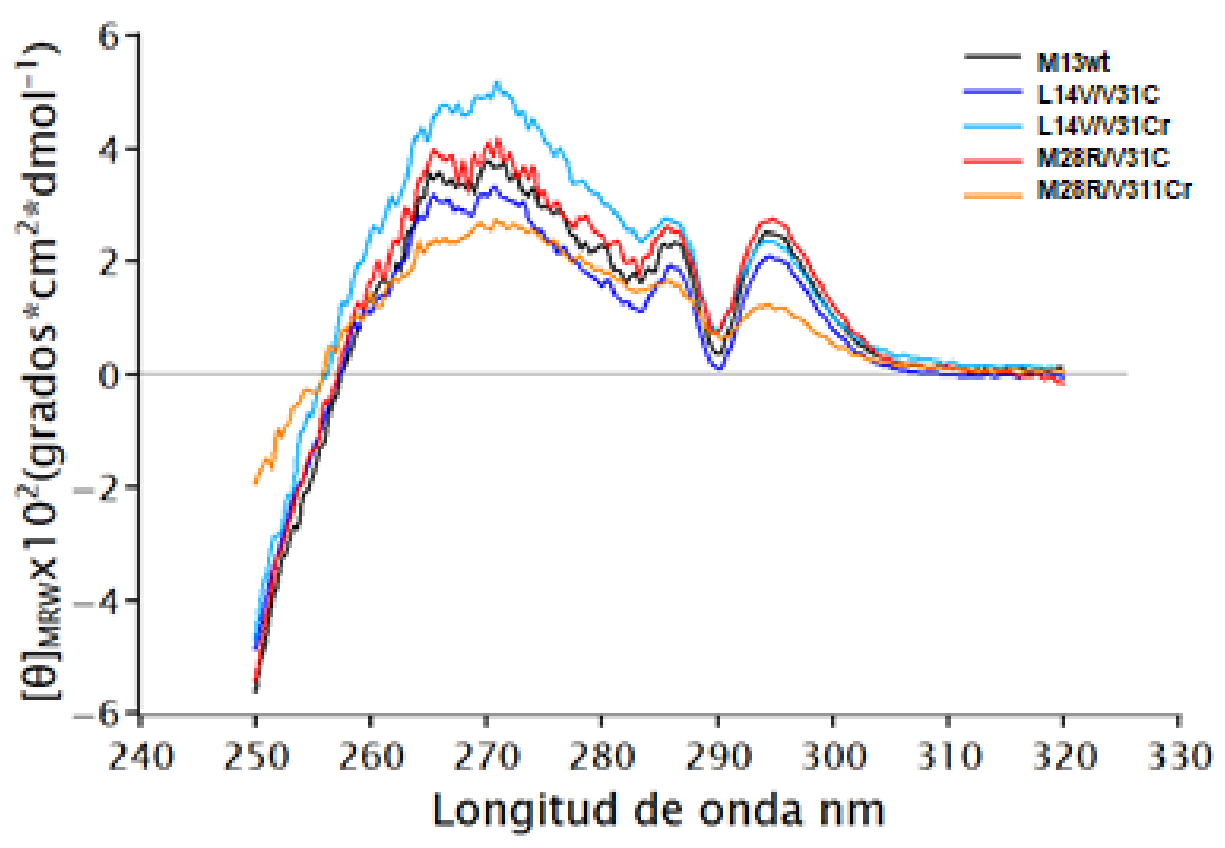

Figura 24. Espectros de DC en la región UV-cercano del fago M13wt y mutantes. 


\subsection{Dispersion dinámica de luz (DLS) del fago M13wt y mutantes}

\subsubsection{Distribución de tamaño de partícula (DLS)}

En la figura 25 se muestra los gráficos de la determinación del perfil de distribución de tamaño de partículas en solución acuosa de fago M13wt y mutantes (L14V/V31C y M28R/V31C). El tamaño de partícula para el M13wt es de $(23.59 \pm 5.4 \mathrm{~nm})$, en un intervalo similar al que se encuentra reportado por Lin Ma, et al., $(49.0 \pm 16.9 \mathrm{~nm})$.[68]

De acuerdo con los cambios puntuales que se le realizaron en la proteína p8 de la cápside del M13wt, se esperaría que el tamaño de la partícula no sufriera cambios importantes en su estructura. En la Figura 25a se observa que los tamaños de las mutantes sin reducir aumentan drásticamente, la mutante L14V/V31C presenta un diámetro de (246.3 $\pm 46.26 \mathrm{~nm})$, es decir 10 veces mayor que el tamaño de M13wt y, en el caso de la mutante M28R/V31C su tamaño es de $(79.82 \pm 15.08 \mathrm{~nm})$ aproximadamente tres veces más grande que el fago nativo.

En la Figura 25b se muestra los tamaños de las mutantes reducidas, mientras que la mutante L14V/V31Cr presenta un diámetro de (456.3 $\pm 110.6 \mathrm{~nm})$, alrededor de dos veces su tamaño antes de la reducción, la mutante M28R/V31C presenta un diámetro (18.31 $\pm 3.8 \mathrm{~nm})$, cuatro veces mayor respecto a la mutante sin reducir. Estas diferencias en el tamaño podrían deberse a la formación de puentes disulfuro interpartícula, es decir entre fagos adyacentes. Sin embargo, después de la reducción se esperaría que el tamaño disminuyera como ocurre en la mutante M28R/V31C, debido al rompimiento de los puentes disulfuro entre las partículas virales, de hecho, se observa que el tamaño es muy similar al del fago wt. En el caso de la mutante L14V/V31C después de la reducción el tamaño de las partículas aumenta lo que probablemente indique que la sustitución del aa en la posición 14 favorece las interacciones entre los fagos causando agregación. 
a)

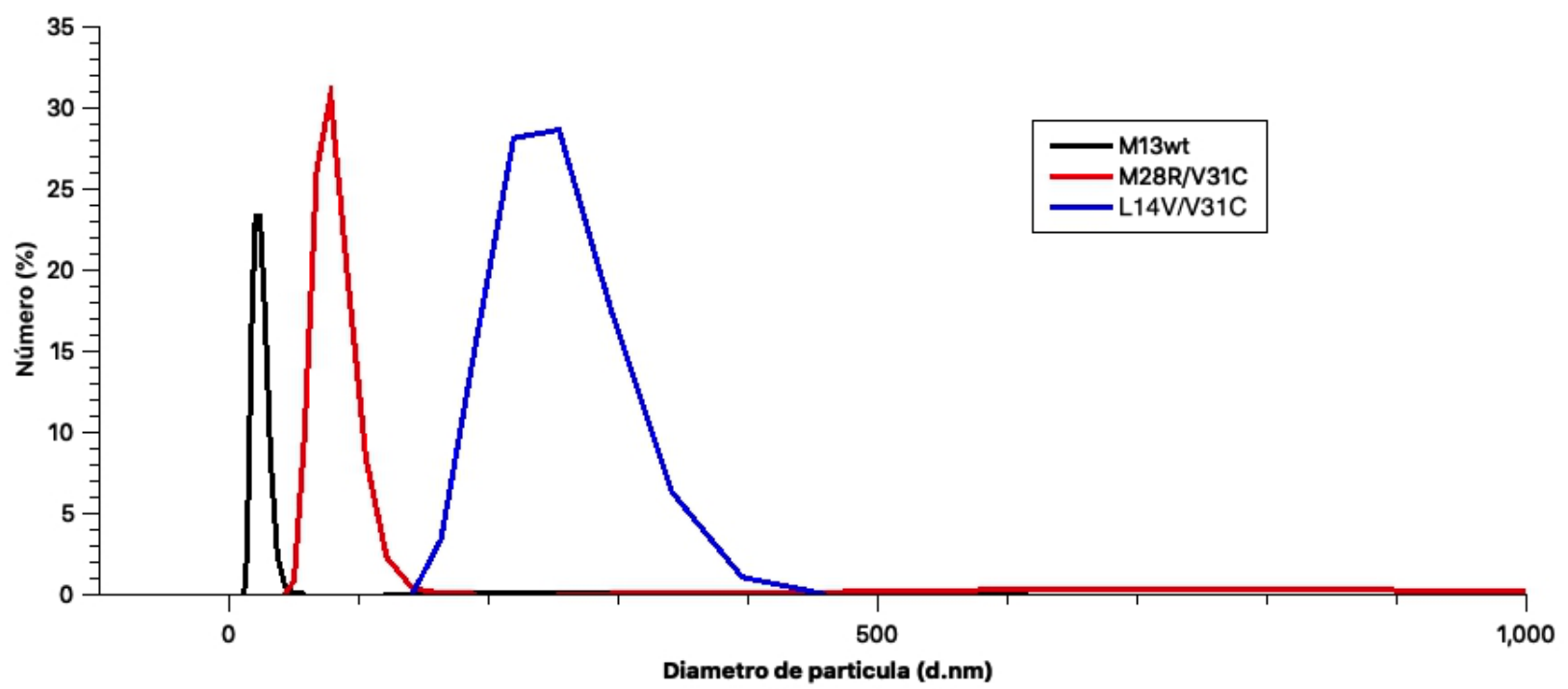

b)

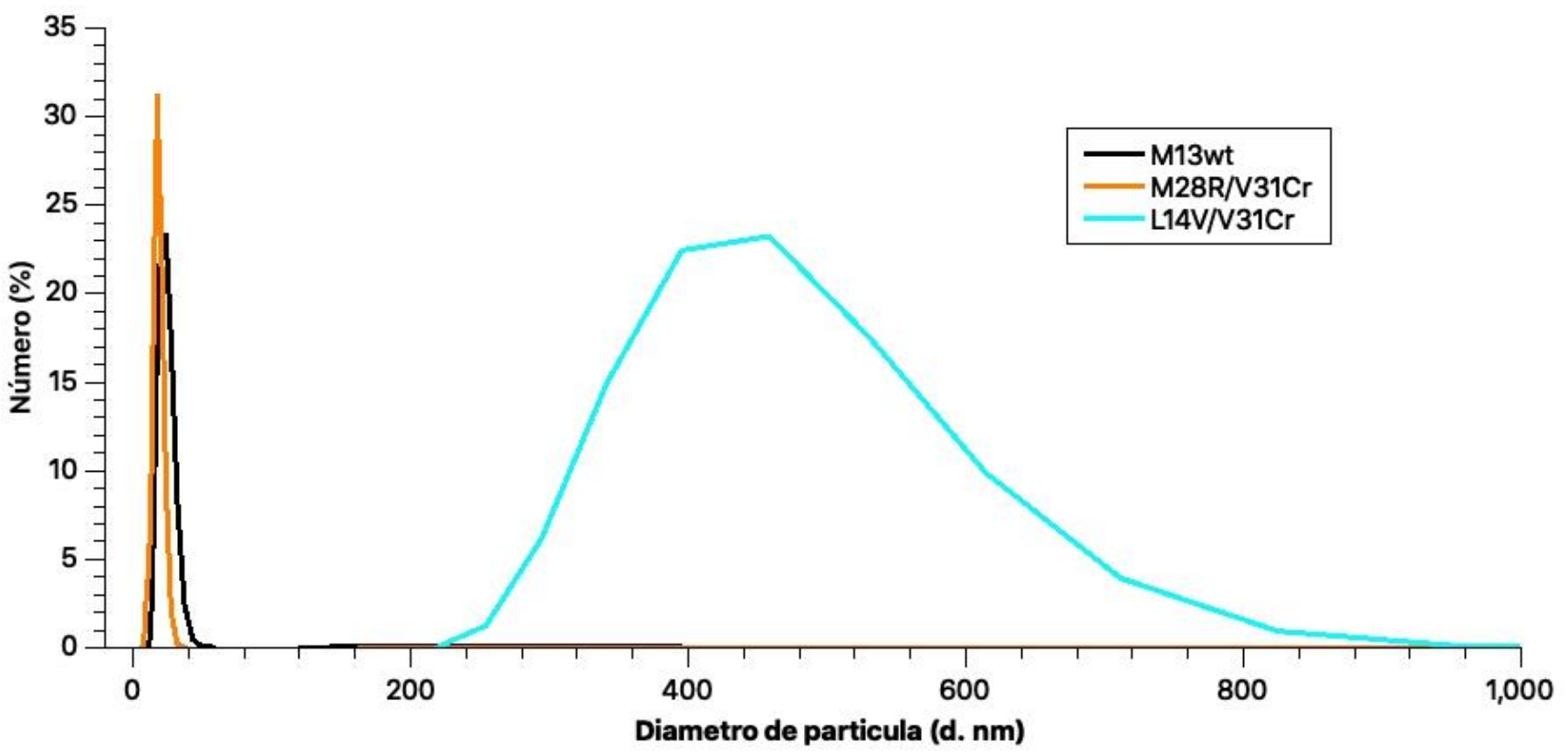

Figura 25. Espectros de DLS, se determinó el diámetro de partícula de M13wt y mutantes (L14V/V31C y M29R/V31C) antes y después del tratamiento reductor. En la figura a) se muestran los tamaños antes de haber sido reducidas y en la b) se muestran los tamaños después de haber sido reducidas. 


\subsubsection{Determinación del punto isoeléctrico mediante el método de Potencial zeta}

(ZP)

La estimación de la carga neta del fago M13 no sólo depende del número de residuos ionizables contenidos en las proteínas, sino también de la molécula de SSADN (grupos fosfato). En este trabajo, es fundamental conocer que cambios se presentan debido a los cambios puntuales en la secuencia de aminoácidos de la proteína. [69;71] La estructura del fago presenta 2700 copias de la p8, que es la proteína mayoritaria de la cápside por lo que se espera modificaciones en el punto isoeléctrico del fago. El punto isoeléctrico M13wt fue de 4.06, muy similar al reportado por Dong et. al. [70]. Las mutantes mostraron cambios importantes en el punto isoeléctrico, la mutante $\mathrm{M} 28 \mathrm{R} / \mathrm{V} 31 \mathrm{C}$ mostró un valor de 3.32 mientras que para la mutante L14V/V31C fue de 3.19 (Ver Figura 26).

En el caso de L14V/V31C reducida, no se pudo determinar el punto isoeléctrico debido a que el sistema no era estable, probablemente debido a que el cambio en la posición 14 provoca que los aminoácidos estén más expuestos y se agreguen las partículas de fagos como ya se mencionó. Por otro lado, la mutante M28R/V31C reducida si es estable y se obtuvo un punto isoeléctrico de 6.3, mayor que la mutante sin reducir y que el fago nativo. Esto pudiera deberse a que los grupos tioles pueden ionizarse fácilmente. Se sabe que la cisteína libre tiene un $\mathrm{pK}_{\mathrm{a}}$ = 8.1; de esta manera, a $\mathrm{pH}$ mayor al $\mathrm{pK}_{\mathrm{a}}$, los grupos tioles se desprotonan. La figura $26 \mathrm{~b}$ ) parece confirmar este hecho, ya que a partir de $\mathrm{pH} 8$ hay una disminución en la carga superficial por la desprotonación de estos grupos. 


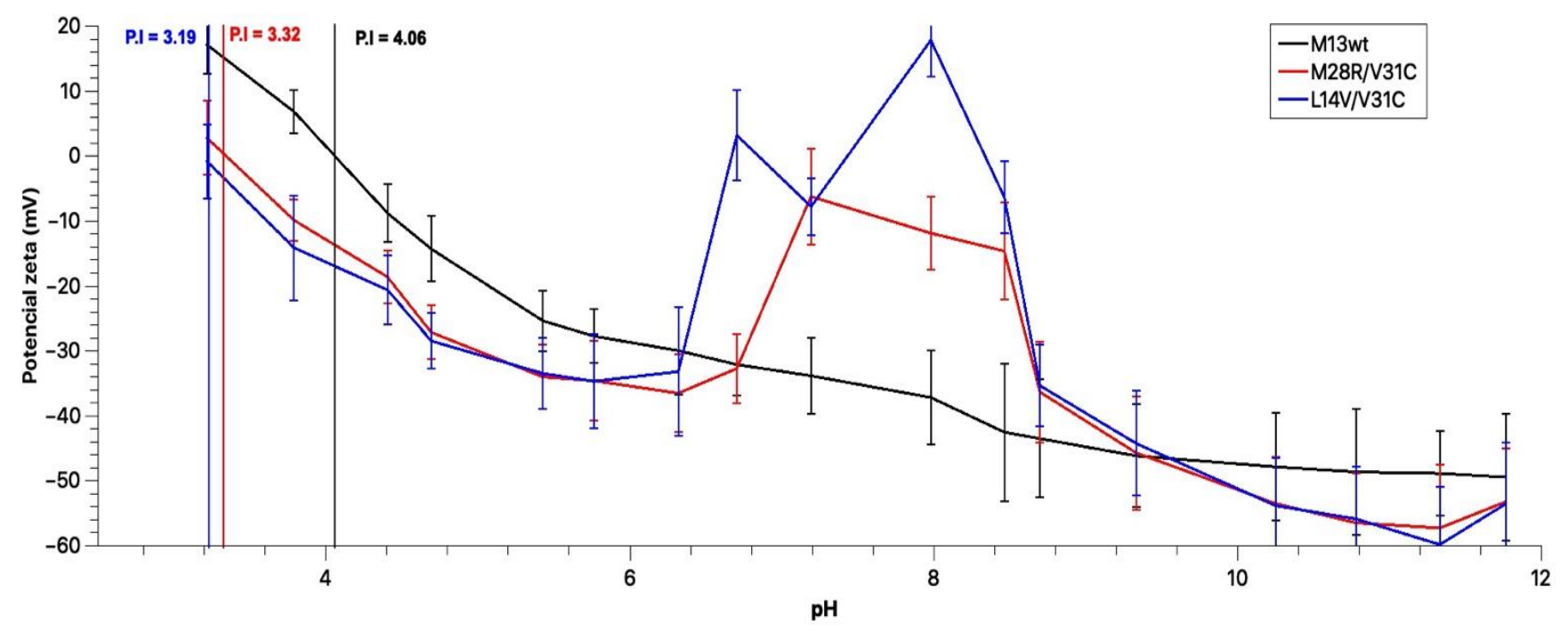

b)

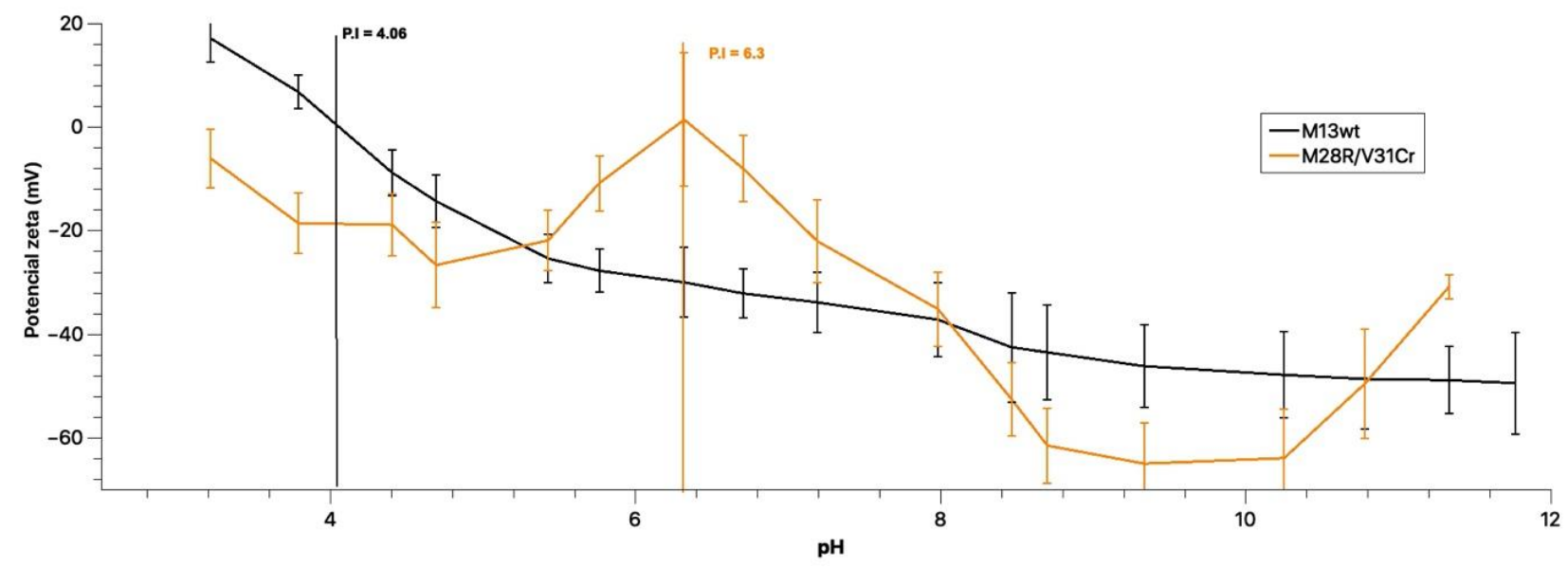

Figura 26. Espectros de DLS, se determinó el punto isoeléctrico de la partícula de M13wt y mutantes (L14V/V31C y M28R/V31C) antes y después del tratamiento reductor. En la figura a) se muestran los tamaños antes de haber sido reducidas y en la b) se muestran los tamaños después de haber sido reducidas. 


\subsection{Bacteriófago M13 y mutantes como plantilla para síntesis de nanomateriales inorgánicos}

\subsubsection{Nucleación y crecimiento de nanopartículas de oro y plata en la cápside del fago M13 y mutantes}

En la figura 27 (a y b) se muestra una fotografía con las imágenes de los tubos de reacción de la síntesis de NP de Au y Ag sobre las diferentes especies de fago. Es claro que las NP de Au (rojo) y $\mathrm{Ag}$ (amarillo) que se forman en presencia de M13wt producen partículas que no se disuelven, pero que corresponden inequívocamente a estructuras de dimensiones nanométricas como lo indica la aparición del plasmón de resonancia superficial (SRP, por sus siglas en inglés) a 525 y 380 nm, respectivamente (Figura 28) [77;78] La formación de NP fue verificada por microscopía electrónica de transmisión. A partir de las micrografías de la figura 29 ( $\mathrm{a} \mathrm{y} \mathrm{b}$ ) se observa la formación de partículas esféricas que van desde $20 \mathrm{~nm}$, hasta estructuras tipo "estrella" que alcanzan los $200 \mathrm{~nm}$. Esto debido a que el fago no es capaz de dirigir y controlar el tamaño ya que no tiene grupos afines a las NP, sin embargo, evita su coalescencia.

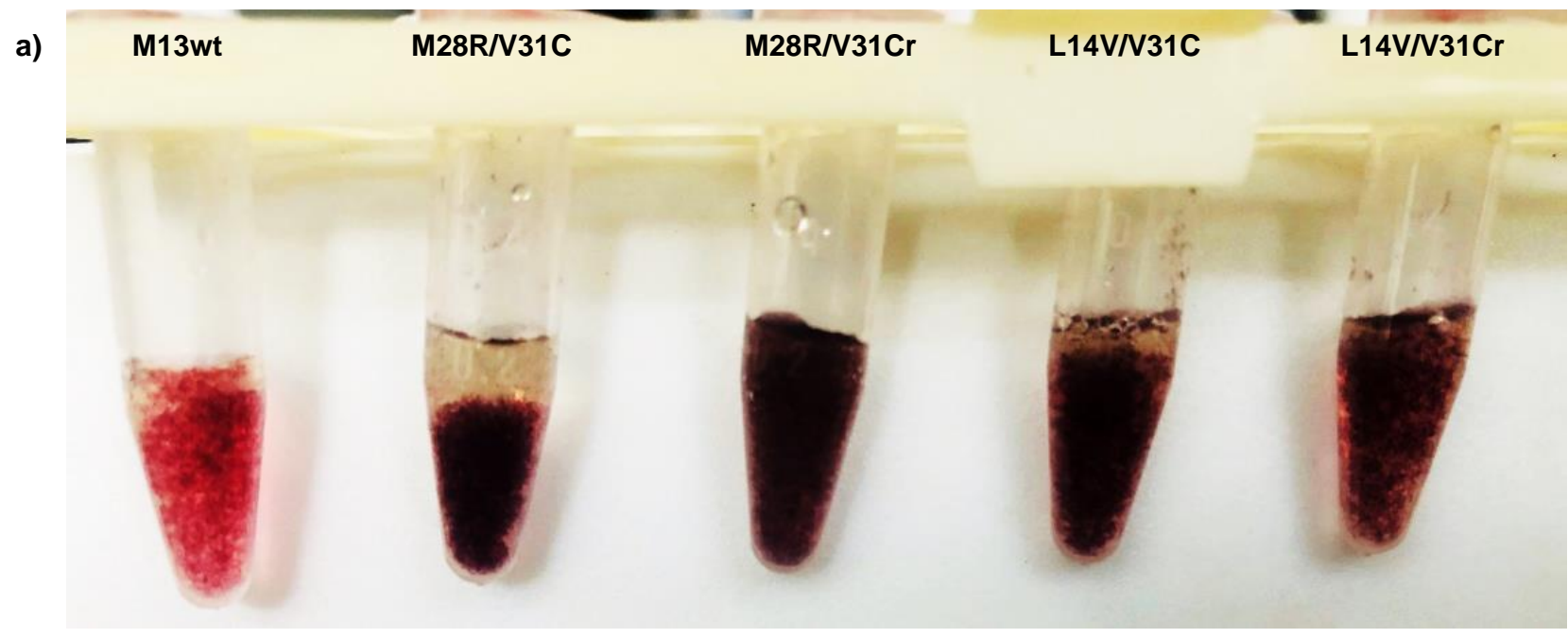

Figura 27. Se muestran las imágenes obtenidas de las reacciones de nucleación del fago y mutantes con a) NP’s de oro. 
b)

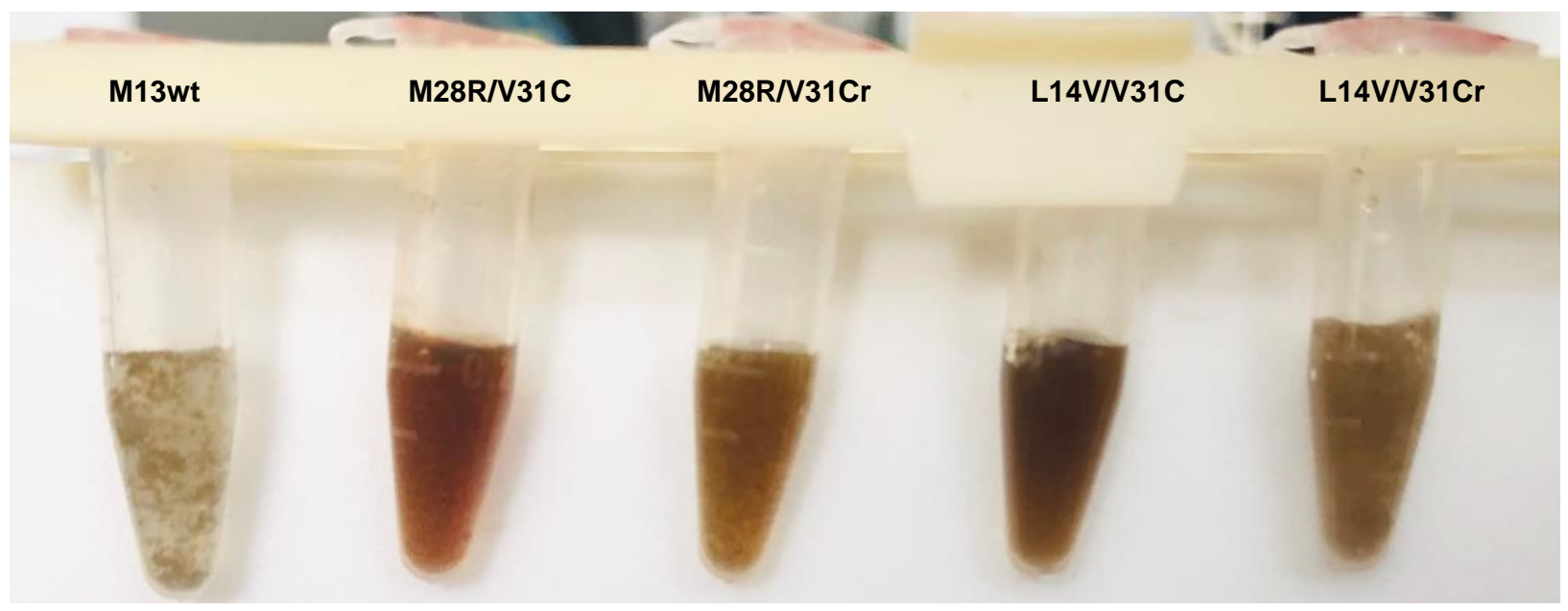

Figura 27. Se muestran las imágenes obtenidas de las reacciones de nucleación del fago y mutantes con a) NP's de oro y b) NP's

La síntesis de las NP en presencia de las mutantes tal como se obtuvieron produce suspensiones moradas $(\mathrm{Au})$ y naranjas-café $(\mathrm{Ag})$ típicas de NP agregadas de manera controlada.[79] Este comportamiento en ambas mutantes es verificado por un ligero corrimiento hacía el rojo del máximo del SPR de las NP de Au. Mientras que en el caso de las NP de Ag el corrimiento es mayor para la mutante M28R/V31C, así como el ensanchamiento asimétrico de la banda asociado a la formación de partículas sobre la superficie del fago. De la figura 30 (a y c) se confirma que las mutantes son capaces de nuclear NP de Au en la cápside, sin embargo, las mutantes no cubren completamente la superficie, lo cual puede deberse a que los grupos S-S no son afines para nuclear NP. En el caso de las NP de Ag ocurre un comportamiento similar.

La reducción del enlace disulfuro y consecuente formación del grupo S-H en las mutantes, no muestra cambios significativos en el aspecto físico de la reacción (Figura 27) o en el máximo del plasmón de resonancia, sin embargo, por microscopía se observan que las NP crecen más homogéneamente en la superficie del fago y el tamaño de las partículas disminuye y son menos polidispersas (Ver Figura $30 \mathrm{~b}$ y d).

Estos resultados nos indican que el fago nativo no puede controlar adecuadamente la formación de NP, pero al introducir grupos afines a los iones de los metales nobles (S-S y SH) estos pueden servir como puntos de nucleación en la formación de NP sobre la superficie de 
tamaño controlado $(\sim 8 \mathrm{~nm})$, convirtiendo al fago en una excelente plataforma para la síntesis de nanomateriales.

a)

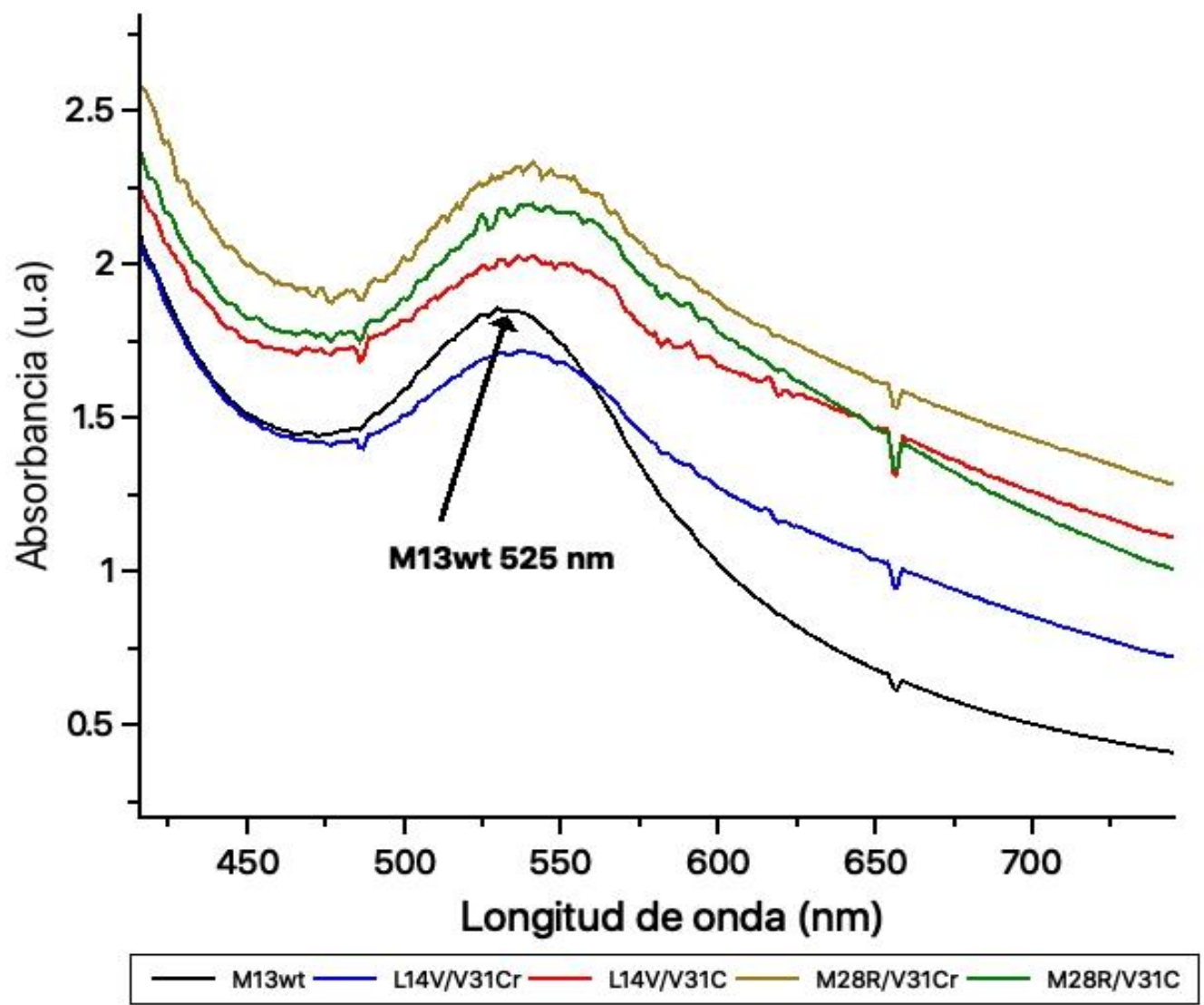

Figura 28. Se muestran las gráficas de los plasmones obtenidos de las reacciones de nucleación del fago y mutantes con a) NP's de oro 
b)

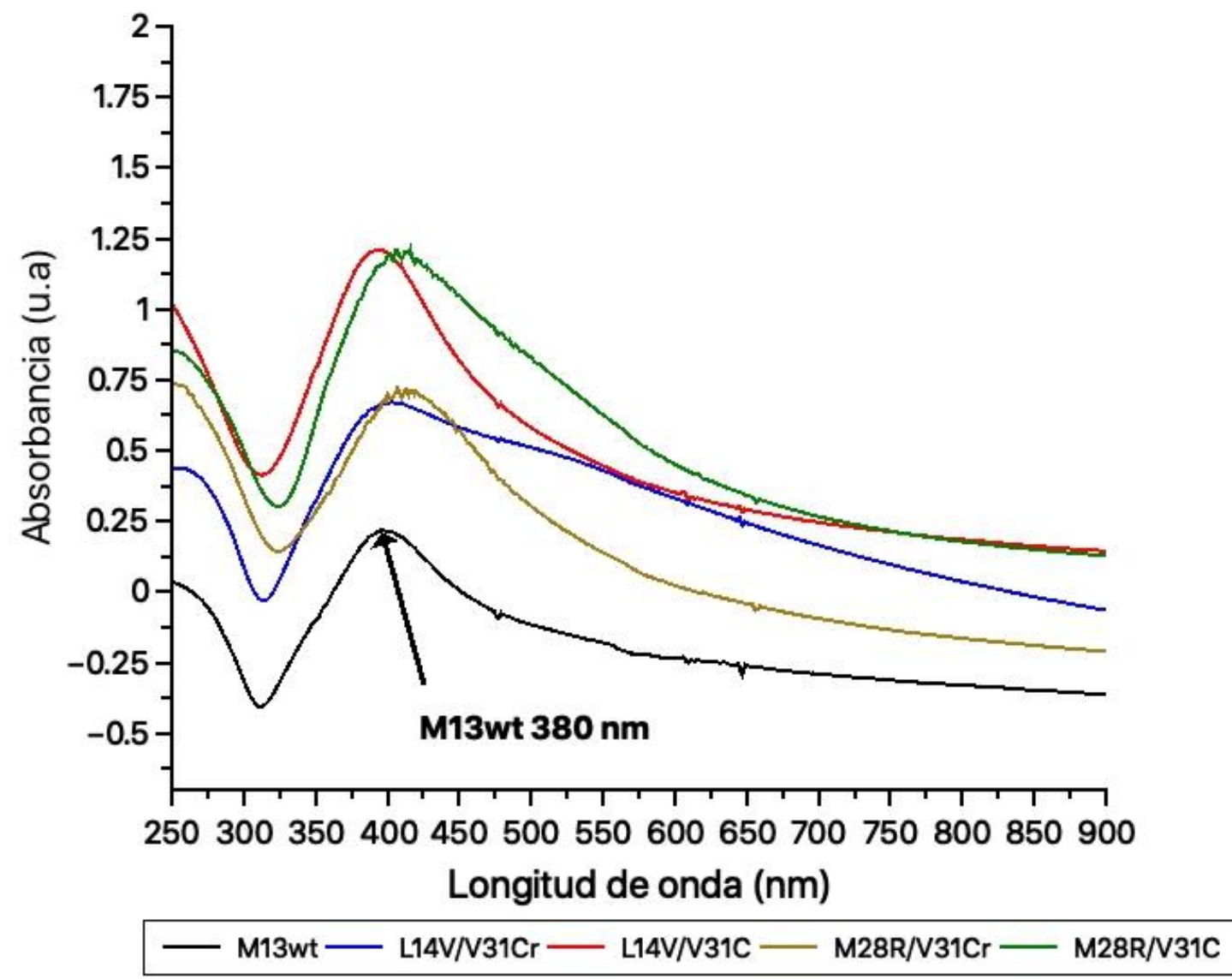

Figura 28. Se muestran las gráficas de los plasmones obtenidos de las reacciones de nucleación del fago y mutantes con b) NP's de plata.

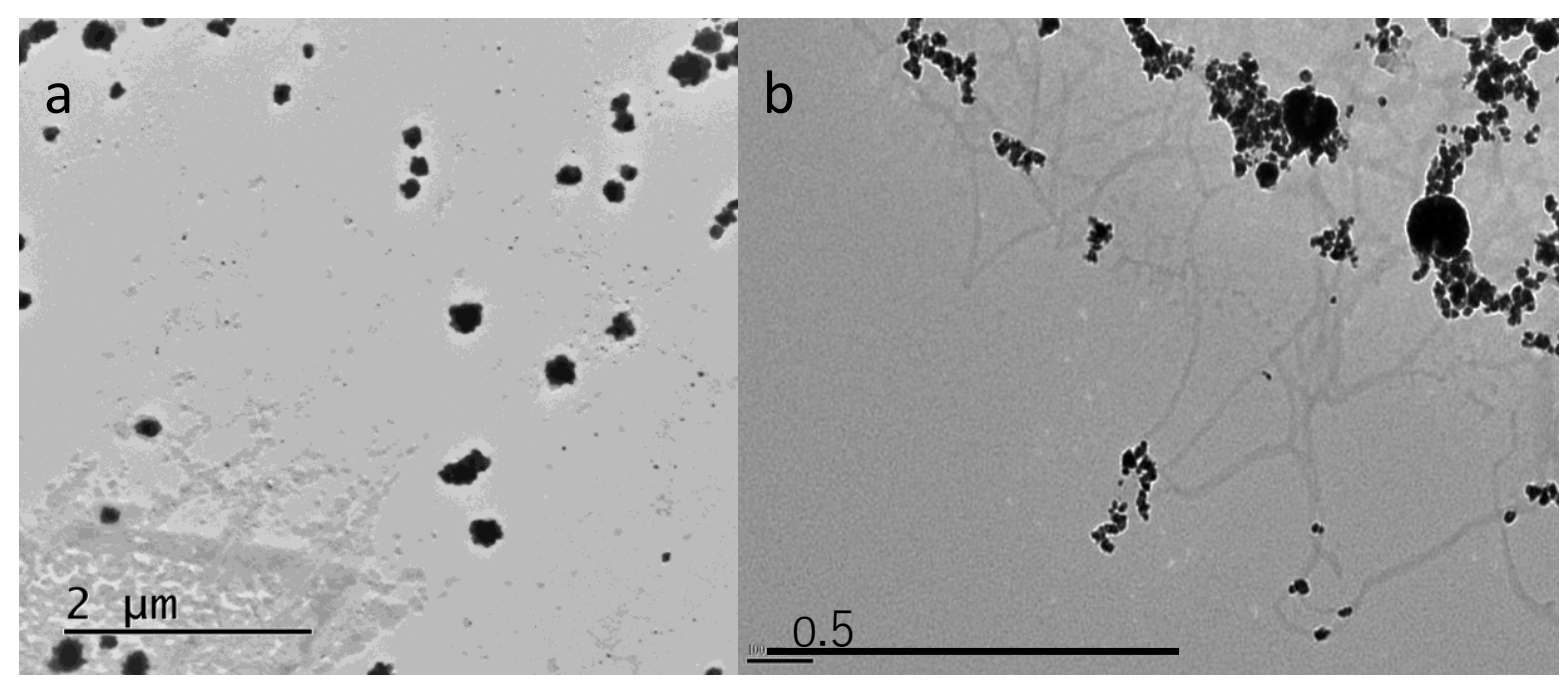

Figura 29. Imágenes de TEM. Síntesis de NPs de a) Au y b) Ag en presencia de fago M13wt. 


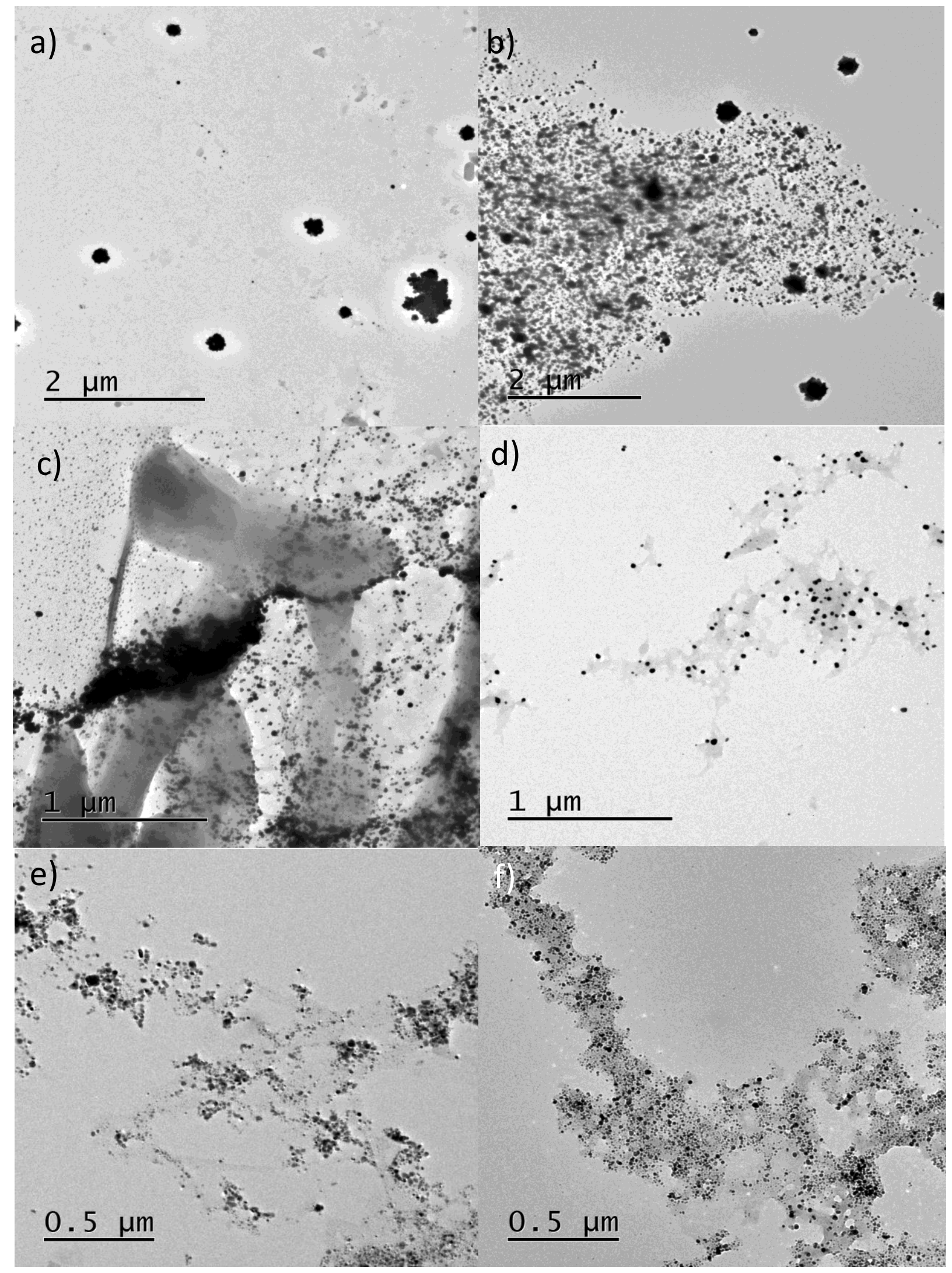

Figura 30. Imágenes de TEM. Síntesis de NPs de Au empleando la mutantes a) L14V/V31C y c) M28R/V31C tal como se obtienen y b) y d) después de reducir, respectivamente. Síntesis de NPs de Ag usando M28V/V31C e) antes y f) después de reducir 


\subsubsection{Cristales líquidos en M13wt y mutantes (L14V/V31C y M28R/V31C)}

La capacidad del bacteriófago de formar espontáneamente cristales líquidos se debe a la interacción entre las partículas vecinas, regidas por la interacción proteína-proteína, dando lugar a diferentes fases de cristal líquido. El M13wt y las mutantes formaron haces de fibras ordenadas, estableciendo patrones de birrefringencia de luz polarizada, de acuerdo con las posiciones del polarizador $(\mathrm{P})$ y el analizador $(\mathrm{A})$. Las imágenes obtenidas se muestran en la figura 31. El M13wt muestra el clásico patrón (fingerprint pattern) de un LC colestérico, cuando el ángulo del polarizador es $45^{\circ}$ respecto de la normal. Este patrón ya había sido observado previamente. [40;74]

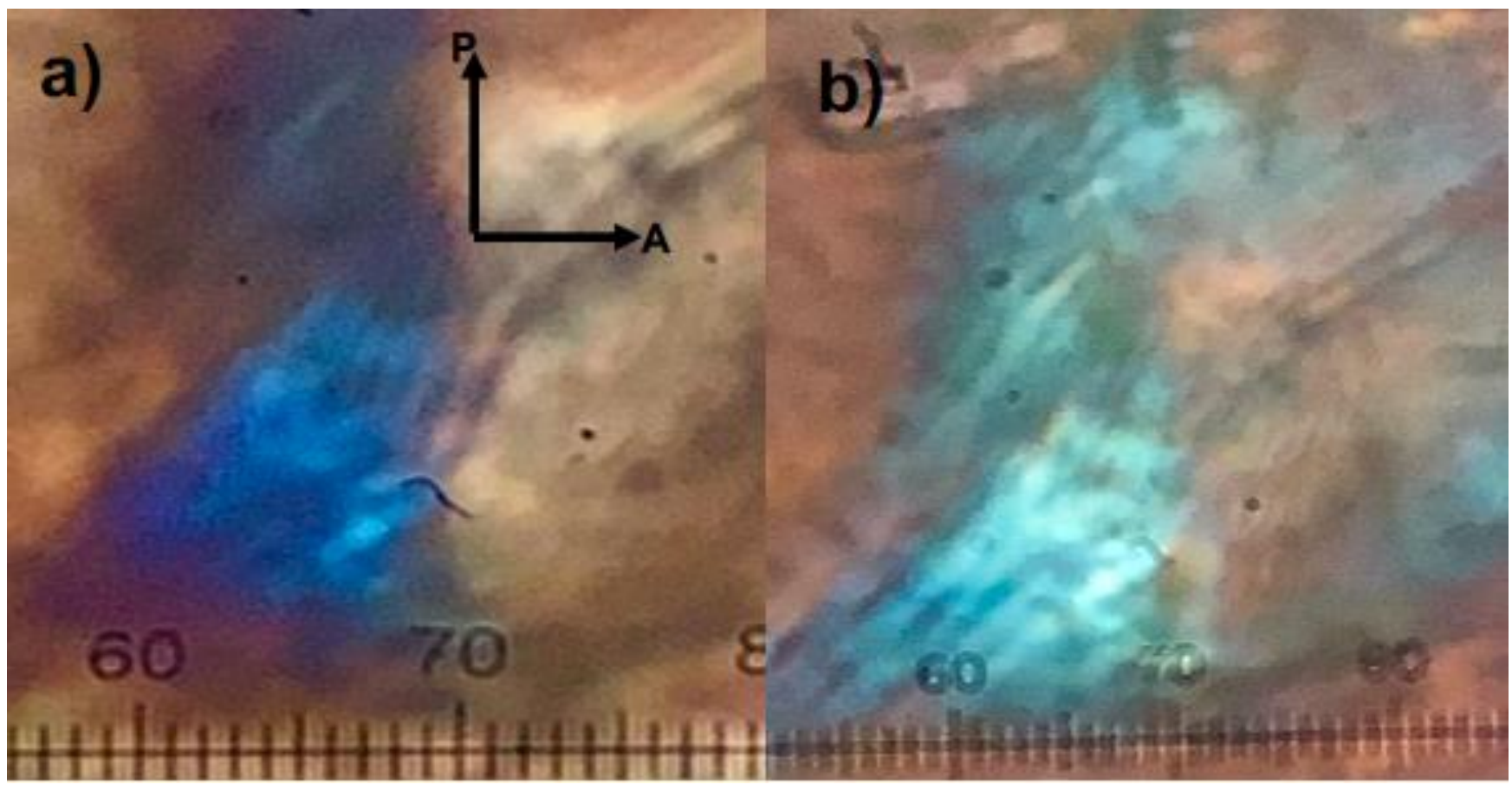

Figura 31. Cristal líquido de M13wt a una concentración de $7 \mathrm{mgmL}^{-1}$, se muestra la estructura caracteristica de una fase colestérica. 
Debido a que las interacciones de los aminoácidos de la p8 son los responsables de la formación de distintas fases de LC, cualquier cambio de aminoácido realizado puede inducir cambios en las fases de LC. En la figura 32, se muestra la L14V/V31C sin reducir y reducida, observándose el mismo patrón de tipo colestérica, sin embargo, la concentración es menor al M13wt. Este resultado ya ha sido documentado por otros autores, que han encontrado una relación entre la concentración (LC liotrópicos) y la secuencia de aminoácidos de la p8. [74] Adicionalmente, se observa que la muestra no reducida forma otro tipo de fase más parecida al patrón un LC nemático. Probablemente el rompimiento de los puentes disulfuro modifica la tensión superficial de la partícula viral dando lugar a la transición de fase.

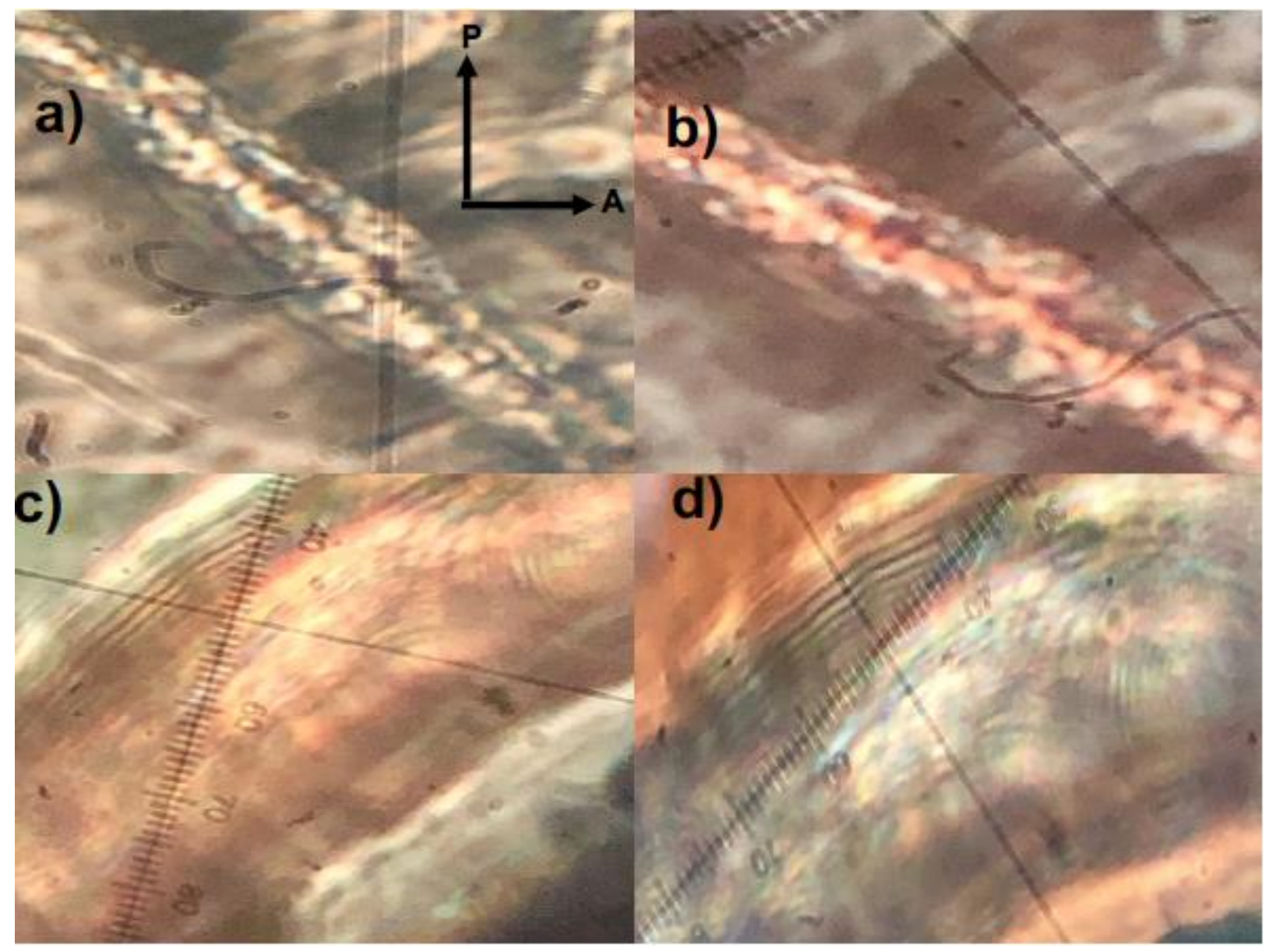

Figura 32. Cristal líquido del fago L14V/V31C a una concentración de $0.1 \mathrm{mg}^{*} \mathrm{~mL}^{-1}$. Las imágenes a) y b) son de la muestra sin reducir, mientras c) y d) son reducidas, en cada imagen se presenta la estructura característica de "fingerprint pattern" colesterica. 
Las imágenes de M28R/V31C sin reducir se muestra en la Figura 33 a y b, en esta se observa nuevamente el patrón de fase colestérica, mientras que para la mutante reducida no se observa claramente ningún patrón, sin embargo, si se forma una fase de LC ya que la muestra cambia la polarización de la luz. Este efecto puede deberse a que el espaciamiento entre cada partícula viral disminuye considerablemente y no tenemos la resolución para ver este efecto o bien que la fase está formada por muchos microdominios.

De estos resultados se confirma que mutaciones en la p8 pueden alterar las condiciones de organización entre las partículas provocando la formación de distintas fases de LC.

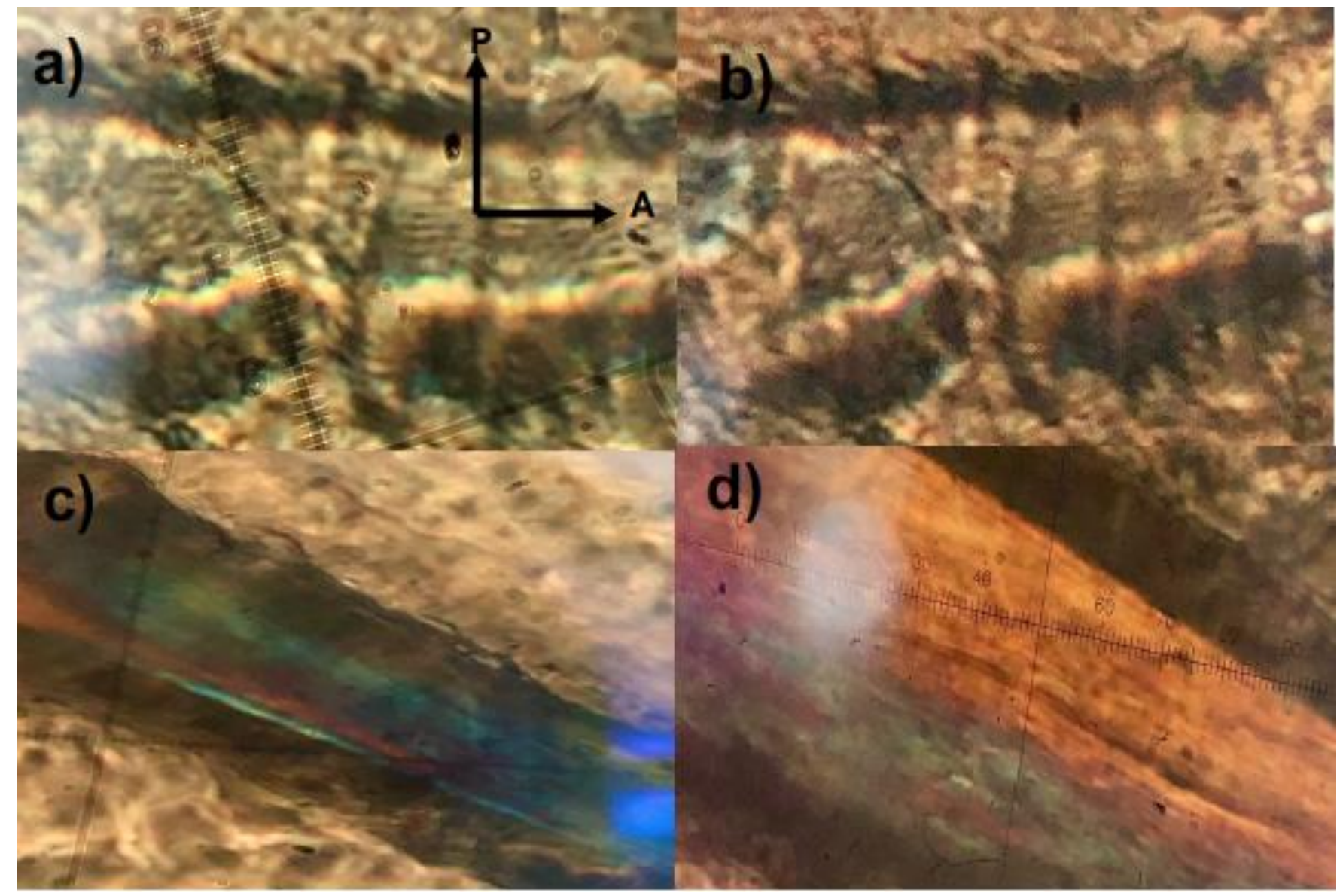

Figura 33. Imagen del fago M28R/V31C a una concentracion de $0.1 \mathrm{mgmL}^{-1}$. a) y b) son de la muestra sin reducir y, c) y d) son reducidas, 


\section{Capítulo 5}

\section{Conclusiones y perspectivas}

\subsection{Conclusiones y perspectivas}

Se logró obtener 2 mutantes en cantidades suficientes para su caracterización, a pesar de que el rendimiento fue menor respecto del fago M13wt.

Los experimentos de DC mostraron que la proteína p8 (proteína mayoritaria en la cápside) en las mutantes tiene una estructura global en la que predomina la hélice $\alpha$. Sin embargo, se observaron diferencias cuantitativas en los contenidos de estructura secundaria entre las diferentes variantes del virus, particularmente en las mutantes de M13 tratadas con un agente reductor

Las cisteínas introducidas formaron puentes disulfuro, estas modificaron de manera importante las propiedades espectrales en la región del visible (UV-Vis), así como el tamaño del fago, hidrofobicidad y punto isoeléctrico.

La reducción de los puentes disulfuro permitió regenerar los grupos $\mathrm{SH}$, sin afectar la estructura del fago. Los grupos tiol estuvieron lo suficientemente expuestos para funcionar como puntos de nucleación de iones de metales nobles, que posteriormente fueron reducidos y generaron NP de Au y Ag.

Las NP de Au y Ag tiene un tamaño y forma controlada debido a que son estabilizadas por las proteínas p8. Además, las NP crecieron sobre la superficie del fago como lo muestran los resultados.

Se logró obtener LC del M13wt y de las mutantes. Demostrando que la secuencia y la concentración influyen en la formación de LC liotrópicos.

Las conclusiones de este trabajo nos permiten comenzar a comprender como la identidad de los aminoácidos en la proteína principal de la cápside puede afectar las propiedades del fago M13; sin embargo, el desarrollo de este trabajo nos abre nuevos criterios, tales como: 
Si se realizan mutaciones de aminoácidos en la región C-terminal de la proteína p8, que afectaciones habrá en el ensamblado y empaquetamiento del fago. Y a partir de esta modificación que alteraciones tendrá en las propiedades para organizarse en fases de cristal líquido.

De los métodos de dip-coating, spin-coating o layer by layer, que método es mejor y como afecta en la formación de estructuras de cristal líquido.

A partir de estas estructuras de cristal líquido, que tan viable es para emplearse como plataforma para sintetizar y organizar materiales con propiedades de interés tecnológico. 


\section{Referencias}

1. Nature.com. (s.f.). Obtenido de Nature: https://www.nature.com/subjects/biomimetics

2. Yi, K. D. and Papaefthymiou D. G. (2014). Nanobiomaterials development and aplications. Press Taylor \& Francis Group .

3. Zhang, Z., Ortiz. O., Goyal, R. amd Kohn, J. (2014). Biodegradable polymeres. Principles of tissue engineering , 441-473.

4. Ozin, G. A. (1992). Nanochemistry: synthesis in diminishing dimensions. Advanced materials, 4(10), 612-649

5. Narayan, R. (Ed.). (2017). Nanobiomaterials: Nanostructured materials for biomedical applications. Woodhead publishing series in biomaterials .

6. Martakov, I. S., Torlopov, M. A., Krivoshapkina, E. F., Kalikina, P. A., Navrotskaya, A. G., Koshel, E. I. (2018). Biotemplate synthesis of porous alumina fibers ans filters whit controlled structureand properties. Journal of the Taiwan Institute of Chemical Engineers, 9.

7. Ben-Yoav, H. (2012). Tobacco Mosaic Virus Biotemplated Electrochemical Biosensor. ResearchGate.

8. Xiang Lan, Xuxing Lu, Chenqi Shen, Yonggang Ke, Weihai Ni and Qiangbin Wang. (2015). Au Nanorod Helical Superstructures with Designed Chirality. Journal American Society, 137, 457-462.

9. Seal, S. (2008). Functional nanostructures: Processing, characterization and applications nanostructure science and technology. (D. L., Ed.) Ottawa, Ontario, Canada: Springer.

10. Whitesides, G. M., Mathias, J. P. and Seto, T. C. (1991). Molecular self-assembly and naochemistry: a chemical strategy for the synthesis of nanostructures. Science, 254(5036), 1312-1319.

11. Palesko, J. A. (2007). Self Assembly: The science of things that put themselves together. Champan and Hall/CRC. 
12. K. Subramani nad W. Ahmed. (2012). Self-Assembly of Proteins and Peptides and Their Applications in Bionanotechnology and Dentistry. En Emerging Nanotechnologies in Dentistry Materials, Processes, and Applications (págs. 209-224). Oxford, UK: William Andrew of Elsevier.

13. Whitesides, G. M. and Grzybowski, B. (2002). Self-assembly at all scales. Science, 295(5564), 2418-2421.

14. Berbezier, I. nad De Crescenzi, M. B. (2015). Self-assembly of nanostructures and naomaterials. Journal Nanotechnol, 6, 1397-1398.

15. Denis, A. (2018). introduction to liquid crystals. Journal of Molecular Liquids, 267(1), 520541.

16. Tschierske, C. (Ed.). (2012). Liquid Crystals: Materials Design and self-assembly (Vol. 318). Springer-Verlag Berlin Heidelberg .

17. Introduction to liquid crystals. (s.f.). Obtenido de Barret Research Group Homepage : http://barrett-group.mcgill.ca/tutorials/liquid_crystal/LC02.htm (imagen).

18. Ermakov S., Beletskii A., Eismont O., Nikolaev V. . (2016). Brief Review of Liquid Crystals. En Liquid Crystals in Biotribology. Springer International Publishing Switzerland.

19. Thomas R. Jahn and Sheena E. Radford. (2005). The yin and yang of protein folding. FEBS Journal, 272, 5962.5970.

20. Gromiha, M. M. (2010). Protein Stability . Protein Bioinformatics, 209-245.

21. Mateu, M. G. (2013). Assembly stability and dynamics of virus capsids. Archives of biochemistry and biophysics, 531(12), 65-79.

22. Sawada, T. Filamentous virus-based soft materials based on controlled assembly through liquid crystalline formation. Polym J. 49(2017),639-647.

23. Santiago V. N and Dueñas M. (2004). Caracteristicas generales de los bacteriofagos filamentosos . Combinatoria Molecular, 57-68.

24. Arthur Kornberg, T. (s.f.). DNA Replication. New York: W.H. Freeman and Company. 
25. E., W. R. (1996). Biology of the Filamentous Bacteriophage. Phage Display of Peptides ans Proteins, 1-20.

26. Glucksman, M. J., Bhattacharjee, S., and Makowski, L. (1992). Three-dimensional structure of a cloning vector. Journal of Molecular Biology, 226(2), 455-470.

27. Tsuboi, M., Overman, S. A. and Thomas, G. J. (1996). Orientation of Tryptophan-26 in Coat Protein Subunits of the Filamentous Virus $\mathrm{Ff}$ by Polarized Raman Microespectroscopy. Biochemistry, 33(32), 10403-10410.

28. Marvin, D. (1998). Filamentous phage structure, infection and assembly. Current Opinion in structural Biology, 8, 150-158.

29. Hemminga, M. A. (2009). Viruses: Incredible nanomachines. New advances whit filamentous phages. Springer, 541-550.

30.González, C. J. L., Vieyra, E. M. T., Vera, R. L. I. and Hernandez, A. A. (2018). Enviromental adjustments of the cooperativity in M13 phage thermal denaturation. . Thermochimica Acta, 672, 53-59.

31. Papavoine, C. H. M., Christiaans, B. E. C., Folmer, R. H. A. Konings, R. N. H. and Hilbers, C. W. (1998). Solution structure of the M13 major coat protein detergent micelles; a basis for a model of phage assembly involving specific residues. Journal Molecular Biology , 282(2), 401-419.

32. Steven D. Branston, Emma C. Stanley, John M. Ward, and Eli Keshavarz-Moore. (2013). Determination of the Survival of Bacteriophage M13 from Chemical. Biotechnology and Bioprocess Engineering, 18, 560-566.

33. Linus Olofsson, Jonas Ankarloo, Per Ola Andersson and lan A. Nicholls. (2001). Filamentous bacteriophage stability in non-aqueous media. Chemistry and Biology, 8, 661-671.

34. Pouya Moghimian, Vesna Srot, Benoit P. Pichon, Sandra J. Facey, and Peter A. Van Aken. (2016). Stability of M13 Phage in Organic Solvents. Journal of Biomaterials and Nanobiotechnology, 7, 72-77. 
35. Jack Griffith, Marcia Manning and Kathi Dunn. (s.f.). Filamentous bacteriophage contract into hollow spherical particles upon exposure to a chloroform-water interface. Cell, 23, 747-753.

36. Joñezyk E., Klak M., Miedzybrodzki R. and Gorsid A. . (2011). The incluence of external factors on bacteriophages. Folio Microbiol , 1991-200.

37. Makowski, L. (1994). Phage Display: structure, assembly and engineering of filamentous bacteriophage M13. Current Opinion in Structural Biology, 4(2), 225-230.

38. Amir R. K., Karen A. W., Joan M. Boggs ans Charles M. D. (1995). Accessibility and Dynamics of Cys Residues in Bacteriophage IKE and M13 Major Coat protein Mutants. Biochemistry, 34, 12388-12397.

39. Woo-Jar Chung., Oh, J., Kwak, K. et al. (2011). Biomimetic self-templating supramolecular . Nature , 364-368.

40. Shuaiyu Liu, Tingting Zan, Si Chen, Xiaodong Pei, Henmin Li and Zhenkun Zhang. (2015). Thermoresponsive Chiral to Nonchiral Ordering Transformation in the Nematic Liquid-Crystal Phase of Rodlike Viruses: Turning the Survival Strategy of a Virus in to Valuable Material Properties. Langmuir, 31, 6995-7005.

41. Irais Vera-Robles, Jaqueline González-Gracida, Armin Hernández-Gordillo, and Antonio Campero. (2015). Using the M13 Phage as a Biotemplate to Create Mesoporous Structures Decorated with Gold and Platinum Nanoparticles. Langmuir, 31(33), 91889197.

42. D. Stopar, R.B. Spruijt, C.J.A.M. Wolfs, M.A. Hemminga, Mimicking initial interactions of bacteriophage M13 coat protein disassembly in model membrane systems, Biochemistry 37 (1998) 10181-10187.

43. K.E. van Holde, W.C: Johnson, P. S. Ho. "Principles of Physical Biochemistry". Capítulo 10. Prentice-Hall, New Jersey (1998).

44. LI, W.; Suez I.Szoka, F. C., Reconstitution of the M13 major coat protein and it's transsmembrane peptide segment on a DNA templete. Biochemistry,2007,46 (29), 8579-8571.

45. Principles of Physical Biochemistry, Chapter 10, Van Holde, K.E; Curtis-jhonson, W.; Shing-Ho, P. Pearson Prentice Hall, 2006, pp 482. 
46. Provencher and Glockner, Biochemistry 20, 33-37, 1981; Anal. Biochem 287, 252-260, 2000

47. Anal. Biochem. 209, 32-44, 1993; Anal. Biochem 287, 252-260, 2000.

48. Lee Whitmore, B. A. Wallace; Biopolymers 89, 2007; Nucleic Acids Research, 2004, Vol. 32

49. Lee Whitmore, B. A. Wallace; Biopolymers 89, 2007; A. J. MILES, L. WHITMORE, and B.A. WALLACE. Spectral magnitude effects on the analyses of secondary structure from circular dichroism spectroscopic data. Protein Science (2005), 14:368-374

50. Sreerama and Woody. Analytical Biochem. 287, 252-260, 2000.

51.Jackson, M.; Mantsch, H. H. The Use and Misuse of FTIR Spectroscopy in the Determination of Protein Structure. Crit. Rev. Biochem. Mol. Biol. 1995, 30, 95-120

52.T.E. Creighton. "Proteins: structures and molecular properties". Capítulo 1. W.H. Freeman (1992); E. H. Strickland. Aromatic Contributions to Circular Dichroism Spectra of Proteins. CRC. Crit. Rev. Biochem, 2: 113-175 (1974).

53. E. H. Strickland. Aromatic Contributions to Circular Dichroism Spectra of Proteins. CRC. Crit. Rev. Biochem, 2: 113-175 (1974)

54. Sharon M. Kelly, Thomas J. Jess and Nicholas C. Price. (2005). How to study proteins by circular dichroism. Biochimica et Biophysica Acta, 1751, 119 - 139.

55. L. I. Vera-Robles, Luis E. A., Michel P., J. Luis H. P. and Emmanuel H. Poniatowski. (2016). A biological approach for the synthesis of bismuth nanoparticles: Using Thiolated M13 phage as scaffold. Langmuir, 32(13), 3199-3206.

56. Branston, S. D., Stanley, E. C., Ward, J. M. and Keshavarz-Moore, E. (2013). Determination of the Survival of Bacteriophage M13 from Chemical and Physical Challenges to Assist in Its Sustainable Bioprocessing. Biothecnology and bioprocess Engineering, 18, 560-566.

57. Lin, Y., and Mao, C. (2011). Bioinspired supramolecular sel-assembly toward soft nanomaterials . Frontiers of materials science, 247-265.

58. Ho. Yang., Woo-Jae Ch.,Sean M. and Seung-Wuk L. (2013). Assembly of bacteriophage in to functional material. The chemical record, 13, 43-59. 
59. Jonathan K. P. and Nicole F. S. (2011). The art of engineering viral nanoparticles. Mol. Pharm, 8(1), 29-43.

60. Mao, C. (2004). Virus-based toolkit for the directed synthesis of magnetic ans semiconducting nanowires. Science, 303 (5655), 213-217.

61. Meszaros, B., Tompa, P., Simon, I. and Dosztanyi Z. (2007). Molecular Principles of the Interactions of Disordered Proteins. Journal Molecular Biology, 372, 549-561.

62. Nam K. T., Peelle B. R., Lee S. W and Belcher A. M. (2004). Genetically driven assembly of nanorings based on the M13 virus. Nano Letters, 4(1), 23-27.

63. Narayan, R. (Ed.). (2017). Nanobiomaterials: Nanostructured materials for biomedical applications. Woodhead publishing series in biomaterials .

64. Park, P. J.-E.-W. (2014). M13 bacteriopphage displaying DOPA on surfaces: fabrication of various nanoestructured inorganic materials without time-consuming screening processes. Applied Materials and Interfaces, 6, 18653-18660.

65. Pil J. Y., K. T.-K. (2006). Sapontaneous assembly of viruses on multilayer polymer surfaces. nature materials, 5, 234-240.

66. Seal, S. (2008). Functional nanostructures: Processing, characterization and applications nanostructure science and technology. (D. L., Ed.) Ottawa, Ontario, Canada: Springer.

67. Vidal, M. (2001). Proteins interaction domains . Encyclopedia of genetics, 1551-1552.

68. Ling, M. (2016). Labe-free analysis of single viruses with a resolution comparable to that of electron microscopy and the throughput of flow cytometry, Angew. Chem. Int., 55, 16.

69.Zimmermann, K. (1986). The ionic properties of the filamentous bacteriophages Pf1 y fd. The journal of biological chemistry.,4, 261. 1653-1655.

70. Dong, D. (2013). A simple and rapid method to isolate purer M13 phage by isoelectric precipitation. Appl Microbiol Biotechnol.,97, 8023-8029

71. Kaszuba. M. (2010). High-concentration zeta potential measurements using lightsacttering techniches. Phil. Trans. R. Soc. A. 368. 4439-4451. 
72. Sidhu. S. (2001). Engeneering M13 for phage display. Biomolecular engeneering. 18. 57-63.

73. Tom. S. (2016). Engineered phage films as scaffolds for $\mathrm{CaCO}_{3}$ biomineralization. Nanoscale. 34. 15696-15701.

74. Tomar. S. (2007). DNA-Protein interactions as the source of large-length-scale chirality evident in the liquid crystal behavior of filamentous bacteriophages. J. Am. Che. Soc. 129. 3367-3375.

75. M. Wolpert, P. Hellwig. (2006), Spectrochimica Acta Part A64, 987-1001.

76. C. N. R. Rao, R. Venkataraghavan and T. R. Kasturi. (1964), Canadian Journal of Chemistry, 42, 36-42.

77. J. Wang, K. M. Koo, Y. Wang, and M. Trau. (2018), Anal. Chem. 90, 12698-12705.

78. N. R. Jana, L.Gearheart, and C. J. Murphy. (2001), Langmuir 17, 6782-6786.

79. H. Li and L. Rothberg. (2004), PNAS. 28, 14036-14039. 


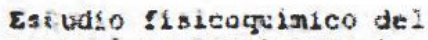
ensertic moleculd 6 de 12 particula dej bactez:0 190 N13 $y$ nitantéa
In la Cived de Mexleo, se presertaror a las 1]:00 horay cel dL 24 del mes de maxzo del ano zozo en lo unidad Iztapalapa de le Bnfveraldad autopona Metrogolitana, los scyeritos witembros del. Jurteb:

OR, ANERES HERSANDEZ ARMNA

DRA. CLREDIA GUPSALUFE BRNITEZ CAREOZR

DR. SAFAEL AETURS ZUAI LIAGA LUKA

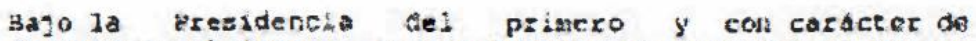
Secretarlo el bltioo, se reunieron para proceder al Fexdnon do irado cuya denominscion aparece ai rargen, para la obtención del igrado de:

MASSTRA EN CXERCIAS fQUIMTCA:

DE: JESSTCA YARTIMEZ JMKENEZ

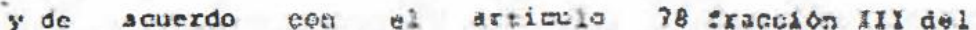

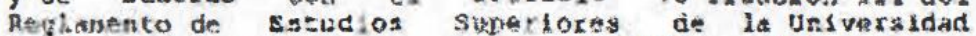
Altosoma Mestopolisane. los nifmbros del jurado Yosololarom:

VESSICA MARTINEZ MMENEZ ALUMANA

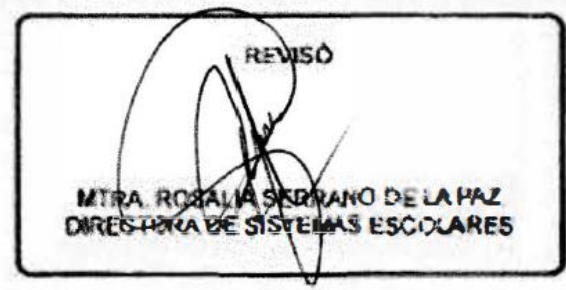

DIRECTDR DE LA DIMSION DE CQ

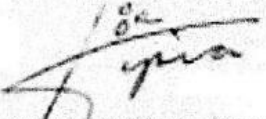

OR. JESUS ALSERTO OCHOA TAPIA

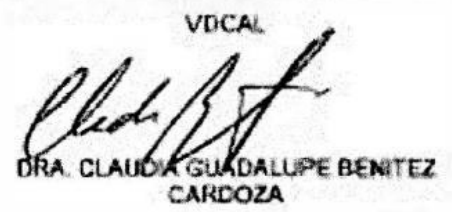

PRESIDENTE<smiles>CCCCCCCCCCCCCCCCC</smiles>
DR ANURES HERNANDE2 WRANA \%

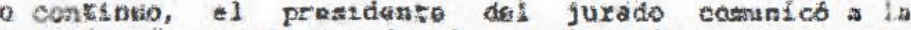
interasada es resultado de la avalnación y, en case sprobatorito, le fue romacia la protagta. 